Portland State University

PDXScholar

Fall 11-28-2018

\title{
Age-based Differences in the Usefulness of Resources: a Multi-Study Investigation of Work and Well-being Outcomes
}

Lale Muazzez Yaldiz

Portland State University

Follow this and additional works at: https://pdxscholar.library.pdx.edu/open_access_etds

Part of the Occupational Health and Industrial Hygiene Commons, and the Psychology Commons Let us know how access to this document benefits you.

\section{Recommended Citation}

Yaldiz, Lale Muazzez, "Age-based Differences in the Usefulness of Resources: a Multi-Study Investigation of Work and Well-being Outcomes" (2018). Dissertations and Theses. Paper 4650.

https://doi.org/10.15760/etd.6534

This Dissertation is brought to you for free and open access. It has been accepted for inclusion in Dissertations and Theses by an authorized administrator of PDXScholar. Please contact us if we can make this document more accessible: pdxscholar@pdx.edu. 
Age-based Differences in the Usefulness of Resources: A Multi-Study Investigation of Work and Well-being Outcomes

by

Lale Muazzez Yaldiz

A dissertation submitted in partial fulfillment of the requirements for the degree of

Doctor of Philosophy

in

Applied Psychology

Dissertation Committee:

Donald M. Truxillo, Chair

Todd Bodner

Berrin Erdogan

Margaret B. Neal

Portland State University 2018 
(C) 2018 Lale Muazzez Yaldiz 


\begin{abstract}
The labor force is aging globally. It is projected that the number of older workers will increase in the workforce in the near future. At the same time, it is estimated that workplaces will grow more age-diverse, where younger and older workers will work side-by-side more often than they used to. These demographic shifts in the workforce necessitate a further understanding of the differences between the values, needs and motivation, and work outcomes of employees of different ages. To this end, few studies to date have investigated whether job-related resources are differentially useful for the work and non-work outcomes of younger and older workers. Guided by Conservation of Resources (COR) theory and two lifespan development theories (Selection-OptimizationCompensation, SOC; Socio-emotional Selectivity Theory, SST), this dissertation suggests that the utility of resources is age-dependent. Specifically, this dissertation includes three studies that expand our knowledge of age-based differences in the usefulness of job-specific, social, and personal resources, and how they relate to various job attitudes, different forms of job performance, and employee well-being. Study 1, which was published in the Journal of Vocational Behavior, examines the moderating role of age in the relationship between baseline resources (skill discretion, leader-member exchange, and procedural fairness) and perceived stress after one year in a sample of U.S. construction workers $(N=243)$. As hypothesized, the findings of this study showed that these autonomy and support resources were more important for older workers: When resources were high in the workplace, all employees reported lower levels of stress. However, when resources were low, older workers experienced greater stress compared
\end{abstract}


to their younger colleagues. In Study 2, multi-source data from Turkish manufacturing employees $(N=156)$ are utilized to investigate the age-based differences in the link between social support resources (leader-member exchange, perceived organizational support) and supervisory ratings of in-role performance and organizational citizenship behaviors in a cultural context other than the U.S. It was hypothesized that these social support resources would be more important for older workers' performance. However, the findings showed that both leader-member exchange and perceived organizational support were considered as equally important by older and younger workers to perform well at work. Finally, Study 3 explores whether resource from job (decision-making autonomy) and personal resources (optimism, perceived work ability) differentially relate to work attitudes (job satisfaction, work engagement) and well-being (perceived stress, emotional exhaustion) of older and younger nurses $(N=111)$ working in the Pacific Northwest, U.S. The findings of this study supported that the usefulness of decisionmaking autonomy and optimism were more pronounced for older workers. Overall, the results suggested that, when these resources were low, all employees had lower job satisfaction and work engagement, and greater emotional exhaustion and perceived stress independent of their ages. However, under high resource conditions, older employees shined at work and in life: When resourceful, they enjoyed their job more and felt strong and vigorous at work, and they perceived an overall sense of control over life as well as had an ease of mind at and outside of their work environments. Taken together, the findings of these three studies suggest several implications for theory and practice, particularly those pertaining to the key role that age may play in understanding different 
workers' needs for job-related resources and how this may affect their work attitudes, behavior, and well-being. Theoretical implications suggest that COR theory can be integrated with lifespan development theories to address the age-related differences in the resource utility. In addition, the findings of this dissertation highlight the need to examine employee age as a main study variable to explore the boundary conditions of various resources - work and non-work outcomes. Implications for practice include recommendations such as facilitating job crafting and job redesigns for older workers, developing managerial trainings on relationship building with subordinates, creating a fair work environment through transparent organizational policies and practices, and improving personal capacities through stress management interventions. Avenues for future research are discussed as well, including identifying additional resources (e.g., overqualification, support from coworkers and family), and work and well-being outcomes (e.g., objective health measures such as sleep, sick days, and injuries) that may show age-based differences based on lifespan development theories. Finally, this dissertation highlights the need to replicate these study findings across industries, job types, gender, and culture as the usefulness of resources may be context-specific. 


\section{Dedication}

To my mom and dad -always caring and encouraging. 


\section{Acknowledgements}

I would like to express my sincere gratitude to my doctoral advisor and dissertation chair, Dr. Donald Truxillo, for his continuous support and guidance. From the early days of my doctoral studies, he has been a true mentor by listening to me, believing in my abilities, and inspiring me to achieve further. Providing me several opportunities to develop as a student, he also helped me transition to my new life in the U.S. Thanks to his reassuring presence, these past six years were an enjoyable and memorable journey.

I would also like to thank my dissertation committee members for their exceptional guidance and encouragement throughout this process. Dr. Todd Bodner, for sharing his expertise on research methodologies and pointing out several areas to improve this dissertation. A special thanks to Dr. Berrin Erdogan, for not only supporting my studies but also being a caring mentor during my life at Portland State University. Her genuine concern and guidance helped me overcome many challenges that I faced in academic and personal life. To Dr. Margaret Neal, my external reviewer, for her careful eyes and invaluable feedback as an expert on aging studies.

I would also like to thank Dr. Leslie Hammer for her generous support and giving me the chance to be a part of a collaborative research team. Thanks to this experience, I was able to work with many great people over the years and learn from them. 
I would also like to acknowledge the Oregon Healthy Workforce Center (www.ohsu.edu/ohwc), a National Institute for Occupational Safety and Health (NIOSH) Center of Excellence in Total Worker Health (grant number U19OH010154). Part of the data utilized in the first study of this dissertation was collected through the Safety and Health Improvement Program (SHIP) funded by the OHWC. Likewise, I would like to thank Dr. David Cadiz for his collaboration over the years. Part of the data utilized in the second study in this dissertation were collected through his collaboration with the Oregon Nurses Association, OR. Last, I would like to thank NIOSH (Grant number T03OH008435-11) for supporting my doctoral studies through the Graduate Training in Occupational Health Psychology (OHP) fund.

Finally, I would like to thank my family. To my mom and dad, for believing in me, listening to me, and working hard to help me follow this path. None of this could have been possible without your exceptional love, efforts, and support. To my sister and brother, for bringing joy to my life over the years even though I have been miles away from home. To my husband -my love, my travel and dance partner, a five-star cook, and a caring dad - for being a fantastic supporter both in good and tough times so that I could focus on my studies. Last, to my beautiful Sunshine, for rewarding me with incredible smiles and kisses in the mornings of long and sleepless nights. I feel blessed to have you all in my life. 


\section{Table of Contents}

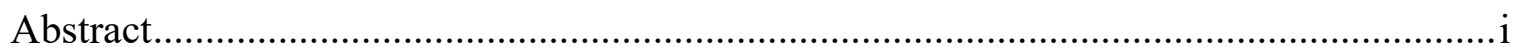

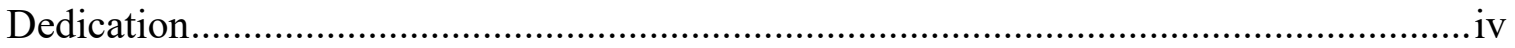

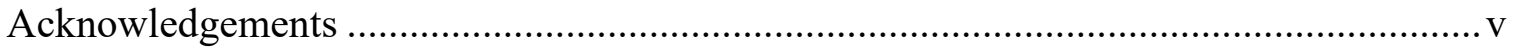

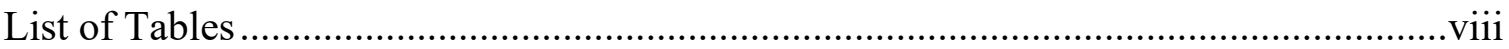

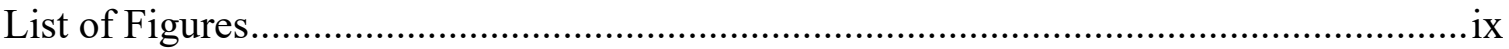

Chapter 1

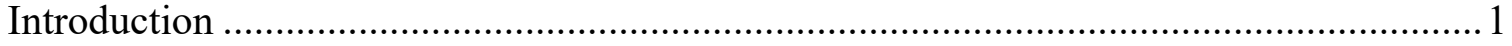

Chapter 2

Theoretical Background: Age-based Differences in the Usefulness of Resources:

Integrating Conservation of Resources (COR) Theory and Lifespan Resource Models .. 19

Chapter 3

Do Resources Matter for Employee Stress? It Depends on How Old You Are.

Chapter 4

Age-based Differences in the Relationship between Social Support Resources and

Different Forms of Job Performance.

Chapter 5

Investigating the Relationship Between the Job-related and Personal Resources and Employee Attitudes and Well-being: The Moderating Role of Age ................................ 106

Chapter 6

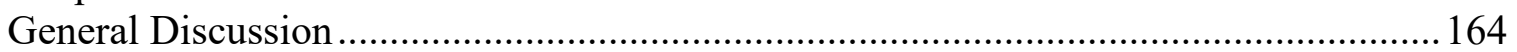

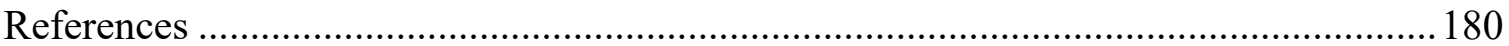




\section{List of Tables}

Table 3.1 Means, Standard Deviations, and Intercorrelations among Study Variables .... 73

Table 3.2 Results of Moderated Regression Analyses: Perceived Stress.........................74

Table 3.3 Results of Moderated Regression Analyses: Perceived Stress.........................75

Table 3.4 Results of Moderated Regression Analyses: Perceived Stress........................ 76

Table 4.1 Means, Standard Deviations, and Intercorrelations among Study Variables .. 102

Table 4.2 Results of Moderated Regression Analyses: Employee Performance ............ 102

Table 4.3 Results of Moderated Regression Analyses: Employee Performance ............ 102

Table 5.1 Means, Standard Deviations, and Intercorrelations among Study Variables .. 142

Table 5.2 Results of Moderated Regression Analyses: Job Satisfaction........................ 143

Table 5.3 Results of Moderated Regression Analyses: Work Engagement .................... 144

Table 5.4 Results of Moderated Regression Analyses: Perceived Stress....................... 145

Table 5.5 Results of Moderated Regression Analyses: Emotional Exhaustion .............. 146

Table 5.6 Results of Moderated Regression Analyses: Job Satisfaction........................ 147

Table 5.7 Results of Moderated Regression Analyses: Work Engagement .................... 148

Table 5.8 Results of Moderated Regression Analyses: Perceived Stress ....................... 149

Table 5.9 Results of Moderated Regression Analyses: Emotional Exhaustion .............. 150

Table 5.10 Results of Moderated Regression Analyses: Job Satisfaction...................... 151

Table 5.11 Results of Moderated Regression Analyses: Work Engagement .................. 152

Table 5.12 Results of Moderated Regression Analyses: Perceived Stress ..................... 153

Table 5.13 Results of Moderated Regression Analyses: Emotional Exhaustion ............ 154 


\section{List of Figures}

Figure 1.1 Proposed theoretical models examined in Study 1, Study 2, and Study 3...... 17

Figure 1.2 Overall summary of the proposed relationships examined in this dissertation.18

Figure 3.1 Summary model of the proposed relationships examined in Study $1 \ldots \ldots \ldots \ldots . . .77$

Figure 3.2 The interaction between skill discretion and age on perceived stress............. 78

Figure 3.3 The interaction between LMX and employee age on perceived stress...........79

Figure 3.4 The interaction between procedural fairness and employee age on perceived stress.

Figure 4.1 Summary model of the proposed relationships examined in Study 2........... 105

Figure 5.1 Summary model of the proposed relationships examined in Study 3........... 155

Figure 5.2 The interaction between decision-making autonomy and employee age....... 156

Figure 5.3 The interaction between decision-making autonomy and employee age on work engagement

Figure 5.4 The interaction between decision-making autonomy and employee age on emotional exhaustion.

Figure 5.5 The interaction between optimism and employee age on job satisfaction..... 159

Figure 5.6 The interaction between optimism and employee age on work engagement. 160

Figure 5.7 The interaction between optimism and employee age on perceived stress.... 161

Figure 5.8 The interaction between optimism and age on emotional exhaustion.

Figure 5.9 The interaction between perceived work ability and employee age on emotional exhaustion. 
Chapter 1: Introduction

The world population continues to age rapidly (U.S. Census Bureau, 2016). According to the most recent statistics shared by the U.S. Census Bureau (2016), people age 65 and over comprise 8.5 percent or over 617 million of the total population in the world in 2015, and, it is projected that this aging trend will increase rapidly over the next 35 years. Specifically, it is projected that the proportion of older people will be more than $12 \%$, or around 1 billion, of the total population by 2030 ; and it may even exceed 16 percent in only 33 years, reaching nearly 1.6 billion by 2050 . In other words, these statistics illustrate that the number of older people in the world will grow by $150 \%$, equal to an annual increase of 27 million from 2015 to 2050 . While these projections point out a consistent increase in the size of older population, this is not the case for younger population. The proportion of those under age 20 is expected to remain rather constant with less than a $4 \%$ increase from 2015 to 2050 . At the same time, the working age group, those between 20 and 64, will grow moderately by $25 \%$ within the same time period.

There are two key forces that contribute to the aging of the population in the industrialized counties. First, the total fertility rates have been dropping in the economically developed countries. In fact, for the first time in history, the older population, those 65 and older, is projected to exceed the number of births and children under age 5, almost doubling by 2050 (U.S. Census Bureau, 2016). Thus, it will become more difficult to replace older workers as they retire due to these low fertility rates. Second, global life expectancy at birth is increasing due to the availability and the quality 
of health care services in the developed countries and the reduction in both communicable and noncommunicable diseases, such as cardiovascular disease and diabetes (World Health Organization; WHO; 2016). According to WHO statistics (2016), the average life expectancy in the world was 71.4 years in 2015 (73.8 for female; 69.1 for men); and it even exceeded 80 years in twenty-nine countries from different regions across the world, such as Switzerland, Spain, France, Italy, Japan, Singapore, Australia, the Republic of Korea, and Canada. The U.S. Census Bureau (2016) projected that the global life expectancy will continue to increase, reaching 76.2 years by 2050 . Specifically, average life expectancy in North America was 79.9 years (82.2. for female; 77.4. for men) in 2015, and it is expected to increase to 84.1 ( 86.2 for female; 81.9 for men) in 2050. Similarly, average life expectancy in the European Union countries is expected to increase from 77.3 in 2015 to 82.1 in 2050 , and reach at 84.7 for males and 89.1 for females by 2060 (European Commission, 2015). Furthermore, the WHO (2016) projections demonstrate that people in most industrialized countries will not only live longer but they will also maintain a good health that is free from diseases or injuries. For example, an average male in the U.S. at age 65 is expected to live in full health for another 12.9 years, and an average female at age 65 is expected to have another 14.8 healthy years (U.S. Census Bureau, 2016).

These projections about the global aging of the population have two major implications for the workforce. First, it is expected that older people will stay active in the workforce longer, due to reasons such as increases in retirement ages in many developed countries, to deal with their diminished retirement benefits, and to save money 
for their life after retirement (Bloom, 2011; Hertel \& Zacher, 2015; Truxillo, Cadiz, \& Rineer, 2014). Thus, we will continue to see an increased number of older employees in the workplace. Based on the most recent U.S. Bureau of Labor Statistics (BLS; Toossi, 2012a), while there were only 18.7 million older workers who were 55 years and above, or nearly $13 \%$ of the labor force in 2000 , this age group reached 24.3 million, or $16 \%$ of the labor force in 2005 , and it increased to 30 million, constituting nearly $20 \%$ of the labor force, in 2010. According to the BLS (Toossi, 2012a), this increase in the participation rate of older workers is projected to grow further, reaching approximately 41 million workers and accounting for nearly a quarter of the total U.S. work force by 2020 and remaining almost steady until 2050 (Toossi, 2012b). Similarly, the median age of the working population has also increased consistently over the years (Toossi, 2012a), rising from 36.4 years in 1990 to 39.3 years in 2000 and to 41.7 years in 2010 . This increase in the median age is expected to continue, reaching 42.8 years in 2020. Finally, within the age range of 55 to 74, the majority of older workers are projected to be on the younger side. Specifically, more than three fourths of these workers are projected to be between 55 and 64 years old.

This aging of the workforce is no different in the European region. The employment rate of older people between ages 55 and 64 rose continuously in the EU countries between 2002 and 2013, and it is projected that the share of older workers (aged 55 to 64 ) in the EU will rise from 15\% in 2013 to $20 \%$ in 2060 (European Union Commission, 2015). This projected increase is even higher for countries such as Greece, 
Spain, Italy, Portugal, Slovakia, and Hungary, where older workers are expected to comprise more than half of the labor force by 2060 (European Union Commission, 2015).

The second implication of a rapidly aging population for the workforce is the increase in age-diverse workplaces (Dychtwald, 2000). As the share of older people increases in the total population and formal policies and regulations allow them to stay longer in the workforce, workplaces will grow more age-diverse, where younger and older workers will work side-by-side more often than they used to (Finkelstein \& Truxillo, 2013; Kunze, Boehm, \& Bruch, 2011; Yaldiz, Fraccaroli, \& Truxillo, 2017). Although age diversity can be advantageous for organizations where both younger and older workers are recognized as valuable resources who contribute to workplaces and communities, an age-diverse workforce requires a recognition of the differences in values, needs, motivations, attitudes, and behaviors between older and younger workers (Kunze \& Boehm, 2013).

Despite the projections that we will continue to see an increased number of older workers and an age-diverse workforce in the coming decades, practitioners and researchers know little about how to identify and address the needs of employees of different ages or how to manage age-diverse employee groups (Burke, 2015). Only in recent years have researchers addressed many issues around older workers and called for studies to examine the needs, work motivations, attitudes, performance, work outcomes, and health and well-being of this emerging age-diverse workforce and to inform organizational policies, practices, and workplace interventions for workers of different 
ages (Baltes \& Finkelstein, 2011; Burke, 2015; Fisher, Chaffee, Tetrick, Davalos, \& Potter, 2017; Truxillo, Cadiz, \& Hammer, 2015).

In an attempt to understand the dynamics of the aging workforce, studies have been conducted to examine how age is related to a number of work-related factors. Although past Industrial-Organizational/Organizational Behavior research has treated age as a statistical control variable, researchers are now studying age as a key study variable to uncover its associations with work attitudes and outcomes. Moreover, meta-analytic studies have shown that age is related to many job-related factors, including different dimensions of job performance ( $\mathrm{Ng} \&$ Feldman, 2008), job attitudes (Ng \& Feldman, 2010), work motivation (Kooij, De Lange, Jansen, Kanfer, \& Dikkers, 2011), and employee health and well-being ( $\mathrm{Ng} \&$ Feldman, 2012, 2013). The results of these studies are summarized in the second chapter of this dissertation, including age-related changes in physical and cognitive capacities, personality characteristics, work motivation, job attitudes, and job performance.

Although the abovementioned studies shed light on the main effect of age on various work outcomes, whether the associations between work-related factors, or job resources such as social support from leaders or decision-making autonomy on one's job, and work outcomes differ for older and younger employees remains mostly unanswered. This gap in the literature has been addressed by recent reviews (Halbesleben, Neveu, Paustian-Underdahl, \& Westman, 2014; Truxillo et al., 2014), pointing out the need to investigate employee age as a moderator between job resources and work outcomes such as well-being, job attitudes, and job performance. As shown by lifespan development 
theories, or "Life Span Resource Models" (Hobfoll, 2002) (e.g., Selection-OptimizationCompensation (SOC); Baltes \& Baltes, 1990; Socio-emotional Selectivity Theory (SST); Carstensen, Isaacowitz, \& Charles, 1999), human needs, motivations, and goals change as individuals age which challenges the implied assumption of mainstream resource theories (e.g., Conservation of Resources Theory (COR); Hobfoll, 1989) that the relationship between job resources and employee outcomes is robust across all ages. For example, based on Socio-emotional Selectivity Theory, as individuals age, perceptions about one's time left in life shift from being expansive to being limited. This shift in time orientation, in turn, influences the motivation to engage in social interactions for individuals of different ages. Specifically, the theory suggests that limited time perceptions would motivate older people to seek more emotional satisfaction out of social interactions, resulting in investing more in emotionally meaningful goals. On the other hand, having an open-ended time orientation, younger people would utilize social interactions primarily to gain knowledge and advance in their professional career. Based on these main assumptions of SST, then, this dissertation claims that while the utility of resources that help gain career-related knowledge and career advancement would be higher at younger ages, the importance of resources that can lead to emotional satisfaction in life and at work would increase by age.

Moreover, research has shown that not only affect-related goals but also strategies to select goals and maintain performance in life are influenced by age (e.g., SelectionOptimization-Compensation). Briefly, the SOC model suggests that in the face of diminishing physical and cognitive capacities with age, people actively engage in 
different strategies to maintain successful functioning and capitalize on available resources that may help offset any negative consequences in performance. Based on this basic tenet of the SOC model, then, the present dissertation suggests that the utility of resources that help ease cognitive load or mobilize energies and time to perform well at work or in life would increase by age. A thorough discussion of these resource-based theories, COR (Hobfoll, 1989), SOC (Baltes \& Baltes, 1990), and SST (Carstensen et al., 1999), is provided in the second chapter of this dissertation.

To conclude, empirical and meta-analytic studies, lifespan resource theories, and recent critical reviews of COR theory (e.g., Halbesleben et al., 2014) point out a possible moderating role of age on the link between job resources and employee outcomes which needs to be tested empirically. Capitalizing on this gap in the IO/OB literature, the purpose of this dissertation is to examine these relationships via three empirical studies.

\section{Statement of Purpose}

Recognizing age-based differences in needs, goals, and motivation, the aim of this dissertation is to examine whether certain job resources are differentially related to the well-being, work attitudes, and different forms of job performance of employees of different ages. Through a series of three studies, this dissertation aims to investigate the usefulness of different job resources for younger and older employees in relation to specific employee outcomes. Taking an integrative approach, each study focuses on different employee outcomes, including well-being (e.g., perceived stress, emotional exhaustion), work attitudes (e.g., job satisfaction, work engagement), and different forms of job performance (e.g., in-role performance, organizational citizenship behaviors). 
The first study (Yaldiz, Truxillo, Bodner, \& Hammer, 2018; Chapter 3)

investigates age as a moderator in the relationship between job-specific resources (e.g., skill discretion) and social support resources (e.g., leader-member exchange (LMX), perceived fairness) and employee stress, an important well-being outcome. The sample consisted of construction and field workers from two public works departments located in a city in the Pacific Northwest U.S. Utilizing data from the Safety and Health Improvement Program (SHIP), this study was conducted as part of the Oregon Healthy Workforce Center (OHWC), one of four Total Worker Health ${ }^{\mathrm{TM}}$ Centers for Excellence funded by the National Institute for Occupational Safety and Health (NIOSH). Data were collected as part of a longitudinal workplace intervention project, SHIP, which lasted for 12 months and aimed to improve employee health, safety, work-life balance, and wellbeing.

The second study (Chapter 4) examines the moderating role of age in the relationship between social support resources (e.g., perceived organizational support (POS) and LMX) and supervisory ratings of job performance dimensions, including inrole performance and organizational citizenship behaviors directed towards the individuals (OCBI) and towards the organization (OCBO). The uniqueness of this study is two-fold. First, unlike the first study, which examines employee reports of perceived stress as a well-being outcome, this study focuses on different dimensions of job performance as outcomes and utilizes multi-source data. Specifically, employees evaluated their own perceptions about job resources, whereas task performance and citizenship behavior performance ratings were obtained from their supervisors. In this 
respect, the results of this study help illustrate whether the perceived usefulness of resources by older and younger workers relates differently not only to their well-being but also to their performance at work. Second, the results of this study provide an opportunity to look at the importance of resources in a culture other than the U.S., since data for this study were collected from retail workers in Turkey. Unlike the U.S. which has an individualistic (separated/independent) culture, Turkey is recognized as a predominantly collectivistic society (relational/interdependent culture) (Hofstede, 1984), where building and maintaining close relationships with one's environment are valued and encouraged by people (Erdogan, Kraimer, \& Liden, 2004; Pasa, Kabasakal, \& Bodur, 2001; Pellegrini \& Scandura, 2006). Accordingly, individuals learn to value objects/resources based on cultural norms within which they grow up and live. Due to variations in norms and valued things across cultures, what is considered to be useful by members of a society may not be seen as equally helpful or important by members of other cultures (Markus \& Kitayama, 1991). The role of cultural context in shaping the perceived usefulness of resources is highlighted by recent reviews and merits investigation (e.g., Halbesleben et al., 2014; Hobfoll, 2002). Therefore, this study provides insight about how older and younger workers from a non-Western society differ in their perceptions about the value of resources to perform well at work. In this respect, the results of this study inform future research to conduct cross-cultural investigation.

Finally, the third study (Chapter 5) investigates employee age as a moderator in the relationship between job-specific (e.g., decision-making autonomy) and personal resources (e.g., optimism, perceived work ability) and work attitudes and well-being 
outcomes, such as job satisfaction, work engagement, perceived stress, and emotional exhaustion. In collaboration with the Oregon Nurses Association (ONA), data for this study were collected from registered nurses in the state of Oregon in the U.S. using timelagged, on-line surveys (Pre-screening, Time 1, Time 2). Utilizing a matched-sample study design, perceptions of job resources were collected in the first survey, whereas selfreports of work outcomes were obtained in the second survey. This final study aims to uncover additional work attitudes and well-being outcomes while exploring the relative value of optimism and perceived work ability as personal resources for younger and older workers. To date, work ability has been studied mostly as an outcome, and the few studies investigating work ability as an antecedent have focused only on its relationship to employee withdrawal behaviors such as absence from work and sick leaves while neglecting other employee outcomes (McGonagle, Beatty, \& Joffe, 2014; McGonagle, Fisher, Barnes-Farrell, \& Grosch, 2015). Capitalizing on this gap in the literature, this study approaches work ability as a personal resource and aims to uncover its association with different job attitudes and well-being outcomes.

It is important to note that this body of work defines an older worker as one who is at the later stages in his or her career. Instead of utilizing a specific age or age range to address older and younger workers, the three studies in this dissertation investigate age as a continuous variable. Recent research on work and aging (Hertel \& Zacher, 2015; Truxillo et al., 2014, 2015; Yaldiz et al., 2017a) suggests that using arbitrary cut-offs to define older workers (e.g., over-40/under-40 years based on the Age Discrimination in Employment Act in the United States) is not theoretically or methodologically 
meaningful, and that age should be treated as a continuous variable to explain meaningful amounts of variance in work outcomes. Accordingly, Study 1, Study 2, and Study 3 treat age as a continuous variable and utilize employee reports of chronological age. To report the study findings conveniently, "younger workers" and "older workers" are operationalized as $1 \mathrm{SD}$ below and above the mean age of the sample, respectively.

In conclusion, the summary models of the proposed relationships in each study are presented in Figure 1.1.

In summary, bringing together these three distinct yet related empirical studies, this dissertation aims to answer the following overarching research questions:

1) Do certain job resources hold the same value for employees of different ages in relation to various work outcomes, or is the usefulness of resources agedependent? (Overarching research question across Study 1, Study 2, and

\section{Study 3)}

2) Can we detect age-related differences in the link between job resources and well-being utilizing a 1-year time-lagged study design? (Study 1)

3) How are job resources related to different forms of job performance for employees of different ages? Are certain job resources equally valuable for younger and older workers to achieve in-role performance and citizenship behaviors? (Study 2)

4) How does the importance of certain job-specific and personal resources differ for younger and older workers in relation to different job attitudes and wellbeing outcomes? (Study 3) 
5) What is the generalizability of the findings that demonstrate age-based differences to explain the relationship between job resources and work and well-being outcomes? In other words, is the age-based relationship between certain resources and work and well-being outcomes generalizable to other industries, job types, and cultures? (Overarching research question across Study 1, Study 2, and Study 3)

Investigating the abovementioned research questions, this dissertation aims to make three theoretical contributions to the organizational literature. First, this study expands COR theory (Hobfoll, 1989) to examine the relative usefulness of resources with age. Although COR theory has been widely used to investigate the relationships between different resources and work attitudes, work outcomes, and well-being, research that has utilized COR theory has failed to incorporate time-related issues to explain the associations between resources and employee outcomes. Recently, Halbesleben and colleagues (2014) pointed out this gap in COR theory and addressed age as an example of time-related concerns that need to be investigated. Specifically, they called for future research to shed light on the shifting value of resources with age. Although a few studies have examined age-based differential effects of job-specific factors on employee outcomes recently (e.g., Zaniboni et al., 2016; Zaniboni, Truxillo, \& Fraccaroli, 2013; Zaniboni, Truxillo, Fraccaroli, Bertolino, \& McCune, 2014), the current dissertation is different from these studies in three ways. First, this dissertation is guided by COR theory, whereas prior studies were based on different theoretical frameworks (e.g., SOC) and therefore failed to specifically address the aforementioned time-related limitation of 
the theory. Second, the current dissertation focuses on at least one resource from jobspecific, personal, and social support domains as a focal antecedent to gain a comprehensive understanding of the usefulness of resources, whereas the scope of the antecedents in aforementioned studies was limited to decision authority, task and skill variety only. Third, in addition to investigating a wider range of resources, this dissertation focuses on a number of different forms of job outcomes, as well. Unlike prior research which studied a limited number of well-being outcomes and attitudes towards work, the current study takes into account a variety of employee outcomes, including not only job attitudes and employee well-being but also different forms of job performance.

The second contribution is relevant to the abovementioned difference in the scope of focal outcomes between prior research and the current dissertation. Bringing three empirical research projects together, this dissertation helps explain different employee outcomes in relation to age-based differences in the usefulness of resources at work. Specifically, the findings of this study shed light on understanding how employee age and certain resources interact to explain (a) attitudes towards jobs such as job satisfaction and work engagement; (b) subjective well-being including perceived stress and emotional exhaustion; and (c) supervisory ratings of task performance and organizational citizenship behavior performance.

The third contribution of the current dissertation is investigating the generalizability of the study findings to different industries, job types, and cultures. As the value of any object/resource is defined within a given context (e.g., Halbesleben et al., 2014), the findings of these three studies help demonstrate, for example, whether 
older and younger employees from an individualistic and a collectivistic culture would similarly value certain resources. Even though these three studies have not been specifically designed to make a cross-cultural comparison, I believe that the findings from these studies help inform future research.

The findings of this dissertation have practical implications for organizations. This study attempts to provide an enhanced understanding about which resources are valued more, or perceived as more critical, by older and younger workers to explain their well-being, attitudes towards job, and performance at work. In this respect, the three studies are relevant to the field of Occupational Health Psychology (OHP). Specifically, OHP is defined as "the application of psychology to improving the quality of work life, and to protecting and promoting the safety, health, and well-being of workers" (NIOSH, 2010). Identifying the utility of resources on different work and well-being outcomes for employees of different ages, the findings of this study aim to improve the quality of work life and well-being of workers. The results of this dissertation can inform organizational decisions to develop better policies, practices, and workplace interventions that would benefit an age-diverse workforce and help identify ways that would attract, motivate, and retain older workers (Hertel \& Zacher, 2015).

Based on the results of these studies, a detailed discussion is provided in the final chapter (Chapter 6) and includes recommendations such as those for job crafting, job redesigns, managerial trainings on relationship building with subordinates, and stress management interventions to strenghten personal capacities (Kulik, Ryan, Harper, \& George, 2014; Truxilo, Cadiz, Rineer, Zaniboni, \& Fraccaroli, 2012; Truxillo et al., 
2015). I also suggest future research directions, such as investigating the age-based value of job resources in work and family domains. The overarching summary model of the relationships examined in this dissertation is presented in Figure 1.2. 


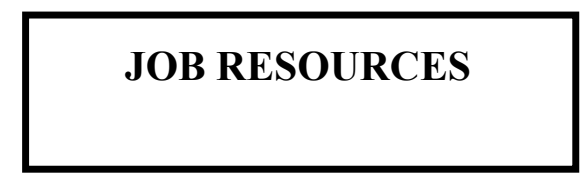

\section{WORK AND WELL-BEING OUTCOMES}

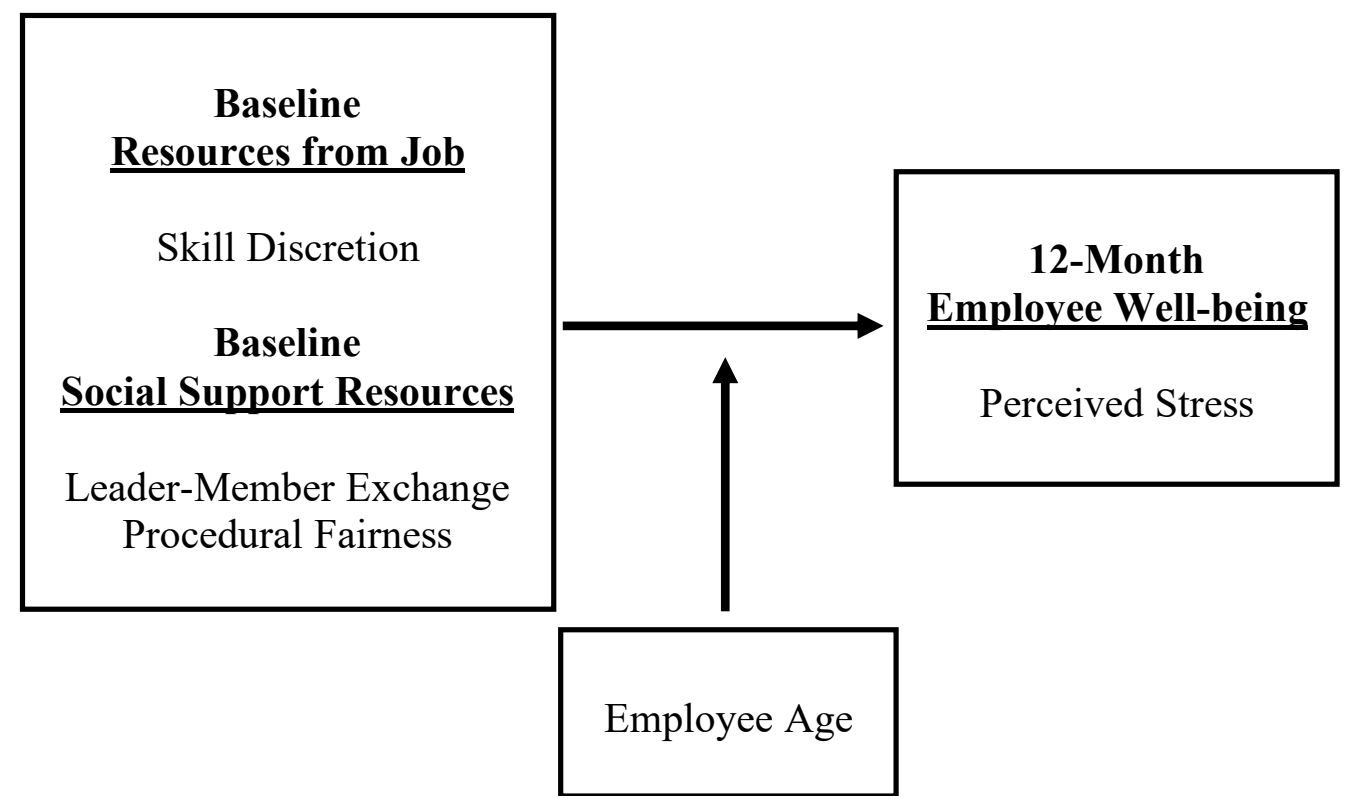

Study 1. The proposed model examining the interaction between baseline resources from job and social support resources and employee age on the perceived stress assessed at 12-month.

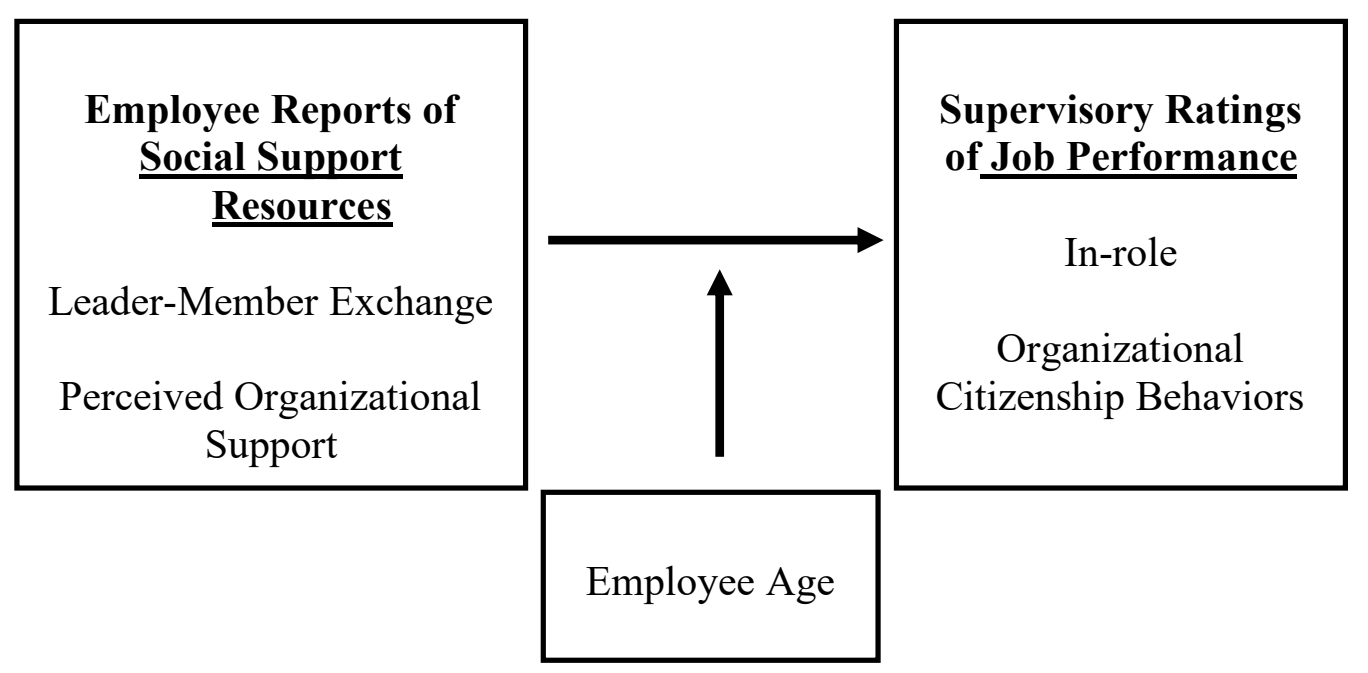

Study 2. The proposed model investigating the interaction between employee reports of social support resources and employee age on supervisory ratings of different forms of job performance. 


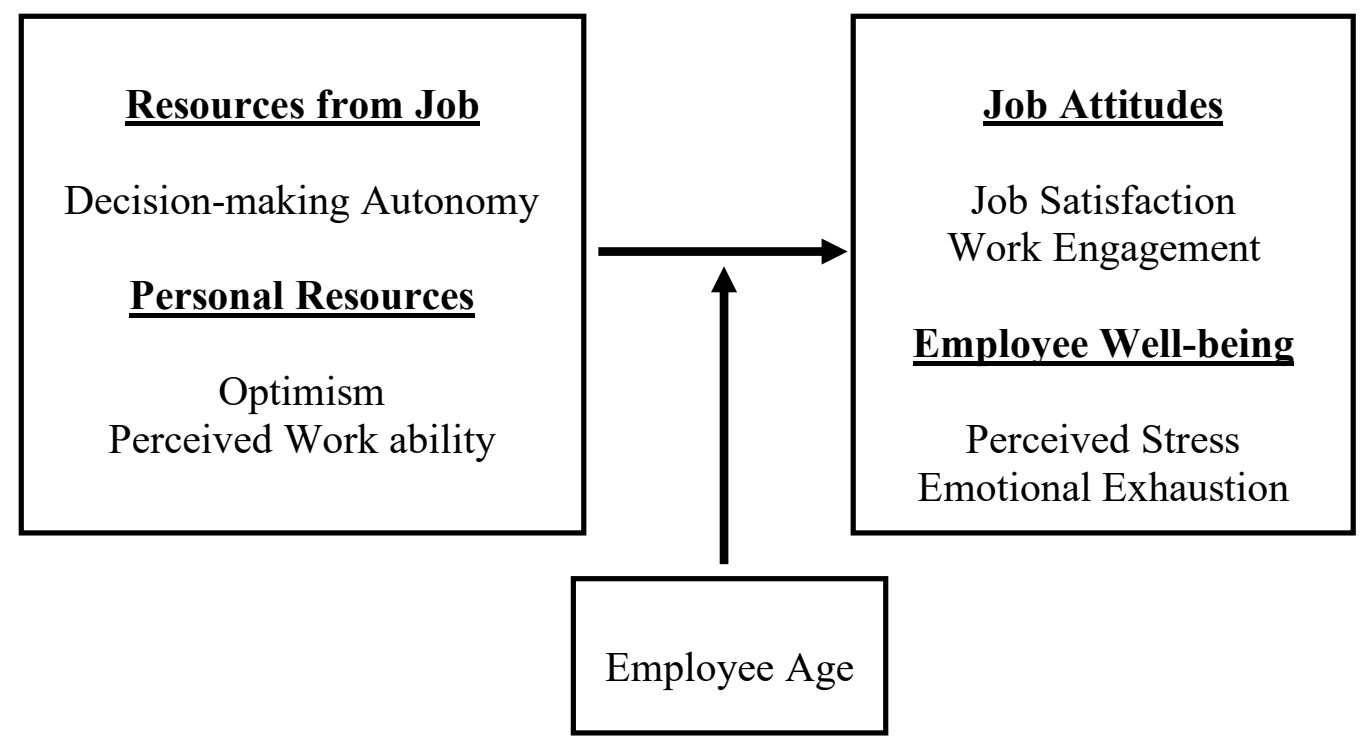

Study 3. The proposed model examining the interaction between resources from job and personal resources and employee age on job attitudes and employee well-being assessed with a 1-week time lag study design.

Figure 1.1 Proposed theoretical models examined in Study 1, Study 2, and Study 3. 


\begin{tabular}{|c|c|}
\hline \multicolumn{1}{|c|}{ JOB RESOURCES } & $\begin{array}{c}\text { WORK AND WELL-BEING } \\
\text { OUTCOMES }\end{array}$ \\
Resources from Job \\
Skill Discretion \\
Social Support Resources \\
Procedural Fairness
\end{tabular}

Figure 1.2 Overall summary of the proposed relationships examined in this dissertation. 


\section{Chapter 2: Theoretical Background: Age-based Differences in the Usefulness of Resources: Integrating Conservation of Resources (COR) Theory and Lifespan \\ Resource Models}

This dissertation capitalizes on two different resource theories to examine whether older and younger workers perceive the value of job resources differently in relation to their work and well-being outcomes. First, I utilize Conservation of Resources Theory (COR; Hobfoll, 1989) as the overarching theoretical framework to demonstrate that factors such as job characteristics, social support, and personal capacities are considered as job resources which relate to work attitudes, work outcomes, and employee wellbeing. Although COR theory provides a useful theoretical background to the proposed studies in this dissertation, it is inadequate to address the age-specific aspects of the aforementioned research questions. Therefore, I expand on lifespan development theories, or "Life Span Resource Models" (Hobfoll, 2002; p. 313) to explain the role of age in determining the valence of job resources. Specifically, I draw on Socio-emotional Selectivity Theory (SST; Carstensen et al., 1999) and Selection-OptimizationCompensation Theory (SOC; Baltes \& Baltes, 1990) as two different yet complementary models.

The following section summarizes the main principles of COR theory and introduces specific job resources that are of interest to this dissertation. Next, age-related changes in different life domains (e.g., physical, cognitive, personality characteristics, work motivation, work attitudes, job performance) are outlined, and Lifespan Resource Models (i.e., SOC and SST) are integrated into the discussion to establish the main 
arguments of this dissertation about age-related differences in the usefulness of resources. I summarize how these models approach age-based shifts in goals and motivation, which in turn influence the importance of resources for older and younger individuals.

\section{Conservation of Resources Theory (COR; Hobfoll, 1989)}

COR theory $($ Hobfoll, 1989) suggests that people are motivated to protect their current resources (conservation), seek to obtain new resources (acquisition), and experience stress when confronted with an actual or a potential loss of resource or when they fail to renew resources after spending from their resource reservoir. In this respect, COR theory is considered as a resource-adaptation model (Hobfoll, 2002). Specifically, the theory posits that resource loss is key to the stress experience, and therefore people seek to obtain, retain, and protect their resources in order to maintain well-being. The theory also suggests that the ability to gain new resources becomes especially important in the face of resource loss to pursue life goals and restore emotional well-being.

COR theory describes resources very broadly as things that people value such as objects (e.g., home), personal characteristics (e.g., self-esteem, mastery), conditions (e.g., socio-economic status, employment, marriage), and energies (e.g., time, money, knowledge). Due to this wide conceptualization of a resource, COR theory has been extensively used in organizational behavior (OB) literature over the past years to investigate a variety of psychological factors as a resource and to explain how they relate to different employee outcomes. Based on a recent review of COR theory (Halbesleben et al., 2014), example resources that have been examined within COR theory includes 
constructive resources (e.g., rewards, reinforcements, autonomy, decision authority, skill discretion, control, participation in decision making, resilience), conditions (e.g., job security), social support resources (e.g., from supervisor, coworkers, organization, spouses, customers), energy resources (e.g., time away from work, recovery from work), key resources (e.g., emotional intelligence, self-esteem, core self-evaluations, conscientiousness, emotional stability), and macro resources (e.g., family-friendly work place policies). Resources that are examined as focal predictors in this dissertation are introduced below.

Social support resources. According to COR theory, support from social environment is a key resource and those who have social support are more stress-resistant and have better mental and physical health (Hobfoll, 2002). Social support resources help individuals cope with work demands, reduce demands at work, and mobilize and expand existing resources to meet the environmental demands (Chen, Westman, \& Eden, 2009). Social support may come from a variety of sources such as from one's supervisor, coworker, organization, spouse, and other family members ( $\mathrm{Ng}$, Eby, Sorensen, \& Feldman, 2005; Sonnentag \& Pundt, 2015; Terry, Nielsen, \& Perchard, 1993; Viswesvaran, Sanchez, \& Fisher, 1999). Two types of important work-related support resources in the organizational literature are support from supervisors/leaders (e. g., leader-member exchange; LMX) and support from organization (e.g., procedural fairness and perceived organizational support; POS) (Halbesleben, 2006).

LMX as a social support resource. LMX (Dienesch \& Liden, 1986) refers to the quality of the reciprocal relationships between a leader and employee dyad that is 
characterized by trust, liking, loyalty, and professional respect. Empirical studies have consistently shown that higher-quality LMX is associated with a number of favorable employee outcomes. For instance, studies that examined the link between LMX and employee well-being demonstrated that LMX is related to lower levels of emotional exhaustion and cynicism (Bekker, Halbesleben, \& O’Hair, 2005; Jiang, Law, \& Sun, 2014) and burnout (Huang, Chan, Lam, \& Nan, 2010; Thomas \& Lankau, 2009;

Viswesvaran et al., 1999); and higher levels of work engagement and positive emotions (Bakker \& Bal, 2010; Xanthopoulou, Bakker, Demerouti, \& Scahufeli, 2009, 2012). In addition to well-being outcomes, meta-analyses have shown that employees who had higher-quality LMX relationships also had more favorable attitudes towards their jobs such as higher organizational commitment, job satisfaction, career satisfaction, and lower turnover intentions, as well as higher job performance including task performance and citizenship behaviors (Dulebohn, Bommer, Liden, Brouer, \& Ferris, 2012; Gernster \& Day, 1997; Ng et al., 2005; Ng \& Sorensen, 2008; Rockstuhl, Dulebohn, Ang, \& Shore, 2012). Despite the vast research on LMX, the relative value of LMX to the well-being and job performance of older and younger workers has remained unexamined.

Perceived organizational support (POS) as a social support resource. POS refers to employee beliefs about the extent to which the organization values their efforts, considers their best interest when making decisions, and cares about their well-being (Eisenberger, Huntington, Hutchison, \& Sowa, 1986; Rhoades \& Eisenberger, 2002). Research on employee health and well-being has shown that POS is related to reduced psychological and physical strains such as general fatigue and burnout (Cropanzano, 
Howes, Grandey, \& Toth, 1997). In addition, meta-analyses (Rhoades \& Eisenberger, 2002; Riggle, Edmonson, \& Hansen, 2009) have demonstrated that POS is associated with higher organizational and affective commitment, job satisfaction, in-role and extrarole performance, and lower intention to leave and reduced turnover. Despite the welldocumented main effect of POS on employee outcomes, research investigating the boundary conditions of these relationships is yet limited (Riggle et al., 2009).

Fair treatment as a social support resource. Fairness is another organizational resource that helps individuals regulate their relationships with their environment (Cropanzano, Bowen, \& Gilliland, 2007). Procedural justice refers to the perceived fairness of decision-making processes through which the outcomes (e.g., pay, promotion, rewards) are distributed in an organization (Leventhal, 1980; Thibaut \& Walker, 1975). Procedural fairness focuses on the perceived control of the processes and addresses six specific characteristics of a work environment. Accordingly, it reflects the degree to which organizational policies and procedures are consistent across people and over time; based on accurate information; applied in an unbiased fashion; offering opportunities to correct unfair decisions; are representative of all parties affected by the decisions; and are based on ethical grounds. In other words, work environments with high procedural fairness are transparent about how decisions are made and implemented, do not discriminate against any members, value employee input when making key decisions, and allow channels for employees to speak up their concerns.

In terms of employee health and well-being outcomes, lower procedural justice perceptions are related to increased perceived stress (Judge \& Colquitt, 2004) and 
psychological distress including emotional exhaustion, depression, and anxiety (Tepper, 2001), increased negative emotions such as anger and negative mood (CohenCharash \& Spector, 2001; Colquitt et al., 2013), higher anger and hostility towards the company (Barclay, Skarlicki, \& Pugh, 2005), and increased sickness-based absence, poor self-rated health and increased sleep problems (Elovainio, Kivimäki, \& Helkama, 2001; Elovainio, Kivimäki, Steen, \& Vahtera, 2004; Elovainio, Kivimäki, \& Vahtera, 2002; Elovainio, Kivimäki, Vahtera, Keltikangas-Järvinen, \& Virtanen, 2003). In addition to these health and well-being outcomes, meta-analytic findings (Cohen-Charash \& Spector, 2001; Colquitt et al., 2013) have shown that, among other forms of fairness (i.e., distributive, interpersonal, informational), procedural justice is strongly associated with relation-based employee attitudes such as trust, organizational commitment, perceived organizational support, relationships with supervisors, and intention to recommend the organization to others, and work outcomes including task performance, citizenship behaviors, and counter productive work behaviors. Although meta-analytic studies that investigated the main effects of demographic characteristics on fairness perceptions did not find a significant association between age and perceived fairness, how age and fairness perceptions may interact to predict employee well-being remains unanswered (Cohen-Charash \& Spector, 2001).

Resources from job. Job characteristics, or resources from job, refer to how the work is carried out by employees and the range and nature of tasks associated with a particular job (Hackman \& Oldham, 1975; Morgeson \& Humphrey, 2006). Different job characteristics have been widely examined to explain work outcomes in organizational 
literature, and I focus on decision-making autonomy and skill discretion (skill variety) as two distinct job-specific resources in this dissertation.

Decision-making autonomy as a job-specific resource. The first resource from job, job autonomy, is described as the extent to which a job allows freedom, independence, and discretion in decision making, work scheduling, and work methods to perform tasks (Morgeson \& Humphrey, 2006). Autonomy on one's job has an intrinsic motivational role that helps individuals increase their efforts and engagement (Kuhnel, Sonnentag, \& Bledow, 2012). Meta-analyses have shown that, among other types of job characteristics, job autonomy is strongly and positively associated with work attitudes and outcomes, including job satisfaction, and objective and subjective reports of job performance, and negatively associated with absenteeism (Fried \& Ferris, 1987; Humphrey, Nahrgang, \& Morgeson, 2007; Spector, 1986). In terms of well-being outcomes, job autonomy is negatively related to anxiety, burnout, and stress (Humphrey et al., 2007). Additional studies have also supported that job autonomy relates to emotional exhaustion (Diestel \& Schmidt, 2012) and work engagement (Kuhnel et al., 2012; Xanthopoulou et al., 2009). Job autonomy at work can have multiple facets, such as decision-making autonomy, work scheduling autonomy, and work methods autonomy (Morgeson \& Humphrey, 2006). Decision-making autonomy refers to the freedom to make decisions at work (Karasek et al., 1998). Compared to other types of job autonomy, both meta-analyses and empirical studies have demonstrated that decision-making autonomy is the strongest predictor of employee attitudes such as job satisfaction (Humphrey et al., 2007; Morgeson \& Humprey, 2006). Therefore, the current dissertation 
focuses on this specific form of autonomy to expand understanding of its relationship to different job attitudes and well-being outcomes.

Skill discretion as a job-specific resource. Another resource from job that this dissertation examines is skill discretion. Skill discretion refers to the degree to which one's job provides opportunities to use a variety of skills and flexibility to choose from those skills set (Hackman \& Oldham, 1975; Karasek et al., 1998). As skill discretion provides an opportunity to utilize multiple skills at work and gives a sense of control about which skills to utilize, it is considered as challenging, motivating, and engaging for employee performance (Morgeson \& Humphrey, 2006). Meta-analytic findings and empirical studies have also demonstrated that skill variety/skill discretion is positively related to job satisfaction, organizational commitment, and job involvement; and negatively related to employee well-being such as overall health (McGonagle et al., 2014), burnout and exhaustion (Humphrey et al., 2007; Morgeson \& Humphrey, 2006). Evidence from initial studies examining the age-based differential relationship between job characteristics and job attitudes (Zaniboni et al., 2016; Zaniboni et al., 2014; Zaniboni et al., 2013) showed that skill variety was not related to turnover intentions of younger workers, whereas turnover intentions decreased significantly among older workers as skill variety increased.

To summarize, based on COR theory, individuals who are provided with opportunities to make work-related decisions on their own and to choose from their skills about how to perform work would be in a better position to allocate their existing 
resources, and they would be more capable to deal with stressful demands of their jobs (e.g., Hobfoll, 2002; Parker \& Ohly, 2008).

Personal resources. Personal resources are described as internal means that help individuals function, appraise situations positively, and deal with stress (Hobfoll, 2002). In this respect, the availability of personal resources enables individuals to be more stress-resistant and help them achieve their goals (McGonagle et al., 2015). In the current dissertation, I examine two personal resources that have been understudied in relation to worker health and well-being.

Optimism as a personal resource. Optimism as a personality trait is defined as the tendency to believe that one will generally experience good versus bad outcomes in life (Scheier \& Carver, 1985). Studies have shown that individuals with higher optimism tend to persistently and effectively pursue goals in life (Segerstrom \& Solberg Nes, 2006; Solberg Nes, Segerstrom, \& Sephton, 2005), actively pursue social relationships with friends and families (Brissette, Scheier, \& Carver, 2002), and tend to focus less on negative aspects of their lives (Scheier et al., 1989). In terms of well-being, studies have shown that those with higher optimism are likely to have more favorable physical and mental health, and they tend to deal with demanding environmental conditions more effectively (Hobfoll, 2002). For example, in a longitudinal study conducted with law students over a 10-year period (Segerstrom, 2007), it is found that optimism is negatively related to poor psychological health, including depression and anxiety, and also, optimism assessed at the baseline is negatively related to follow-up reports of physical health symptoms such as pain and gastrointestinal symptoms. 
Studies that examined optimism as a personal resource with employee samples have yielded similar results. For example, Mache and colleagues (2012) found that optimism is moderately and positively related to work engagement in a sample of German health care workers. Similarly, Xanthopoulou and colleagues (Xanthopoulou, Bakker, Demerouti, \& Schaufeli, 2007) illustrated that optimism is associated with higher work engagement and lower levels of exhaustion in a sample of engineers in the Netherlands. Finally, being optimistic was associated with higher job satisfaction and lower levels of emotional exhaustion, mental distress, and physical symptoms such as back pain and headache in a Finnish sample of working adults (Mäkikangas \& Kinnunen, 2003). In this vein, from a resource-based perspective, optimism helps individuals mobilize resources and even accumulate more resources over time such as skills, friendship, and better physical and mental well-being (Segerstrom 2007; Hobfoll, 2002; Mäkikangas \& Kinnunen, 2003). As noted in previous research (Palgi, Shrira, Ben-Ezra, Cohen-Fridel, \& Bodner, 2011), studies are needed to examine the boundary conditions of the link between optimism and well-being outcomes such as investigating how optimism relates to the well-being of older and younger individuals.

Perceived work ability as a personal resource. Perceived work ability is defined as employees' assessment of their own physical and mental capacities to continue performing their job (Ilmarinen, 2007, 2009; Tuomi, Ilmarinen, Jahkola, Katajarinne, \& Tulkki, 1998). As proposed by Bakker and Demerouti (2007), mental and physical capacities, namely the foundations of one's work ability, constitute personal resources for employees to accomplish their jobs. As work ability is a recent construct, however, 
research on work ability in the IO/OB literature is limited, and existing studies have examined work ability mostly as an outcome rather than as a predictor of work attitudes and well-being. When investigated as an antecedent, studies have shown that work ability is related to retirement intentions, retirement, disability leave, sick leave, and absence from work (Ahlstrom, Grimby-Ekman, Hagberg, \& Dellve, 2010; von Bonsdorff et al., 2011; McGonagle et al., 2015). However, as noted in previous research (McGonagle et al., 2015), in addition to these withdrawal behaviors, research on work ability should extend to other work outcomes, including individual well-being and job performance. In addition to theoretical contributions of uncovering how work ability relates to various well-being and work outcomes, this line of research may also have practical contributions such as helping design better workplace interventions to promote employee health and well-being. Thus, to fill this gap in the organizational and occupational health literature, this dissertation aims to investigate work ability as a personal resource and how it relates to job attitudes and well-being outcomes of people of different ages including job satisfaction, work engagement, perceived stress, and emotional exhaustion. As for its relationship to age, although previous research has reported that work ability declines with increasing age (e.g., Fisher et al., 2006; Ilmarienen et al., 1991; Tuomi et al., 1998), recent studies with over a thousand health care workers from six different countries (McGonagle et al., 2014) found that age was not related to work ability in any of these national samples, pointing out a need for further examination of this relationship (e.g., Fisher et al., 2017). 
After this introduction to the focal job resources of the current dissertation and how they relate to different work outcomes, the following section integrates age-related changes in different life domains and two Lifespan Resource Models into the discussion to explain the expected age-based differences in the usefulness of resources.

\section{Shifting Value of Resources with Age: Lifespan Resource Models}

Although COR theory has been widely used in the organizational literature, its broad conceptualization of resources has raised concerns over time. As opposed to its original definition, which describes a resource merely as anything that holds value to someone, two main arguments were developed later to redefine the value of a resource (e.g., Baltes, 1997; Halbesleben et al., 2014; Hobfoll, 2002). The first argument proposes that resources should be goal-focused; thus a resource is considered as anything that individuals perceive as helpful in attaining their goals or satisfying their needs. While the first argument highlights the fact that resources are important in the eye of the beholder as long as they align with individuals' goals, the second argument challenges the assumption that the value of resources are universal. The arguments posit that the value of a resource can vary significantly depending on the person and the context (e.g., Baltes, 1997; Halbesleben et al., 2014; Hobfoll, 2002). For example, Halbesleben and colleagues (2014) suggested that what is perceived as important or preferable to a person might not hold the same value for others due to individual differences in goals and needs. Moreover, they suggested that context-specific differences such as growing up in an individualistic (independent) versus collectivistic (interdependent) culture are also influential on the variability of resource value. 
Soon after acknowledging that resources may not be equally important to everyone, recent reviews (e.g., Halbesleben et al., 2014) have also pointed out another limitation in COR theory. Specifically, these reviews argued that COR theory is limited for explaining time-related issues about the dynamic nature of resources. As stated by work motivation theories (Inceoglu, Segers, \& Bartram, 2012; Kanfer \& Ackerman, 2004), it is known that needs and motivation change with age, hence it is reasonable to expect that the usefulness of resources that help individuals attain their goals would also change with age. Although COR theory posits that one's resources fluctuate over time through experiencing loss and gain spirals, how the usefulness of resources differs across people of different ages has remained unanswered (Halbesleben et al., 2014).

To address this gap about the age-based time-related concerns in COR theory, I utilize two different Lifespan Resource Models (i.e., SOC and SST) to explain why we would expect to detect age-related differences in the importance of resources. The next session starts with a summary of age-related changes within the person, including physical, cognitive, and personality-related changes, and changes in work motivation, attitudes towards job, and job performance. Next, I expand on SOC and SST to build the main arguments of this dissertation.

\section{Age-Related Changes within the Person.}

Physical changes. As individuals age, neurological and biological capacities diminish gradually. For example, sensory capacities decline over time causing impaired vision, hearing, and smell (Papalia, Sterns, Feldman, \& Camp, 2007), muscular strength and endurance become weaker, and motor functions slow down resulting in slower 
reaction times and performance (Kaplan, 1993). All of these may pose challenges to coping with physical demands of everyday life. Although age-related physical decline is inevitable, it is noteworthy to add that these changes show between-person variability, and there are many factors other than age, such as race, gender, lifestyle (e.g., diet), and environment (e.g., air pollution) that may influence the severity of physical decline.

Cognitive changes. Research on age and cognitive ability has shown that different types of cognitive abilities (i.e., fluid and crystallized intelligence) are affected differently by age (Cattell, 1943, 1987). Fluid intelligence refers to the capacity for processing novel information, abstract reasoning, short-term memory, learning, and problem solving; this type of intelligence has been shown to peak at young adulthood and then decline throughout one's life (Schaie, 1996). On the other hand, crystallized intelligence consists of one's general knowledge, verbal expressions, vocabulary, and experiences accumulated over life. Although fluid intelligence tends to decline after young adulthood, crystalized intelligence has been shown to increase though middle age and beyond (Baltes, 1997). In other words, individuals experience a loss-and-growth process in their cognitive abilities over a lifespan via diminishing fluid capacities and enriching crystallized intelligence (Ackerman, 2014; Kanfer \& Ackerman, 2004; Klein, Dilchert, Ones, \& Dages, 2015). Similar to physical abilities, factors other than age, such as culture and cohort effects, are also influential on cognitive capacities (Hertel \& Zacher, 2015; Salthouse, 2014).

Changes in personality characteristics. Unlike the commonly held belief that personality is stable across the lifespan, research has demonstrated that some personality 
traits change over time. For example, in their meta-analysis, Roberts and colleagues (Roberts, Walton, \& Viechtbauer, 2006) found mean-level changes in most of the Big Five personality traits (FFM; Costa \& McCrae, 1992) as people age. Examining 92 longitudinal studies, they concluded that as people age, mean-level increases were observed in agreeableness (e.g., being altruistic and compliant, friendly, trusting, tolerant, flexible, courteous), conscientiousness (e.g., being orderly and self-disciplined, dependable, hardworking, responsible, careful), and emotional stability (e. g., not being depressed and anxious). Age-related changes in Big Five personality traits have been also supported by empirical studies demonstrating that mean-level agreeableness and conscientiousness increased over time (Soto \& John, 2012; Specht, Egloff, \& Schmukle, 2011), while neuroticism declined (Soto, John, Gosling, \& Potter, 2011).

Changes in work motivation. In line with the abovementioned within-person changes in physical and cognitive capacities and changes in personality traits over a lifespan, research has shown that work motivation also changes with age. Describing four major areas that develop across one's life (i.e., loss, growth, reorganization, and exchange), Kanfer and Ackerman (2004) proposed an integrative framework on agerelated work motivation. Specifically, loss refers to the diminishing fluid intelligence by age and growth addresses accumulation of crystallized intelligence over time. Reorganization points out restructuring goals due to age-related changes in non-ability traits such as personality, emotion, and affect. As an example of reorganization around affect, older people tend to avoid conflicts and prefer investing in emotionally meaningful relationships due to changes in one's perceptions about their remaining time 
in life. Finally, exchange refers to changes in primacy motives in relation to one's shifting values, self-concept, and vocational interests over time. Specifically, older adults tend to focus on generativity motives, improving their emotion control strategies, and they prefer transactions that support positive affect, self-concept, and identity. For example, related to emotions, Carstensen and colleagues (Carstensen, Paspuathi, Mary, \& Nesselroade, 2000) conducted a study with 184 individuals between ages 18 and $94(M=$ 55.0, $S D=20.4$ ) recording their expressed emotions five times a day for a week. The findings revealed that although both younger and older individuals reported a comparable number of positive emotions, older adults reported fewer negative emotions than their younger counterparts, which may indicate a more effective use of emotional regulation tactics at older ages.

In sum, Kanfer and Ackerman (2004) proposed that older and younger adults would be motivated by different factors at work due to the shifts in these four themes over a lifespan. They argued that older workers tend to use accumulated job knowledge to compensate for the decline in fluid intelligence to perform well at work and pursue intrinsically motivated tasks that affirm their self-concept. On the other hand, younger workers will tend to focus on growth to advance in their careers and participate in learning and development activities to gain required job knowledge and skills.

Kanfer and Ackerman's age-related work motivation framework (2004) found support in meta-analyses and empirical studies. Investigating 86 studies in their metaanalysis, Kooij and colleagues (2011) found that age was significantly and negatively associated with growth motives (e.g., development or advancement at work) and extrinsic 
work-related motives (e.g., promotion, recognition, compensation, and benefits), whereas it was significantly and positively related to intrinsic work-related motives (e. g, job characteristics related to accomplishment, job enjoyment, and existing skill utilization). Thus, the results supported that older workers were more interested in working on interesting jobs and accomplish meaningful tasks, exercising autonomy and utilizing skill variety at work, and helping others such as mentoring or coaching.

Moreover, investigating two samples with over 10,000 working adults from ages 25 and under to those 56 and over in the United Kingdom, Inceoglu and colleagues (2012) detected important age-group differences in work motivation. Compared to younger workers, older workers perceived jobs that require expansive personal resources (e.g., competition and power) to be less motivating, and they reported lower preference for extrinsic rewards such as material reward, career progression, status, and recognition. In contrast, older worker groups reported a higher preference for intrinsically rewarding jobs where they have autonomy and a chance to help others.

Changes in job attitudes. Job attitudes refer to "evaluations of one's job that express one's feelings toward, beliefs about, and attachment to one's job" (Judge \& Kammeyer-Mueller, 2012). Meta-analytic findings (e.g., Ng \& Feldman, 2010) have shown that older workers generally hold more favorable attitudes towards their jobs, colleagues, and organizations. For example, age is positively associated with job satisfaction, organizational commitment, organizational identification and loyalty, satisfaction with coworkers and supervisors, interpersonal trust, and intrinsic work motivation. 
Changes in job performance. Examining 380 studies with an overall sample age ranging between 17 and $59(M=36.6, S D=8.8), \mathrm{Ng}$ and Feldman (2008) demonstrated that age was not related to core task performance, whereas they found a positive relationship between age and organizational citizenship behaviors (OCB), a form of contextual performance. In line with the age-related differences in work motivation discussed above, these findings may point out that older workers may attempt to offset the negative consequences of declining fluid intelligence by using improved crystallized intelligence which may reflect as improved citizenship behaviors at work. In other words, taking advantage of their job knowledge, professional expertise, and experience accumulated throughout the years, it would be reasonable for older workers to approach work-related issues on a higher level than younger colleagues with limited job knowledge and experience (Salthouse, 2012).

After reviewing age-related changes in different domains across a lifespan, the next session summarizes two Lifespan Resource Models, which approach human development as a continuous process. In this respect, they provide a theoretical background about how people successfully adapt to age-related changes in life and at work.

Selection-Optimization-Compensation Theory (SOC; Baltes \& Baltes, 1990). The SOC model suggests a dynamic process through which individuals select goals, attempt to gain and optimize resources to meet those goals, and show specific efforts to manipulate resources to successfully maintain their goals when facing with resource loss or when their resources do not fit well with the environmental conditions (Hobfoll, 2002). 
In other words, the SOC model suggests that individuals are motivated to use different strategies to keep functioning successfully by attempting to offset negative consequences of declining resources due to age such as cognitive and physical capacities (Baltes, 1996).

From a resource-based approach, the SOC model advocates that the use of selection, optimization, and compensation strategies may help older individuals in different ways, such as mobilizing limited resources or increasing them, maintaining their performance in a challenging environment when resources are scarce, and regulating resources for possible threats to resource loss (Baltes, Zhdanova, \& Clark, 2011).

Selection strategies refer to the identification, selection, and prioritization of goals, outcomes, and goal structures so that limited resources can be used effectively to match one's needs. Selection of goals can either occur voluntarily being based on one's preference (e.g., choosing to advance in one's career before having kids), or it can occur involuntarily due to internal or external resource loss (e.g., choosing to develop better relationships with supervisors when perceived job security is low). Selection strategies include actions such as narrowing down goals and prioritizing them. For example, an older employee may choose to focus on a few projects at a time, while an older Tango dancer may choose to rehearse only a limited number of sequences to preserve time and energy.

Once goals are selected, optimization takes place by reviewing (a) one's existing resources such as personal (e.g., knowledge, skills, and abilities) or social resources (e.g., support from others) and (b) examining necessary improvements of available resources to optimize performance. These strategies include practicing existing skills more frequently, 
learning new skills, and improving in time and energy management. For instance, to retain their knowledge on a software program, older professionals may want to practice their skills more often than they used to do.

Finally, compensation strategies consist of exerting efforts to offset a potentially weak performance due to limited or lost resources. For example, hiring a personal assistant to help with administrative work would save time and energy for an older manager's other life domains (Baltes et al., 2011) whereas collaborating with a younger partner on a stage may help an older Tango artist deliver a faster show to audiences.

In sum, the SOC model offers an integrative approach to explain age-related differences in employee well-being, work attitudes, and job performance. Research findings support that older workers were more content with their work life (i.e., reported higher job satisfaction) by actively performing these SOC strategies (Schmitt, Zacher, \& Frese, 2012) and increased their work ability by using SOC strategies along with higher job control (Weigl, Müller, Hornung, Zacher, \& Angerer, 2013). Further, delivering SOC training enhanced mental well-being of health care employees such as nurses when job control was low (Müller, Heiden, Herbig, Poppe, \& Angerer, 2015).

\section{Socio-emotional Selectivity Theory (SST; Carstensen, Isaacowitz, \& Charles,}

\section{9).}

While the SOC model focuses on age-related losses and gains in one's resources and offers strategies to maintain performance, SST explains motive changes across adulthood based on reorganization of goals around affect (Kanfer \& Ackerman, 2004). The theory suggests that the primary purpose of social interactions differs between individuals of 
different ages based on their perception of remaining time in life. Specifically, SST posits that younger individuals tend to have an expansive perception of time whereas older individuals have a more restricted future time perception (Carstensen et al., 1999). As a result of this difference in time perspectives, younger individuals tend to have a future orientation and engage in social interactions primarily to seek information, growth, and future opportunities. Translated to the workplace, younger workers feel more comfortable pursuing knowledge-related goals such as gaining job knowledge and participating in trainings to advance in careers. In contrast, as individuals age, the purpose of social interactions changes from gaining material rewards to obtaining affective rewards and enhancing one's self identity (e.g., Kanfer \& Ackerman, 2004; Truxillo et al., 2012). As their perception about the remaining time in life is limited, older individuals tend to consider time as a more valuable commodity, try to make the most sense out of the present, avoid conflicts, and choose to invest their existing resources (i.e., energy and time) in emotion-related goals such as building and maintaining meaningful social relationships. Consequently, spending more time with close family members and friends or mentoring colleagues at work would become more meaningful goals for social relatedness.

In sum, in line with the theory, there are reasons to expect that the assumption that the relationships between individuals' resources and work and nonwork outcomes would be robust may not hold true for people of different ages. Expanding on this possibility, the overarching claim of this dissertation is that the importance of resources in relation to work and well-being outcomes would differ based on age. Examining a series of three 
studies, in line with SST, I expect that resources that are instrumental for engaging in social interactions that provide emotional satisfaction and foster one's self-regard at work will be more important for older workers compared to their younger counterparts. Among these resources, I examine leader-member exchange (LMX), perceived fairness in procedures, and perceived organizational support (POS). In addition to these affectrelated resources, based on SOC, I expect that the utility of resources that help mobilize energies and time to perform well at work will be higher for older workers compared to younger workers. As examples of these resources, I examine job-specific resources including skill discretion and decision-making autonomy and personal resources including optimism and perceived work ability. It is important to state that although differentiating between SST- and SOC-related resources is possible, this differentiation may not always be mutually exclusive. For example, a higher quality LMX relationship can be perceived as more important by older workers to perform well at work as it may help (a) fulfill the relatedness need, and/or (b) maintain resources such as time and energy to perform a job rather than dealing with conflict with supervisors at work (Truxillo \& Burlacu, 2015). Thus, I utilize both perspectives whenever SOC and SST may individually bring different explanations to argue the value of abovementioned resources.

\section{A Series of Three-Study Investigation}

The following chapters in this body of work include the manuscripts of the three studies: Study 1 (Chapter 3), Study 2 (Chapter 4), and Study 3 (Chapter 5). The document ends with a general discussion and conclusion (Chapter 6) that ties all the three studies 
together. This final chapter summarizes the motivation of the current dissertation, discusses the theoretical and practical implications of the study findings, acknowledges potential limitations of these studies, and suggests avenues for future research. 
Chapter 3: Do Resources Matter for Employee Stress? It Depends on How Old You Are

\author{
Lale M. Yaldiz, Donald M. Truxillo, Todd Bodner, \& Leslie B. Hammer \\ Portland State University \\ (Published, Journal of Vocational Behavior)
}

Note. The official citation that should be used in referencing this material is:

Yaldiz, L. M., Truxillo, D. M., Bodner, T., \& Hammer, L. B. (2018). Do resources matter for employee stress? It depends on how old you are. Journal of Vocational Behavior, 107, 182-194. doi: 10.1016/j.jvb.2018.04.005)

\title{
Author names and affiliations:
}

Lale M. Yaldiz ${ }^{\text {; }}$ lyaldiz@pdx.edu

Donald M. Truxilloa; truxild@pdx.edu

Todd Bodner ${ }^{\mathrm{a}}$; tbodner@pdx.edu

Leslie B. Hammer ${ }^{\mathrm{a}, \mathrm{b}}$; hammerl@pdx.edu

aPortland State University, Department of Psychology, P.O. Box 751, Portland, OR 97207-0751, USA

bregon Health \& Science University, Oregon Institute of Occupational Health Sciences, 3181 SW Jackson Park Road -L606 Portland, OR 97239, USA

\section{Corresponding author:}

Correspondence should be addressed to Lale M. Yaldiz (lyaldiz@pdx.edu) 


\section{Acknowledgements:}

Funding: This work was supported by the Oregon Healthy Workforce Center (www.ohsu.edu/ohwc), a National Institute for Occupational Safety and Health (NIOSH) Total Worker Health Center of Excellence [grant number U19OH010154]. The first author was supported by a grant from NIOSH [grant number T03OH008435-11], Graduate Training in Occupational Health Psychology, during her work on the project. 


\section{Highlights:}

- When resources were high, all workers had lower levels of stress.

- When resources were low, older workers experienced greater stress.

- Usefulness of job resources was examined for older and younger workers.

- Age examined as a moderator of baseline job resources - stress link at 12-months.

- Extends Conservation of Resources theory utilizing lifespan development models. 
Abstract

This study sought to understand the age-based differences in the usefulness of job resources in relation to employee stress. We extended Conservation of Resources theory by integrating two lifespan development models (Selection-Optimization-Compensation and Socio-emotional Selectivity theories) to argue that job resources would be differentially beneficial - or harmful when lacking - to the stress of older and younger workers. Utilizing time-lagged data, we examined the moderating role of age in the relationship between baseline work-related resources from the job (skill variety), supervisor (leader-member exchange), and organization (procedural fairness) and perceived stress at the 12-month follow-up in a sample of U.S. construction workers $(N=$ 243). As hypothesized, our findings indicated that the relationship between these three job resources and perceived stress was stronger for older workers. Specifically, when resources were high in the workplace, both older and younger workers reported lower levels of stress. However, when these resources were low, older workers experienced greater stress compared to their younger colleagues. These findings support that age is a boundary condition of job resources - stress link, and highlight the importance of understanding the needs and motivation of employees of different ages is key to maintaining worker well-being.

Keywords: Employee stress, Job resources, Lifespan development, Older worker, Aging workforce 


\section{Introduction}

The aging of the world population has affected the composition of the labor force in two important ways. First, older people will be an active part of the workforce longer due to reasons such as increases in retirement ages in many developed countries, dealing with their diminished retirement benefits, and saving money for their life after retirement (Bloom, 2011; Hertel \& Zacher, 2015; Truxillo, Cadiz, \& Rineer, 2014). As reported by the U.S. Bureau of Labor Statistics (BLS; Toossi, 2012), while there were only 18.7 million older workers who were 55 years and above in 2000 (nearly 13\% of the labor force), this age group reached to 30 million constituting nearly $20 \%$ of the labor force in 2010. This increase in the participation rate of older workers is projected to grow further reaching approximately 41 million workers accounting for nearly a quarter of the total U.S. work force by 2020. As the number of older workers has increased, so has the median age of the U.S. workforce. The median age has risen from 39.3 years in 2000 to 41.7 years within a decade in 2010 , and is expected to be 42.8 years by 2020 .

The second implication of an aging population for the labor force is that workplaces will grow more age-diverse where younger and older workers will work sideby-side more often than they used to (Dychtwald, 2000; Finkelstein \& Truxillo, 2013; Kunze, Boehm, \& Bruch, 2011; Yaldiz, Fraccaroli, \& Truxillo, 2017). Although age diversity may bring advantages to utilize the human potential at its best, managing an age-diverse workforce necessitates an understanding of the differences between the values, motivations, work attitudes, job performance, and well-being of older and 
younger workers (Kunze \& Boehm, 2013; Truxillo, Fraccaroli, Yaldiz, \& Zaniboni, 2017).

To this end, researchers have called for studies to investigate the age-related differences at work to inform organizational policies and practices, and help design workplace interventions for employees of different ages (Baltes \& Finkelstein, 2011; Burke, 2015; Fisher, Chaffee, Tetrick, Davalos, \& Potter, 2017; Hertel \& Zacher, 2015; Truxillo, Cadiz, \& Hammer, 2015). Accordingly, the need to examine the differential effects of job resources on work and non-work outcomes for employees of different ages has also been pointed out by recent critical reviews (Halbesleben, Neveu, PaustianUnderdahl, \& Westman, 2014) in relation to mainstream resource theories (e.g., Conservation of Resources theory; COR; Hobfoll, 1989). Thus, the assumption that the relationship between resources and work outcomes are robust for employees across all ages should be challenged by empirical research (Halbesleben et al., 2014; Truxillo et al., 2014; Truxillo et al., 2017), addressing the need to investigate employee age as a moderator between job resources and employee outcomes. Hence, the age-related differential effects of resources have only recently begun to draw the attention of researchers (e.g., Zaniboni, Truxillo, \& Fraccaroli, 2013; Zaniboni, Truxillo, Fraccaroli, Bertolino, \& McCune, 2014; Zaniboni et al., 2016).

Responding to these calls in the organizational literature, the current study aims to examine the age-related differences in the usefulness of job resources in relation to employee stress, an important well-being outcome. Specifically, this study focuses on three potential job resources: skill discretion, leader-member exchange (LMX), and 
procedural justice that may be differentially beneficial to older and younger workers. We utilize COR theory (Hobfoll, 1989) as an overarching theoretical framework to discuss the usefulness of job resources on stress, and suggest two Lifespan Resource Models (i.e., Selection-Optimization-Compensation; SOC; Baltes \& Baltes, 1990; Socioemotional Selectivity Theory; SST; Carstensen, Isaacowitz, \& Charles, 1999) to explain why we expect to detect age-related differences in the importance of job resources. Utilizing both perspectives, this study seeks to understand the differences in the relative value of job resources on employee stress experienced by older and younger workers. A summary model of the proposed relationships is presented in Figure 3.1.

This study aims to make three contributions to the literature. First, it expands COR theory by questioning the relative value of job resources for younger and older workers. As pointed out by Halbesleben and colleagues (2014), the usefulness of resources over the lifespan has not been adequately addressed in COR theory. By investigating employee age as a moderator, we aim to uncover how specific resources from the job, supervisor, and organization may be differentially beneficial - or harmful when lacking - for the stress of older and younger workers.

Second, organizational research on stress is usually criticized because of a heavy reliance on cross-sectional study designs that overlook the long-lasting influence of stressors on stress (e.g., Sonnentag \& Frese, 2012). Addressing this limitation in methodology, the current study utilizes time-lagged data to examine whether job resources at the baseline will be related to employee stress after 12 months. Third, acknowledging that different resources may be perceived as more critical by people of 
different ages, the findings of this study will help organizations with age-diverse work environments develop age-supportive Human Resources practices such as job redesign interventions to support well-being (Fisher et al., 2017; Truxillo et al., 2015).

\section{Theoretical Background}

\section{Stress as an Outcome}

Stress continues to be a burden for employees and organizations across nations (Griffin \& Clarke, 2011). According to the American Psychological Association [APA] (2012), more than one-third of U.S. employees reported that they experienced stress during a normal workday. Moreover, the levels of stress have consistently increased over the past years, while work remains as one of the major sources of stress for people (APA; 2016). Although the detrimental effects of stress on employee health, attitudes at work, and job performance are well documented by past research, and stress is known to be costly to organizations in the forms of increased health insurance claims, absenteeism, and lower productivity (Darr \& Johns, 2008; Richardson \& Rothstein, 2008), there is an important gap in the organizational literature about the role of age in explaining the antecedents of employee stress. The present study addresses this gap.

\section{A resources-based perspective on stress: Integrating COR theory and lifespan}

\section{resource models}

\section{Selection-Optimization-Compensation Theory (SOC; Baltes \& Baltes, 1990).}

Various age-related changes occur in different domains across a lifespan including physical changes (e.g., Papalia, Sterns, Feldman, \& Camp, 2007) and cognitive changes (e.g., Ackerman, 2014; Baltes, 1997; Kanfer \& Ackerman, 2004; Klein, Dilchert, Ones, 
\& Dages, 2015; Schaie, 1996). To offset negative consequences of declining resources due to age such as cognitive and physical capacities, the SOC model (Baltes \& Baltes, 1990) posits that individuals are motivated to use different strategies to keep functioning successfully (Baltes, 1996). According to the SOC model, individuals go through a dynamic process where they select goals, attempt to gain and optimize resources, and exert effort to manipulate resources to maintain their goals when resources are low or do not fit well with their environments (Hobfoll, 2002).

Selection strategies refer to the identification, selection, and prioritization of goals, outcomes, and goal structures so that limited resources can be used effectively to match one's needs. Selection strategies include actions such as narrowing down goals and prioritizing them. For example, an older employee may choose to focus on a few projects at a time to preserve time and energy. Once goals are selected, optimization takes place by reviewing one's existing resources such as personal (e.g., knowledge, skills, and abilities) or social resources (e.g., support from others), and attempting to improve those resources to optimize performance. For instance, to retain their knowledge on a software program, older workers may want to practice their skills more often than they used to do. Finally, compensation strategies consist of exerting efforts to offset a potentially weak performance due to limited or lost resources. For example, hiring a personal assistant to help with administrative work may save time and energy to an older manager in other life domains (Baltes, Zhdanova, \& Clark, 2011). A recent meta-analysis on SOC strategy use found that SOC use was positively related to personal (e.g., age) and contextual (e.g., job autonomy) factors (Moghimi, Zacher, Scheibe, \& Van Yperen, 2017). In addition, 
research has supported that delivering SOC training helped mental well-being of health care employees when job control was low (Müller, Heiden, Herbig, Poppe, \& Angerer, 2015). In summary, utilizing SOC strategies may help older workers in mobilizing limited resources or increasing them, maintaining their performance in a challenging environment when resources are scarce, and regulating resources for possible threats to resource loss (Baltes et al., 2011; Moghimi et al., 2017).

Socio-emotional Selectivity Theory (SST; Carstensen et al., 1999). While the SOC model focuses on age-related losses and gains in one's resources, and offers strategies to maintain performance, SST explains motive changes across adulthood based on reorganization of goals around affect (Kanfer \& Ackerman, 2004). The theory suggests that the primary purpose of social interactions differs between individuals of different ages based on their perception of remaining time in life. Specifically, SST posits that younger individuals tend to have an expansive perception of time, whereas older individuals have a more restricted future time perception (Carstensen et al., 1999). As a result of this difference in time perspectives, younger individuals tend to have a future orientation and engage in social interactions primarily to seek information, growth, and future opportunities. Translated to workplace, younger workers feel more comfortable to pursue knowledge-related goals such as gaining job knowledge and participating in trainings to advance their careers. In contrast, as individuals age, the purpose of social interactions change from gaining material rewards to obtaining affective rewards and enhancing one's self-identity (e.g., Kanfer \& Ackerman, 2004; Truxillo, Cadiz, Rineer, Zaniboni, \& Fraccaroli, 2012). As their perception about the remaining time in life is 
limited, older individuals tend to consider time as a more valuable commodity, try to make most sense out of the present, avoid conflicts, and choose to invest their existing resources (i.e., energy and time) in emotion-related goals such as building and maintaining meaningful social relationships. Consequently, spending more time with close family members and friends or mentoring colleagues would become more meaningful goals for social relatedness for older workers.

Based on these two different yet complementary lifespan resource models, it seems that the usefulness of some resources would not be the same for people of different ages. Thus, we propose that the relationship between some job resources and well-being (e.g., stress) may differ based on age. Specifically, as explained by the SOC model, it is likely that the importance of resources that help mobilize energies and time to perform well at work will be higher for the well-being of older workers compared to younger workers (e.g., Moghimi et al., 2017). Moreover, in line with SST, we suggest that resources that help engage in social interactions, provide emotional satisfaction, and foster one's self-regard at work will be more beneficial for the well-being of older workers compared to their younger counterparts (e.g., Truxillo et al., 2012).

In sum, this study focuses on job-specific and social support (i.e., supervisor and organization) predictors of stress at work (Ng \& Sorensen, 2008; Ng \& Feldman, 2015) investigating one example predictor for each: skill discretion, leader-member exchange, and procedural fairness. The rationales for choosing these three predictors are that, first, these work-related factors are examined as resources by the COR literature, and, second, the usefulness of these resources is expected to differ by age through the lens of the 
lifespan development theories. Specifically, we argue that, compared to younger workers, older workers would value autonomy and supportive treatment at work to a greater degree because these resources enable them to adapt to the psychological and physical changes that come with aging. To develop the study hypotheses, COR is used as a general framework and SOC and SST are utilized to explain how these predictors are considered as valuable resources by older workers in relation to stress.

\section{Hypothesis Development}

\section{Age and Skill Discretion as a Job-specific Resource}

Initial support pointing out age-based differences in the relationship between jobspecific resources and employee outcomes has come from recent studies ( $\mathrm{Ng} \&$ Feldman, 2015; Zaniboni et al., 2016). Skill discretion refers to the degree to which one's job provides opportunities to use a variety of skills and flexibility to choose from those skills set (Karasek et al., 1998; Karasek, 1990). Skill discretion is a type of autonomy which provides employees an opportunity to exercise multiple skills at work, and give them a sense of control about how to reflect their skills to their job. In this respect, skill discretion is considered as challenging, motivating, and engaging to perform at work (Morgeson \& Humphrey, 2006). Meta-analytic findings and empirical studies have shown that skill variety/skill discretion is negatively related to burnout and exhaustion (Humphrey, Nahrgang, \& Morgeson, 2007; Morgeson \& Humphrey, 2006) and positively related to work ability (McGonagle et al., 2014).

Based on the SOC model (Baltes, 1997), we expect that older workers will benefit from skill discretion more as a strategy to compensate age-based declines in cognitive 
capacities to maintain job performance. This type of autonomy on the job will allow older workers to freely choose from their available skills to accomplish tasks instead of following rigid work routines (Moghimi et al., 2017). For instance, as opposed to younger workers, older workers have accumulated more job experience and developed their own ways of doing tasks that have been proven to work successfully for themselves. Thus, through utilizing their experience and skill set gained over time, older workers would save other resources such as time and energy. As an example, Müller and colleagues (Müller et al., 2015) have recently suggested that the use of SOC strategies at work to redesign jobs or engaging in job crafting may improve older workers' well-being. Theories on age-based work motivation (e.g., Kanfer \& Ackerman, 2004; Warr, 1997, 2001) also suggests that extrinsic rewards such as pay and promotion would be perceived as more important by younger people who are at the early stages in their careers whereas older people would have an increased preference for intrinsic rewards such as having autonomy and opportunities for skill utilization. Thus, from a socio-emotional perspective (e.g., SST), jobs that provide opportunities for employee input would foster the feelings of esteem of older workers. Moreover, as older workers perceive a more limited future time left in their careers (Hertel \& Zacher, 2015), in line with COR theory (Hobfoll, 1989), they would feel more stressed when their jobs lack such positive resources. In sum, we suggest that although jobs that facilitate skill utilization would be helpful to maintain a positive state of mind for all workers, this relationship would be stronger for older workers. 
Hypothesis 1. Employee age will moderate the relationship between skill discretion and perceived stress. As skill discretion increases, perceived stress will decrease, and this relationship will be stronger for older employees compared to younger employees.

\section{Age and Social Support Resources at Work: LMX and Fair Treatment}

The organizational literature identifies different sources of social support as a resource to cope with stress (Halbesleben, 2006; Sonnentag \& Pundt, 2015; Terry, Nielsen, \& Perchard, 1993; Viswesvaran, Sanchez, \& Fisher, 1999). Among them, support from the leader (e. g., LMX) and support from the organization (e.g., perceived fairness) are recognized as being strongly associated with employee health and wellbeing (Ng \& Sorensen, 2008).

Supervisor support: LMX. The relationship between leaders and followers is an influential resource for employee well-being (Sonnentag \& Pundt, 2015). Derived from the Social-Exchange Theory (Blau, 1964), LMX theory (Dienesch \& Liden, 1986) is related to the quality of the reciprocal relationships between leader and employee dyads. According to LMX theory, leaders form high-quality relationships characterized by trust, liking, loyalty, and professional respect with some of their employees. Leaders form lower-quality relationships with other employees which is mostly economic and shortterm in nature (Bauer \& Erdogan, 2015). The relationship between LMX and employee well-being outcomes is well documented by research. Empirical studies consistently suggest that higher-quality LMX is associated with lower levels of emotional exhaustion and cynicism (Bekker, Halbesleben, \& O’Hair, 2005; Jiang, Law, \& Sun, 2014) and 
burnout (Huang, Chan, Lam, \& Nan, 2010; Thomas \& Lankau, 2009; Viswesvaran et al., 1999), while it is positively associated with weekly work engagement (Bakker \& Bal, 2010) and daily work engagement and positive emotions (Xanthopoulou, Bakker, Demerouti, \& Scahufeli, 2009, 2012). However, due to the cross-sectional nature of these studies, the long-lasting influence of LMX on employee well-being still remains unclear (Sonnentag \& Pundt, 2015). Moreover, the relative value of LMX to the well-being of older and younger workers has remained unexamined (Truxillo \& Burlacu, 2015). Among limited research on the interaction between age and LMX, Zacher and colleagues (Zacher, Rosing, Henning, \& Frese, 2011) found that the interaction between leader age and leader generativity affects subordinates' LMX perceptions as an outcome. However, as suggested by Truxillo and Burlacu (2015), future studies should examine how LMX interacts with employee age to influence employee outcomes.

This study proposes that the relationship between LMX and perceived stress would be stronger for older employees. Consistent with SST (Carstensen et al., 1999), we expect that the lack of socially meaningful relationships at work will prevent older workers from maximizing their affect-related goals. Having a limited time perception remaining in life, when the conditions at work environment do not help satisfy the need to belong or socialize (Baumeister \& Leary, 1995), older workers would feel more stressed compared to younger workers. From the lens of SOC theory (Baltes, 1997), highquality relationships with supervisors may also provide a strategic function for older workers' resource options. Enjoying a trust-based relationship with superiors who have power over work procedures and access to organizational resources, older workers may 
seek idiosyncratic deals (i-deals) to meet their individual needs such as self-selecting goals at work or negotiating for flexible work hours (Anand, Vidyarthi, Liden, \& Rousseau, 2010). Moreover, a high LMX allows older workers to use compensation strategies by choosing from available resources so that they can maintain time and energy to perform job rather than dealing with conflict with supervisors at work. In summary, we contend that high-quality relationships with supervisors would matter more for the wellbeing of older workers. Compared to younger workers, older workers would experience higher levels of stress when they have poor relationships with their supervisors, and they would feel better when the quality of their relationships is high.

Hypothesis 2. Employee age will moderate the relationship between resources from the supervisor (LMX) and perceived stress. As LMX increases, perceived stress will decrease; and this relationship will be stronger for older employees compared to younger employees.

Support in terms of fair treatment. Based on Social Exchange theory (Blau, 1964), organizations constitute another form of social support as a resource. Fairness, as a form of organizational resource, helps individuals regulate their relationships with their environment (Cropanzano, Bowen, \& Gilliland, 2007). Procedural justice refers to the perceived fairness of decision-making processes through which the outcomes (e.g., pay, promotion, rewards) are distributed in an organization (Leventhal, 1980; Thibaut \& Walker, 1975). This type of fairness capitalizes on the importance of perceived control of the processes and six specific characteristics of a work environment. Accordingly, procedural justice reflects the degree to which organizational policies and procedures are 
consistent across people and over time; based on accurate information; applied in an unbiased fashion; offering opportunities to correct unfair decisions; are representative of all parties affected by the decisions; and are based on ethical grounds. In other words, work environments with high procedural fairness are transparent about how the decisions are made and implemented, do not discriminate against any members, value employee input when making key decisions, and allow channels to voice employee concerns. In terms of employee health and well-being outcomes, meta-analytic results and empirical studies have demonstrated that lower procedural justice perceptions were related to increased perceived stress (Judge \& Colquitt, 2004) and psychological distress including emotional exhaustion, depression, and anxiety (Tepper, 2001), increased negative emotions such as anger and negative mood (Cohen-Charash, \& Spector, 2001; Colquitt et al., 2013), and increased sickness-based absence, poor self-rated health and increased sleep problems (Elovainio, Kivimäki, \& Vahtera, 2002; Elovainio, Kivimäki, Vahtera, Keltikangas-Järvinen, \& Virtanen, 2003). Although meta-analytic studies that investigated the main effects of demographic characteristics on fairness perceptions did not find a significant association between age and justice, how age and justice perceptions may interact to predict employee well-being remains unanswered (CohenCharash \& Spector, 2001).

Based on SST (Carstensen et al., 1999), we expect that perceptions of procedural fairness may help older workers build emotionally meaningful relationships with employers (Greenberg, 2011). In this mutual relationship, employers convey the message that they care about their employees, are interested in hearing their concerns, and no one 
is discriminated against when work-related decisions are made (Nixon, Mazzola, Bauer, Krueger, \& Spector, 2011). We suggest that these positive inputs from organizations would foster a sense of trust (Colquitt et al., 2013) and that they are valued members of the organization - which will satisfy older workers' affect-related goals and help them experience a more positive state of mind. Moreover, fair treatment may be perceived as a more valuable resource for older workers by helping them reduce feelings of uncertainty (Colquitt, 2008; Colquitt et al., 2013) or age-based discrimination at work (e.g., Truxillo et al., 2015) by signaling a steady work environment. Instead of worrying about job security, a fair work environment would help older workers maintain a positive state of mind by focusing on how to utilize their skills and knowledge on job tasks. In summary, we suggest that procedural justice, as a resource, would be more valuable for older workers; hence, it would have a pronounced impact on their well-being.

Hypothesis 3. Employee age will moderate the relationship between support from the organization (procedural justice) and perceived stress. As procedural justice increases, perceived stress will decrease, and this relationship will be stronger for older employees compared to younger employees.

\section{Method}

\section{Participants and Procedures}

Data were collected as part of a larger longitudinal intervention project which lasted for 12 months aiming to improve employee health, safety, work-life balance, and well-being. Participants were construction and field workers from two public works departments located in a city in the Pacific Northwest, U.S. Workers in the first 
organization were responsible for the construction and maintenance of the transportation and sewer systems, while the second organization focused on the water systems of the city. The sample consists of similar occupations from departments such as sewer repair, sewer cleaning, street cleaning, sidewalk repair, street maintenance, paving, construction and maintenance, and water meter readers, and is fairly homogeneous. This worker population is considered a vulnerable population according to the National Institute of Occupational Safety and Health (NIOSH). Bodner and colleagues (Bodner, Kraner, Bradford, Hammer, \& Truxillo, 2014), and Maynard and Ferdman (2009), indicate that these occupations need greater attention in the organizational research.

Data were collected via paper-pencil surveys during company time at three different time points (e.g., baseline, 6 month-follow-up, and 12-month follow-up). A unique participation code was assigned to each employee to match the surveys across all time points. Participation was voluntary and respondents received a $25 \$$-gift card in turn of completion each survey. This study utilized data on employee stress from the 12month follow-up survey which was administered between August 2013 and December 2013, while data on predictor variables and age were collected at baseline between August 2012 and December 2012. Within the larger study, 348 of 520 workers (67\%) participated in the baseline survey, and of these individuals, 243 workers provided data on employee stress measured one year later. This sample of 243 individuals was utilized in all analyses who provided data on both baseline predictors and 12-month stress.

The majority of the sample was White (78.2\%), male (90.1\%), married (63.8\%), and had at least some college education (61.7\%). The age distribution ranged from 24 to 
64 years, and the average age was 43.53 years $(S D=9.56)$. The average job tenure of the sample was 10.20 years $(S D=7.59)$, and the average number of hours worked per week was 42.08 hours $(S D=6.17)$. As for job status, there were 18 supervisors, 45 crew leaders, and 159 crew members in the sample.

\section{Measures}

Age. Recent reviews on work and aging (Hertel \& Zacher, 2015; Truxillo et al., 2014, 2015; Yaldiz et al., 2017) suggests that using arbitrary cut-offs to define older workers (e.g., over-40/under-40 years based on the Age Discrimination in Employment Act in the United States) is not theoretically or methodologically meaningful, and that age should be treated as a continuous variable to explain meaningful amounts of variance in work outcomes. Accordingly, this study treats age as a continuous variable and utilizes employee reports of chronological age. To report the study findings conveniently, "younger workers" and "older workers" are operationalized as 1 SD below and above the mean age of the sample, respectively.

Job resources. Employee reports of job resources were assessed at the baseline. Skill discretion was measured with six items from the Job Content Questionnaire (JCQ; Karasek et al., 1998). Responses ranged from 1 (Strongly disagree) to 5 (Strongly agree). A sample item for skill discretion included, "My job requires me to have a high level of skill." $(\alpha=.76)$. Leader-member exchange was measured with seven items (Scandura \& Graen, 1984) on a 5-point response scale where higher scores indicated a higher quality LMX. Sample items were, "How well does your supervisor understand your job problems and needs?" and "Regardless of how much formal authority he/she has built into his/her 
position, what are the chances that your supervisor would use his/her power to help you solve problems in your work." $(\alpha=.92)$. Procedural justice (Moorman, 1991; Niehoff \& Moorman, 1993) was measured by seven items. Responses ranged from 1 (Strongly disagree) to 7 (Strongly agree). Sample items included, "This organization collects accurate information necessary for making decisions" and "This organization hears the concerns of all those affected by the decisions made" $(\alpha=.95)$.

Perceived stress. Employee stress was assessed with four items (Cohen, Karmarck, \& Mermelstein, 1983) after 12 months the predictors were measured. Respondents were asked to rate their overall stress during the last 30 days on a 5-point scale $(1=$ Never to $5=$ Very often $)$. Sample items included, "How often have you felt that you were unable to control the important things in your life?" and "How often have you felt difficulties were piling up so high that you could not overcome them?" $(\alpha=.73)$.

Control variables. As the data were collected as part of a larger intervention project in two organizations, we controlled for intervention condition (treatment versus control) and organization (Organization A versus Organization B) variables in all analyses. In this study, as baseline job tenure was correlated with age and 12-month perceived stress, we also controlled for tenure (in years).

Analytical Strategy. Moderation hypotheses were analyzed using OLS regression utilizing the PROCESS macro for SPSS (Hayes, 2013). In the regression equations, we regressed perceived stress onto the control variables (intervention condition, organization, job tenure), age, focal predictors (e.g., skill discretion), and the interaction between age and the focal predictor of stress. As recommended by Hayes (2013), age and 
focal predictors were mean centered, and the interaction term was created using the centered variables. We reported the findings for the simple slope analyses for the low (1 SD below the mean) and high (1 SD above the mean) values of age whenever the results yielded a significant interaction effect. Finally, because employees were nested within work groups, we considered using a general linear mixed modeling approach, however the analyses suggested no significant variation on work group means (interclass correlation coefficient [ICC] was 0.02).

\section{Results}

Means, standard deviations, and correlations among the study variables are presented in Table $3 \cdot 1^{1}$. Accordingly, age was positively related to perceived stress $(r=$ $.15, p<.05)$. Job tenure was positively associated with both perceived stress $(r=.16, p<$ $.05)$ and employee age $(r=.50, p<.01)$. Finally, skill discretion, LMX, and justice were not significantly correlated with perceived stress or age.

Hypothesis 1 stated that employee age would moderate the relationship between skill discretion and perceived stress such that the relationship would be stronger for older employees compared to younger employees. As presented in Table 3.2, the interaction between age and skill discretion was significant $\left(B=-.02, F(1,234)=6.45, \Delta \mathrm{R}^{2}=.03, p\right.$ $<.05)$. Simple slope analysis revealed that skill discretion was not related to perceived stress for younger employees $(B=.07, S E=.09 ; t=.79, p>.05)$ whereas it was negatively related to perceived stress for older employees $(B=-.27, S E=.11 ; t=-2.57, p$ $<.05)$. As depicted in Figure 3.2, when skill discretion was low, older employees showed

\footnotetext{
${ }^{1}$ Correlations among all three waves of the focal study variables (three resources and stress) are available from the first author of the manuscript upon request.
} 
higher level of stress, and as skill discretion increased, their level of stress reduced.

Thus, Hypothesis 1 was supported ${ }^{2}$.

Hypothesis 2 predicted that employee age would moderate the relationship between leader-member exchange (LMX) and perceived stress such that the relationship would be stronger for older employees compared to younger employees. As presented in Table 3.3, the interaction effect of age and LMX was significant $(B=-.01, F(1,231)=$ 4.94, $\left.\Delta \mathrm{R}^{2}=.02, p<.05\right)$. Simple slope analysis showed that, there was a significantly negative relationship between LMX and perceived stress for older employees $(B=-.20$, $S E=.08 ; t=-2.46, p<.05)$, however, for younger employees, LMX was not related to perceived stress $(B=.04, S E=.07 ; t=.57, p>.05)$. The plot of this interaction is presented in Figure 3.3. Accordingly, older employees had higher levels of stress as the quality of LMX decreased, and they had lower levels of stress as LMX quality improved, thus supporting Hypothesis 2.

Finally, Hypothesis 3 proposed that employee age would moderate the relationship between procedural justice and perceived stress such that the relationship would be stronger for older employees compared to younger employees. The analyses showed that the interaction between age and procedural fairness was significant $(B=-.01$, $\left.F(1,230)=7.79, \Delta \mathrm{R}^{2}=.03, p<.05\right)($ Table 3.4$)$. Simple slope analysis demonstrated that there was a negative relationship between procedural fairness and perceived stress for older employees $(B=-.18, S E=.06 ; t=-3.32, p<.01)$. For younger employees, procedural fairness was not related to perceived stress $(B=.01, S E=.05 ; t=.29, p>$

\footnotetext{
${ }^{2}$ Based on the recommendation of Spector and Brannick (2011), the three study hypotheses were tested with and without the control variables. The results from the models without the control variables were substantively similar and are available from the first author upon request.
} 
.05). As can be seen in Figure 3.4, older employees had higher levels of stress when they perceived lower fairness, and they experienced reduced stress as their perceptions of fairness increased. Thus, Hypothesis 3 was supported.

\subsection{Additional Analyses}

To rule out alternative explanations, a set of supplemental analyses was conducted with two additional control variables beyond the intervention condition, organization, and job tenure that were used as controls in the primary analyses. Specifically, to control for participants' stress prior to the 12-month assessment, the three study hypotheses were tested controlling for stress assessed at the 6-month data collection ${ }^{3}$. Second, due to the possibility that employees at higher levels in an organization may have greater stress, the three hypotheses were tested controlling for organizational level ${ }^{4}$. In both cases, the results were similar to those reported in the primary analyses, and the three interaction terms remained statistically significant $(p<.05)$.

A drop-out analysis was conducted to ensure that attrition in the sample did not bias results. Out of 348 workers that took the baseline survey, 243 workers participated in the 12-month survey. Thus, there were 105 leavers (30.2\%) and $243(69.8 \%)$ stayers in the sample at the 12-month survey. Following the guideline by Goodman and Blum (1996), we conducted logistic regression analysis (Step 1), and the findings indicated no significant non-random sampling $(p>.05)$. Finally, a single model was tested which included all the three interaction terms simultaneously. Stress was regressed onto the intervention condition, organization, job tenure, age, and the three resources in Step 1,

\footnotetext{
${ }^{3}$ Stress was not assessed at the baseline data collection therefore 6-month stress was used as control in the analyses.

${ }^{4}$ There were 18 supervisors, 45 crew leaders, and 159 crew members in the sample.
} 
and the three, two-way interactions were added to the model in Step 2. Accordingly, the interaction terms improved the model significantly $\left(\mathrm{R}^{2}=.10 ; \Delta \mathrm{R}^{2}=.05, p<.05\right)$. Although only the procedural justice $\mathrm{x}$ age interaction remained statistically significant in the final equation, the nature of the three interactive effects was similar to those found in the primary analyses.

\section{Discussion}

The goal of this study was to address a gap in the literature by examining the relative value of job resources for younger and older workers in relation to their wellbeing. Building on the COR theory and two lifespan resource models, SOC and SST, this study found support for the moderating role of age in the relationship between three specific work-related resources from the job, supervisor, and organization and perceived stress. Utilizing a blue-collar employee sample in a time-lagged study, the findings revealed that baseline skill discretion, LMX, and organizational fairness were differentially related to stress after 12 month for older versus younger employees. More specifically, when these resources were high in the workplace, both older and younger workers reported lower levels of stress. However, when these resources were low, older workers experienced significantly higher levels of stress compared to their younger counterparts. In other words, while the presence of these resources was equally beneficial for all workers, the lack of these resources manifested itself as being more stressful for older workers.

\section{Implications for Research}


This study contributes to the prior research in a number of ways. First, it expands COR theory to investigate the relative usefulness of resources for younger versus older employees. As criticized in recent reviews (e.g., Halbesleben et al., 2014), the findings of this study suggest that the assumption that resources would be equally important to all individuals may not be accurate. Based on SOC and SST, this study pointed out the possibility that the importance of resources may be different across the human lifespan. As people get older, they tend to prioritize affect-based relational goals due to limited remaining time perspective in life (e.g., SST), or reorganize their capacities by developing strategies to use their time and energy more successfully (e.g., SOC). Thus, older workers may perceive resources that may help achieve these goals as more critical for their well-being. Moreover, compared to younger workers, older workers tend to respond more negatively when the work environment lacks these important resources.

Second, regarding job resources, another contribution of this study is that it is one of the first to examine skill discretion, LMX, and organizational fairness from a resources perspective to shed light on their age-based differential relationships with employee wellbeing (Cohen-Charash \& Spector, 2001; Truxillo \& Burlacu, 2015). This gap in the literature is important given the growing interest on age-based differences in employee outcomes. Moreover, one interesting finding of this study is the importance of using of age as a moderating variable in $\mathrm{I}-\mathrm{O} / \mathrm{OB}$ research. The findings showed that skill discretion, LMX, and organizational fairness were not directly related to stress - that is, there were no significant bivariate correlations. But when age was examined as a moderator, significant relationships were revealed for older workers. In this respect, the 
findings of this study contribute to the LMX, organizational fairness, and well-being literatures by suggesting age as a boundary condition of these relationships. Instead of treating chronological age as a control in study models, this study echoes the need to investigate age as a moderator variable to reflect the associations between work characteristics and employee outcomes more accurately (Hertel \& Zacher, 2015; Zacher \& Schmitt, 2016).

The third contribution of this study is related to the methodological criticisms in the organizational stress research. Since most studies that examine employee stress rely on cross-sectional data, the long-lasting influence of stressors cannot be addressed adequately (Ford et al., 2014; Sonnentag \& Frese, 2012). Moreover, recent reviews on age research (Zacher \& Schmitt, 2016) also pointed out the benefits of using time-lagged study designs to uncover how initial work characteristics relate to later occupational wellbeing for younger and older workers. In this respect, in order to illustrate these longlasting relationships between job stressors and stress, this study focused on the three different resources from the job, supervisor, and organization that were assessed at the baseline; and examined whether their interaction with age was related to employee stress 12 months later. The findings supported that the lack of these resources were more detrimental for older workers' health in the long run, highlighting the fact that it is important to consider age differences to explain long-term well-being.

\section{Practical Implications}

This study indicates that job resources such as utilizing different skills at work, having high quality relationships with one's supervisor, and being respected and treated 
fairly at work are considered more critical for the well-being of older workers. In line with previous research and reviews (e.g., Fisher et al., 2017; Hertel \& Zacher, 2015; Truxillo et al., 2015; Zaniboni et al., 2016), the results of this study can inform organizational practices in a number of ways. First, workplace interventions on employee stress should consider the needs of people of different ages. For example, the findings of this study illustrated that, in contrast to younger workers, being deprived of higher quality relationships with their managers leads to higher stress in older workers. Similarly, older workers who cannot feel that they are valued members of their organization may experience a sense of lower well-being than their younger counterparts. This understanding of the differences in motivation and needs across the lifespan is key to support an aging workforce (Inceoglu, Segers, \& Bartram, 2012; Kanfer \& Ackerman, 2004; Kooij, De Lange, Jansen, Kanfer, \& Dikkers, 2011). In this regard, work redesign and managerial training that would speak to the needs of older workers should be implemented. Instead of imposing strict ways of how to do their job just like a "novel employee", work redesign interventions should allow older workers the flexibility to craft their own jobs utilizing their own strengths and job experience accumulated over the years, providing them with opportunities and the autonomy to exercise different skills. From the lens of SOC theory, this enrichment of their jobs would not only facilitate a better fit to the work environment, but would also help maintain a better well-being. Managerial training for supervisors is another key intervention to support the well-being of older workers. Building around the increased affect-related goals across the lifespan, these trainings should emphasize leadership skills about how to build strong 
relationships with older workers and communicate it effectively so that they feel being trusted and valued members of their team. Finally, at the organizational level, this study highlights the importance of fairness perceptions in workplaces. As older workers seem to be more susceptible to experience stress in the face of unfairness, organizations can help their workers have a positive state of mind by implementing transparency in, and consistency across, procedures and decisions (Hertel \& Zacher, 2015; Truxillo et al., 2017; Yaldiz et al., 2017).

\section{Limitations and Future Research}

As with any study, this study has potential limitations that future research should address. First, the findings may not generalize to other employee populations. The sample in this study consisted of blue-collar construction and field workers from two public works departments located in a city in the Pacific Northwest, U.S., and they were primarily White and male. Future studies should examine the relationships that were found in this study in diverse worker groups across industries, jobs, gender, and ethnicities while ensuring a wide age range (e.g., Ng \& Feldman, 2015). Additionally, since the role of cultural context in shaping the usefulness of resources is highlighted by recent reviews (e.g., Halbesleben et al., 2014; Hobfoll, 2002), cross-cultural research is needed to illustrate how different or similar are the age-based differences in the perceived importance of job resources-employee outcomes relationship. Second, guided by the principles of the COR and lifespan resource theories, future work should investigate the associations between a broader range of job resources and employee outcomes such as job attitudes and job performance that would potentially demonstrate age-based 
differences (e.g., Zacher \& Schmitt, 2016). Third, although the current study uses a time-lagged design to illustrate the long-lasting influence of baseline job resources on employee stress after one year, the findings do not imply causality or change over time. Using more rigorous designs, future research should explore how or when age-related changes in the value of work resources occur. Fourth, the outcome in this study, perceived stress (Cohen et al., 1983), is not directly work-related. Instead, it assesses participants' overall stress in life. In this respect, the findings showed that older individuals reported lower levels of stress in life after one year when autonomy and support resources were available at work at baseline. While this finding informs both the work and life domains, more studies are needed to investigate resource-stress link using work-related stress measures. Finally, this study uses self-report measurements of key study variables. To compare the results across sources, future work should collect otherreports including those of supervisors, coworkers, and significant others when appropriate.

\section{Conclusion}

This study contributes to the literature by addressing a gap in the research about the age-based differences in the usefulness of job resources and how they relate to employee stress. Responding to the recent criticisms of COR theory, this study tested the assumption that the value of job resources is robust across individuals by integrating two lifespan development models, SOC and SST, to explain the age-related differences. The findings suggest that when resources from job (e.g., skill discretion), supervisor (e.g., LMX), and organization (e.g., procedural fairness) are high, both younger and older 
workers have lower levels of stress - thus, as expected, the presence of these resources is equally beneficial for the well-being of all workers. However, when these resources are low, older workers report significantly higher level of stress than their younger colleagues. In sum, the importance of skill discretion, LMX, and procedural fairness is higher among older workers, and the lack of these resources in the work environment is more detrimental for their well-being. These findings have several theoretical and practical implications and provide suggestions for future research. 
Table 3.1

Means, Standard Deviations, and Intercorrelations among Study Variables

\begin{tabular}{lrrcccccccc}
\hline Variable & \multicolumn{1}{c}{ M } & \multicolumn{1}{c}{ SD } & 1 & 2 & 3 & 4 & 5 & 6 & 7 & 8 \\
1. Organization & .33 & .47 & & & & & & & & \\
2. Intervention & .65 & .48 & .05 & & & & & & & \\
3. Job tenure & 10.20 & 7.59 & $-.15^{*}$ & -.07 & & & & & & \\
4. Age & 43.53 & 9.56 & $-.14^{*}$ & -.06 & $.50^{* *}$ & & & & & \\
5. Skill discretion & 3.36 & .66 & .12 & -.09 & .05 & .04 & $(.76)$ & & & \\
6. LMX & 3.18 & .88 & .08 & $-.13^{*}$ & .07 & .09 & $.44^{* *}$ & $(.92)$ & & \\
7. Procedural justice & 3.31 & 1.32 & $.19^{* *}$ & .07 & -.08 & .10 & $.26^{* *}$ & $.40^{* *}$ & $(.95)$ & \\
8. Perceived stress & 2.31 & .72 & .00 & -.03 & $.16^{*}$ & $.15^{*}$ & -.05 & -.05 & -.11 & $(.73)$ \\
\hline
\end{tabular}

Notes. $N=243$. Cronbach's alpha in parenthesis on the diagonal. Organization refers to Organization A (0) or Organization B (1). Intervention refers to being involved in the intervention (0) or in the control group (1). Job tenure was measured in years. Age was measured as a continuous variable. Skill discretion, LMX, and perceived stress were measured on a five-point Likert scale ( $1=$ Strongly disagree, $5=$ Strongly agree $)$. Procedural justice was assessed on a seven-point Likert scale where higher scores indicated higher fairness perceptions.

$* p<.05 ; * * p<.01$ 
Table 3.2

Results of Moderated Regression Analyses Predicting 12-Month Perceived Stress Perceived Stress (12-month)

\begin{tabular}{lrrrrrr}
\cline { 2 - 6 } Predictor variable (Baseline) & $B$ & $S E$ & $t$ & $p$ & $\Delta R^{2}$ & $R^{2}$ \\
\hline Organization & .04 & .10 & .40 & .69 & & \\
Intervention & -.07 & .10 & -.67 & .50 & & \\
Job tenure & .01 & .01 & 1.92 & .06 & \\
Skill discretion & -.10 & .07 & - & 1.40 & .16 & \\
Age & .01 & .01 & .96 & .34 & \\
Skill discretion x Age & -.02 & .01 & - & & .01 & $.03 *$
\end{tabular}

$.06^{*}$

Note. $N=241$. Focal predictor and age were mean centered. Interaction term was computed from the mean-centered variables.

$B=$ unstandardized coefficient.

$* p<.05$. 
Table 3.3

Results of Moderated Regression Analyses Predicting 12-Month Perceived Stress Perceived Stress (12-month)

\begin{tabular}{|c|c|c|c|c|c|c|}
\hline Predictor variable (Baseline) & $B$ & $S E$ & $t$ & $p$ & $\Delta R^{2}$ & $R^{2}$ \\
\hline Organization & .07 & .10 & .66 & .51 & & \\
\hline Intervention & -.06 & .10 & -.56 & .58 & & \\
\hline Job tenure & .01 & .01 & 1.95 & .05 & & \\
\hline LMX & -.08 & .05 & $\begin{array}{l}- \\
1.48\end{array}$ & .14 & & \\
\hline Age & .01 & .01 & 1.25 & .21 & & \\
\hline LMX x Age & -.01 & .01 & $2 . \overline{22}$ & .03 & $.02 *$ & \\
\hline
\end{tabular}

$.06^{*}$

Note. $N=238$. Focal predictor and age were mean centered. Interaction term was computed from the mean-centered variables.

$B=$ unstandardized coefficient.

$* p<.05$. 
Table 3.4

Results of Moderated Regression Analyses Predicting 12-Month Perceived Stress Perceived Stress (12-month)

\begin{tabular}{|c|c|c|c|c|c|}
\hline Predictor variable (Baseline) & $B$ & $S E$ & $t$ & $p$ & $\Delta R^{2}$ \\
\hline Organization & .07 & .10 & -.70 & .49 & \\
\hline Intervention & -.01 & .09 & -.13 & .90 & \\
\hline Job tenure & .01 & .01 & 1.63 & .10 & \\
\hline Procedural justice & -.09 & .04 & $\begin{array}{c}- \\
2.30\end{array}$ & .02 & \\
\hline Age & .01 & .01 & 1.66 & .10 & \\
\hline Procedural justice $\mathrm{x}$ Age & -.01 & .01 & $2 . \overline{79}$ & .01 & $.03 *$ \\
\hline
\end{tabular}

Note. $N=237$. Focal predictor and age were mean centered. Interaction term was computed from the mean-centered variables.

$B=$ unstandardized coefficient.

$* p<.05$. 


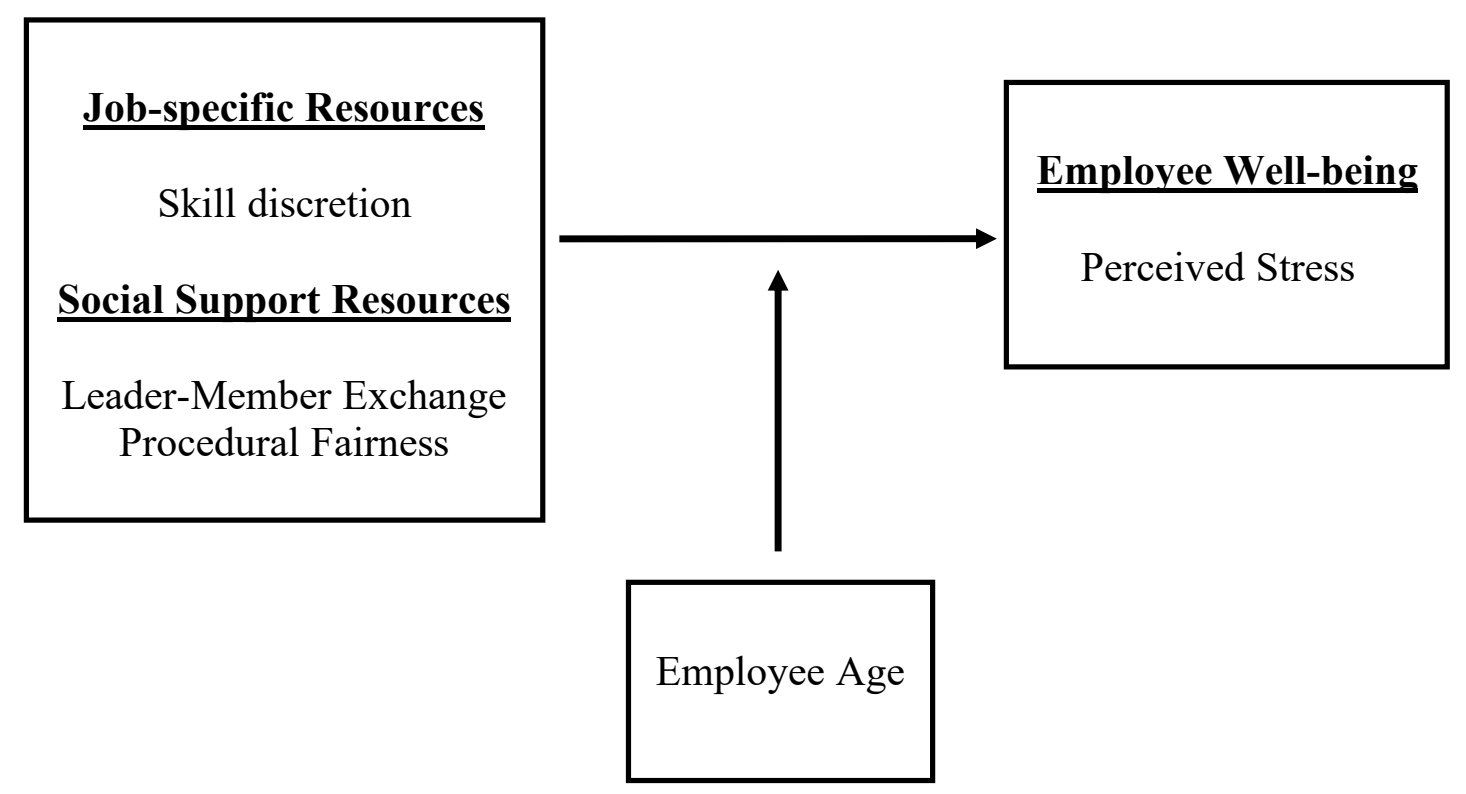

Figure 3.1 Summary model of the proposed relationships examined in Study 1. 


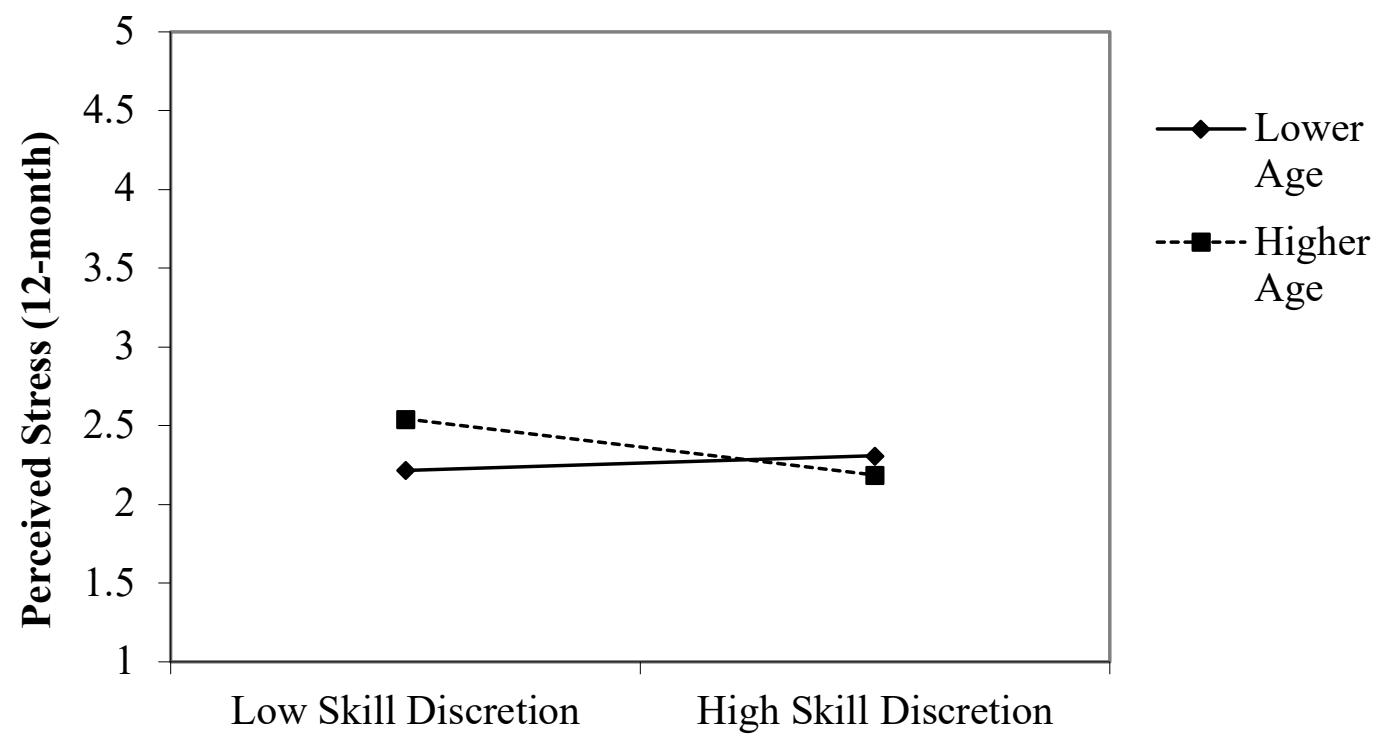

Figure 3.2 The interaction between skill discretion and age on perceived stress. Age $(M=43.53, S D=9.56)$. "Low Age" $=1 \mathrm{SD}$ below the mean $=34$. "High Age" = 1 SD above the mean $=53$. 


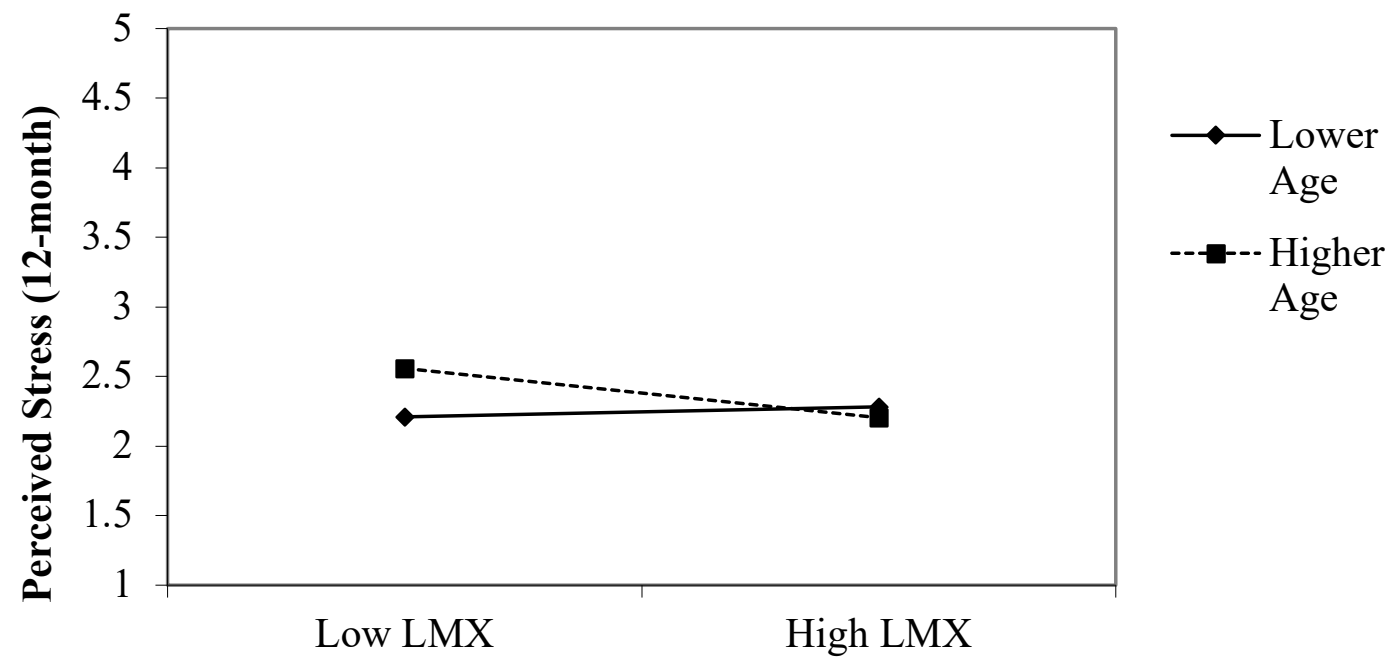

Figure 3.3 The interaction between LMX and employee age on perceived stress. Age $(\mathrm{M}=43.53, \mathrm{SD}=9.56)$. "Low Age" $=1 \mathrm{SD}$ below the mean $=34$.

"High Age" = 1 SD above the mean $=53$. 


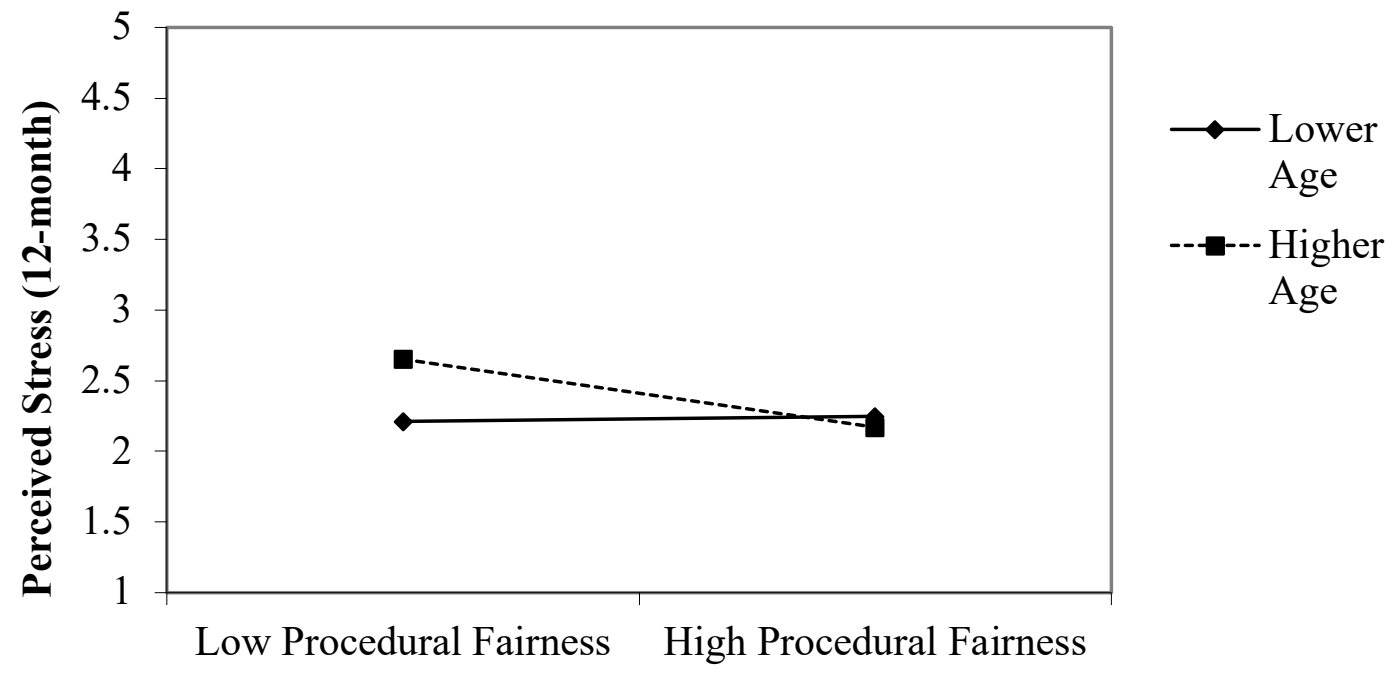

Figure 3.4 The interaction between procedural fairness and employee age on perceived stress.

Age $(\mathrm{M}=43.53, \mathrm{SD}=9.56)$. "Low Age" $=1 \mathrm{SD}$ below the mean $=34$.

"High Age" = 1 SD above the mean $=53$. 
Chapter 4: Age-based Differences in the Relationship between Social Support Resources and Different Forms of Job Performance

Lale M. Yaldiz, Berrin Erdogan, Talya Bauer, Donald M. Truxillo, and Todd Bodner Portland State University

(in preparation for submission) 
Extending the Investigation: Age-based Differences in Social Support Resources and Supervisory Ratings of Job Performance in a Non-U.S. Work Context

The results of the first study of this dissertation (Yaldiz, Truxillo, Bodner, \& Hammer, 2018) provide support for the age-based differential influence of job resources in relation to perceived stress. Under conditions of higher skill discretion, LMX, and procedural fairness, independent of their age, all employees showed lower levels of stress. However, older workers experienced greater stress compared to younger colleagues when these resources were lacking in the work environment.

These findings are promising to further examine the age-based differences in the usefulness of job resources integrating COR theory (Hobfoll, 1982) and SOC (Baltes \& Baltes, 1990) and SST (Carstensen et al., 1999). While this first study contributes to the employee well-being and stress literature, the findings raise additional important research questions to be investigated. For example:

1. If certain resources at work do not hold the same value for older and younger workers, is it also possible to detect age-based differences in the relationship between certain job resources and job performance?

2. How do the interactions between job resources and age relate to different forms of job performance such as in-role performance and OCB?

3. What is the generalizability of the findings to worker samples in a nonU.S. cultural context and other than construction?

Motivated by these research questions and utilizing multi-source data, the second study of this dissertation is presented in this chapter. 


\section{Introduction}

The aging of the population and workforce continues rapidly (U.S. Census Bureau, 2016). According to the projections, we will continue to see an increasing number of older workers in the labor force in the coming decades (U.S. Bureau of Labor Statistics, BLS; Toossi, 2012a, 2012b). This aging trend of the workforce provides many challenges to organizations such as how to manage the needs of older workers and help them maintain a good performance at work (Truxillo, Cadiz, \& Hammer, 2015; Zacher \& Schmitt, 2016). To cope with this changing composition of the age-diverse workplace, organizational researchers have begun to examine the similarities and differences between older and younger workers such as how they differ in their job attitudes, job performance, and well-being outcomes (Ng \& Feldman, 2008, 2010, 2012).

An emerging research area in the aging literature is the age-related differences in the usefulness of job resources, and how they differentially relate to work and non-work outcomes of older and younger workers (Hertel \& Zacher, 2015; Zaniboni et al., 2016; Zaniboni, Truxillo, \& Fraccorali, 2013; Zaniboni, Truxillo, Fraccaroli, Bertolino, \& McCune, 2014). Research in this area has primarily capitalized on two lifespan development theories (e.g., Selection-Optimization-Compensation Theory; SOC; Baltes \& Baltes, 1990; Socio-emotional Selectivity Theory; SST; Carstensen, Isaacowitz, \& Charles, 1999) to explain why some resources would be more important for older workers than younger workers, or vice versa. Parallel to these discussions, recent reviews (Halbesleben, Neveu, Paustian-Underdahl, \& Westman, 2014) on the mainstream resources theories (e.g., Conservation of Resources Theory; COR; Hobfoll, 1989) have 
also highlighted the need to revisit the "time-related" aspects of the theory, and critiqued that the assumption that the resource value is robust across people and situations may not hold true; and this assumption should be challenged by empirical studies. As shown by research on work motivation (Inceoglu, Segers, \& Bartram, 2012; Kanfer \& Ackerman, 2004), individuals' goals and needs change in time; thus, what is perceived as important by older individuals may not be perceived as helpful by younger people. For example, in their studies, Zaniboni and colleagues found that skill variety, a job-specific resource, was not related to turnover intentions of younger workers, whereas it was negatively related to turnover intentions among older workers (Zaniboni et al., 2013); and job autonomy was related to job satisfaction of older workers more than younger workers (Zaniboni et al., 2016). Based on the promising results of these initial studies, scholars in this area have called for future research to shed light on the shifting value of resources with age and to investigate the interactions of age with different work characteristics and on well-being outcomes (Truxillo, Cadiz, \& Rineer, 2014; Zacher \& Schmitt, 2016).

The current study aims to respond to these calls in the organizational literature by examining the moderating role of age in the relationship between social support resources and on-the-job behavior. Specifically, I examine the age-based differential relationships of two resources, leader-member exchange (LMX) and perceived organizational support (POS) to the supervisory ratings of job performance dimensions including in-role performance and organizational citizenship behaviors directed towards the individuals (OCBI) and towards the organization (OCBO). Integrating COR theory (Hobfoll, 1989) with two Lifespan Resource Models (i.e., SOC; Baltes \& Baltes, 1990; SST; Carstensen 
et al., 1999), I explain why these three resources at work would be differently related to job performance of older and younger workers. A summary of the proposed relationships is presented in Figure 4.1.

This study contributes to the literature in three ways. First, investigating employee age as a moderator, I aim to address one of the recent criticisms of COR theory (Halbesleben et al., 2014) about the "contextual" nature of resources. Rather than assuming that the resource value is the same across situations and people, I examine the possibility that the usefulness of resources may be different across the lifespan. Second, this study is among the first that empirically tests the age-based differences in the usefulness of job resources in relation to different forms of job performance. Investigating the age-related differences in both task performance and citizenship behaviors, I aim to identify the key resources that may play a more critique role for older workers to be more successful at their jobs, and to contribute more to their organizations and colleagues. In this respect, the findings of this study may help reduce the negative stereotypes about older workers such as that they are poorer performers compared to younger colleagues (Ng \& Feldman, 2008, 2012; Posthuma \& Campion, 2009) and help support the aging workforce by promoting workplace interventions to improve leadermember relationships and organizational support (Truxillo et al., 2015). Finally, and relevant to the aforementioned contextual nature of resources, this study examines the proposed relationships in a non-Western cultural context by collecting data from employees in Turkey. The role of cultural context on shaping the perceived usefulness of resources is highlighted by recent reviews and it merits investigation (e.g., Halbesleben et 
al., 2014; Hobfoll, 2002). Accordingly, individuals learn to value objects/resources based on cultural norms within which they grow up and live. Due to these variations in norms and values across cultures, what is considered to be useful by members of a specific culture may not be seen as equally helpful by members of another culture (Markus \& Kitayama, 1991). Unlike the U.S., which has an individualistic (separated/independent) culture, Turkey is recognized as a predominantly collectivistic society (relational/interdependent culture) (Hofstede, 1984) where building and maintaining close relationships with one's environment is valued and encouraged by the society (Erdogan, Kraimer, \& Liden, 2004; Pasa, Kabasakal, \& Bodur, 2001; Pellegrini \& Scandura, 2006). Thus, this study aims to provide insights about how older and younger workers from a non-Western society differ in their perceptions about the value of resources to perform well at work. In this respect, the findings from this study may have implications for multi-cultural organizations to raise awareness about the utility of job resources for employees across different cultures.

\section{Theoretical Background}

Building on the importance of resources on individuals' well-being and behavior, COR theory (Hobfoll, 1989) suggests that individuals are motivated to conserve their current resources to maintain well-being and performance. In addition to protecting their resources, they also engage in ways to enrich them, and feel stressed when they experience an actual or a potential resource loss. Capitalizing on COR theory, organizational research identifies a number of social support resources that influence employee performance at work. Specifically, the positive relationship between support 
from leaders and organization and different forms of work performance has been welldocumented by research (e.g., Anderson \& Williams, 1996; Dulebohn, Bommer, Liden, Brouer, \& Ferris, 2012; Erdogan \& Enders, 2007; Hochwarter, Witt, Treadway, \& Ferris, 2006; Meyer, Stanley, Herscovitch, \& Topolnytsky, 2002; Park, Sturman, Vanderpool, \& Chan, 2015; Rockstuhl, Dulebohn, Ang, \& Shore, 2012; Settoon, Bennett, \& Liden, 1996; Witt \& Carlson, 2006). Although COR theory is widely used to address these relationships, it does not adequately address the possibility whether the utility of resources would be differentially beneficial across people and contexts (Halbesleben et al., 2014). Hence, in a rapidly aging workforce, our knowledge of the age-based differences in the relationship between job resources and employee performance is still limited. Integrating lifespan development theories such as SOC (Baltes \& Baltes, 1990) and SST (Carstensen et al., 1999), on the other hand, helps investigate these age-related differences across people (Baltes, 1997; Hobfoll, 2002; Hertel \& Zacher, 2015).

SOC theory (Baltes \& Baltes, 1990) and SST (Carstensen et al., 1999) view agebased changes through different lenses. The basic premise of SOC suggests that individuals are motivated to employ different strategies to maintain performance as they experience age-related changes in their physical and mental capacities. The focus of SST, on the other hand, is the need for reorganization of individuals' affect-related goals within their social environment. For example, based on SOC, older individuals tend to select fewer goals to use their time and energy more efficiently (selection), seek personal or social resources that may help achieve them (optimization), and thus offset any weak performance (compensation). Thus, SOC processes include an active engagement to find 
ways to mobilize one's resources for a better performance (Baltes, Zhdava, \& Clark, 2011). Taking a different view on aging, SST capitalizes on the difference in the remaining time perceptions in life between younger an older people, and suggests that as individuals get older, they tend to develop a more limited time perception in life than younger individuals. Consequently, as opposed to material or growth-related goals, they prioritize maintaining meaningful relationships in their social interactions that satisfy their need to belong, being appreciated, and valued.

As pointed out in the aging literature (e.g., Truxillo et al., 2014; Yaldiz, Fraccaroli, \& Truxillo, 2017), how age relates to job performance is complex, and the interactions of age with different work-related variables merit further investigation. For example, a meta-analysis (e.g., Ng \& Feldman, 2008) found that age was not associated with core task performance but was moderately and positively related to OCB. In sum, utilizing COR theory (Hobfoll, 1989) along with SST (Carstensen et al., 1999) and SOC (Baltes \& Baltes, 1990), I develop the following study hypotheses and explain why I expect to detect differences between older and younger workers' in-role performance and OCB.

\section{Hypothesis Development}

Age and Social Support Resources: Leader-Member Exchange and Perceived Organizational Support

LMX. Supervisors constitute an important social resource for employees (Ilies, Nahrgang, \& Morgeson, 2007). Based on the Social-Exchange Theory (Blau, 1964), LMX theory (Dienesch \& Liden, 1986) refers to the quality of the reciprocal relationships 
between a leader and subordinates. When LMX quality is high, subordinates enjoy trust, liking, loyalty, and professional respect with their leaders (Bauer \& Erdogan, 2015). Although research has shown that higher-quality LMX is associated with a higher level of in-role performance and OCB (Dulebohn et al., 2012; Gerstner \& Day, 1997; Rockstuhl et al., 2012), the relative value of LMX to the job performance of older and younger workers has remained unexamined (Truxillo \& Burlacu, 2015).

I propose that the relationship between LMX and work performance will be stronger for older employees. Based on SOC theory (Baltes, 1997), high-quality LMX would serve as a strategic social resource for older workers to perform better at work (Truxillo \& Burlacu, 2015). As leaders hold power and have access to key organizational resources, older workers would enjoy being in a relationship where they are understood, trusted, and appreciated by their supervisors. Compared to younger workers, this strategic relationship would help them better mobilize their existing resources and allocate their limited time and energy more comfortably to task-related jobs. Similarly, when they are deprived of this kind of supervisory resource, I expect that they would demonstrate lower performance at job than younger colleagues.

Similarly, as for OCB, I expect that older workers would perceive LMX as a more critical resource than younger colleagues. Consistent with SST (Carstensen et al., 1999), LMX would provide a platform to satisfy emotional goals for older workers where they are treated with dignity, respect, and appreciation by their supervisors. Thus, they would want to engage in additional efforts to maintain this meaningful relationship and show higher OCB to reciprocate their leaders. 
Hypothesis 1a, 1b, 1c: Employee age will moderate the relationship between resources from the supervisor (LMX) and a) in-role performance, b) OCBI, c) OCBO. As LMX increases, employees will show higher performance; and this relationship will be stronger for older employees compared to younger employees.

Organizational support: POS. $P O S$ refers to employee beliefs about the extent to which the organization values their efforts, considers their best interest when making decisions, and cares about their well-being (Eisenberger, Huntington, Hutchison, \& Sowa, 1986; Rhoades \& Eisenberger, 2002). POS is distinct from LMX in that while perceptions about the exchange relationships between an employee and a specific leader is the center of LMX, POS is more related to employee perceptions about the organization as an entity (Erdogan et al., 2004; Wayne, Shore, \& Liden, 1997). For example, human recourse practices about offering training and development opportunities or organizational recognition such as promotions help to build perceptions of organizational support (Shore \& Shore, 1995). Based on the reciprocity norms, POS develops (Eisenberger et al., 1986) as workers devote efforts and dedication to their organization and, in turn, are rewarded for their contributions in the forms of both material (e.g., pay, trainings) and non-material (e.g., esteem, affiliation) benefits. When employees perceive higher level of POS, they develop trust and build long-term obligations with their workplace (Rhoades \& Eisenberger, 2002). Meta-analytic findings (Rhoades \& Eisenberger, 2002; Riggle, Edmonson, \& Hansen, 2009) have shown that POS is related to positive employee behaviors including in-role and extra-role 
performance. However, despite the well-documented main effect of POS on employee outcomes, research investigating the boundary conditions of these relationships is still limited (Riggle et al., 2009).

Similar to my expectation with LMX, I suggest that POS would represent both a strategic and a relational resource for older workers. Working for an organization where employee mistakes are tolerable, employee needs and values are recognized, and concerns are listened will foster the feelings of trust to the company (Cropanzano, Howes, Grandey, \& Toth, 1997). Hence, older employees may find it easier to adapt to such an environment and focus on accomplishing their job tasks without worrying about being left behind in hard times. The organization's willingness to take care of employees when support is needed will also help older workers develop long-term relationships with their employers, which may reduce the feelings of job insecurity due to the increased age, especially in job markets where younger labor force is available to hire. Moreover, POS also speaks to older workers' prioritized socio-emotional needs to belong and being appreciated by employers in an exchange of their efforts as an employee. In order to maintain a good relationship with their organizations, older workers would be more motivated to show OCB in their remaining careers than their younger counterparts. For older workers, going the extra mile by helping their team members and the company overall would be a natural consequence of enjoying this high-quality relationship with their employer. In summary, although working in an environment where POS is high would help maintain a better performance for all workers, I expect that this relationship 
will be stronger for older workers; and they will demonstrate poorer performance than younger colleagues when this resource is perceived as low.

Hypothesis $2 a, 2 b, 2 c$. Employee age will moderate the relationship between support from the organization (POS) and a) in-role performance, b) OCBI, c) OCBO. As POS increases, employee performance will increase, and this relationship will be stronger for older employees compared to younger employees.

\section{Method}

\section{Sample and Procedures}

This study was conducted as part of a larger study in collaboration with the School of Business, Portland State University, and a private textile manufacturer located in Istanbul, Turkey. Participants were employees and their managers from departments such as finishing, process control, and fabric warehouse. Data were collected on-site over a four-month period during working hours by the Human Resources department. Data on employee age, LMX and POS were collected from employees, and work performance (in-role and $\mathrm{OCB}$ ) was collected from their respective managers. Employees were invited to complete surveys within the scheduled hours in allocated meeting rooms whereas supervisors filled in the surveys in their offices and submitted their responses in private envelopes. Out of 244 employees and 27 managers, 194 employees and 25 managers participated in the study.

The self-reported age variable was available for 203 participants in the final sample. Among them, the supervisory ratings of job performance were available for 162 
employees. After deleting those who had missing data on educational background and organizational tenure, the remaining sample size was 156 , and this sample was used in the analyses. The average age of the sample is 33.53 years $(S D=6.84)$ ranging from 19 to 56. Although this mean age seems to be on the younger side within the U.S. work context, it is consistent with prior research (e.g., Bayram, Gursakal, \& Bilgel, 2009; Erdogan \& Bauer, 2005; Pellegrini \& Scandura, 2006; Smith, Dugan, \& Trompenaars, 1996) conducted with Turkish employees. The majority of the sample is male $(95.5 \%)$, married (79.4\%), and had at least a high school education $(75.6 \%)$. The average organizational tenure is 8.01 years $(S D=5.33)$. Finally, supervisor span of control differed between 1 subordinate and 13 subordinates, with an average group size of 8.76 $(S D=3.01)$

\section{Measures}

Utilizing Brislin's (1970) back-translation procedures, all scales were translated from English to Turkish, and then back translated to Turkish by a bilingual researcher. The responses ranged from 1 (Strongly disagree) to 7 (Strongly agree).

Age. Chronological age was assessed with a single item by asking respondents their age. Based on the recommendations of recent research on work and age (e.g., Hertel \& Zacher, 2015; Truxillo et al., 2014, 2015), this study treats age as a continuous variable instead of utilizing arbitrary cut-offs (e.g., over-40/under-40 years). Accordingly, younger and older workers are operationalized as those $1 \mathrm{SD}$ below and $1 \mathrm{SD}$ above the mean age of the study sample, respectively. 
Social support resources. Employee self-reports were used to assess resources. $L M X$ was measured with seven items (Scandura \& Graen, 1984). A sample item was, "My supervisor understands my job problems and needs well" $(\alpha=.92)$. POS was measured with eight items (Eisenberger et al., 1986). A sample item included, "The organization values my contribution to its well-being" $(\alpha=.75)$.

Work performance. Supervisors were asked to provide their subordinates names on the surveys and rate their work performance. In-role performance, OCBI, and OCBO were assessed by seven items each (Williams \& Anderson, 1991). Sample items for inrole performance included, "This employee adequately completes assigned duties" $(\alpha=$ .87), for $O C B O$ included, "This employee's attendance at work is above the norm" $(\alpha=$ .66), and for $O C B I$ included, "This employee helps others who have heavy workloads" ( $\alpha$ $=.85)$.

Control variables: To rule out alternative explanations, three control variables were used due to their theoretical relationships with age, LMX, and job performance. Specifically, I controlled for organizational tenure $(M=8.01$ years, $S D=5.33)$, educational level $(1=$ elementary school, $2=$ middle school, $3=$ high school, $4=$ college graduate), and supervisor span of control (group size). In this sample, supervisor span of control was between 1 subordinate and 13 subordinates $(M=8.76, S D=3.01)$.

Analytical strategy. As participants worked within work groups under the supervision of managers, primary analyses were conducted to assess whether the data required multilevel modeling. Intraclass correlation coefficients (ICC) were calculated to determine the degree of dependency within work groups. Manager id's who assessed 
employee performance was used as the nesting variable. There were 156 employees nested under 24 managers. Accordingly, ICC scores were $.42, .66, .55$ for in-role performance, OCBI, and OCBO, respectively, which showed substantial group effects owing to clustering. Since the shared variance in the individual observations violate the OLS assumptions of uncorrelated error terms, a random coefficient regression model is used to test the study hypotheses. Random coefficient random slope models were also considered however a majority of these models showed convergence issues. Therefore, I reported the findings from the random coefficient models. All analyses were conducted in SPSS, Version 24.

\section{Results}

Means, standard deviations, and correlations among the study variables are presented in Table 4.1. Age was positively related to organizational tenure $(r=.74, p<$ $.01)$, education $(r=-.40, p<.01)$, and supervisor span of control $(r=.17, p<.05)$. Education was positively correlated with in-role performance $(r=.25, p<.01)$ and OCBO $(r=.17, p<.05)$. Supervisor span of control was negatively related to OCBI $(r=$ $-.28, p<.01)$ and OCBO $(r=-.30, p<.01)$. The key study variables, age, LMX, and POS, were not significantly correlated with in-role performance, OCBI, and OCBO. Hypotheses 1a-1c stated that employee age would moderate the positive relationship between resources from the supervisor (LMX) and a) in-role performance, b) OCBI, and c) OCBO such that the relationship would be stronger for older employees compared to younger employees. As presented in Table 4.2, the interaction between age and LMX was not significant for a) in-role performance $(\beta=.01, t(146.9)=1.33, p>$ 
$.05)$; b) OCBI $(\beta=.01, t(139.1)=1.64, p>.05)$; and, c) OCBO $(\beta=.01, t(143.3)=$ $1.60, p>.05)$. Thus, Hypotheses $1 \mathrm{a}-1 \mathrm{c}$ were not supported ${ }^{5}$.

Hypotheses $2 \mathrm{a}-2 \mathrm{c}$ stated that employee age would moderate the positive relationship between resources from the organization (POS) and a) in-role performance, b) OCBI, and c) OCBO such that the relationship would be stronger for older employees compared to younger employees. However, the results in Table 4.3 showed that the interaction between age and LMX was not significant for a) in-role performance $(\beta=$ $.00, t(144.2)=-.29, p>.05) ;$ b) OCBI $(\beta=-.00, t(137.4)=-.10, p>.05)$; and, c) OCBO $(\beta=-.00, t(141.1)=-.07, p>.05)$. Thus, no support was found for Hypotheses $2 \mathrm{a}-2 \mathrm{c}$.

\section{Discussion}

The aim of this study was to examine the age-related differences in the relationship between resources from the supervisor (LMX) and resources from the organization (POS) and three types of job performance (in-role performance, OCBI, and OCBO). The uniqueness of this study was two-fold. First, responding to the research calls to examine the potential differences in the resource value across individuals and time as defined by the mainstream resource theories (Halbesleben et al., 2014), I sought to investigate whether the utility of these two specific resources was different for older and younger employees' performance. To my knowledge, this study was the first that investigated how LMX and POS related to different forms of job performance from a lifespan development approach (SOC and SST) integrating with COR theory. Second,

\footnotetext{
${ }^{5}$ Study hypotheses were tested with and without controlling for organizational tenure, educational level, and supervisor span of control. Accordingly, the results were substantially similar.
} 
these relationships were investigated in Turkey, a non-U.S. employment context associated with high collectivistic values (Hofstede, 1984). Given that the cultural context influences which objects or resources are considered valuable by its members (Markus \& Kitayama, 1991), the findings of this study aimed to add to the cross-cultural industrial and organizational psychology literature by allowing comparisons to the studies conducted with U.S. employee samples.

According to the results, data did not support the hypothesized relationships at the $p<.05$ significance level. Specifically, the perceived support from the supervisor (LMX) and organization (POS) did not significantly interact with age to influence supervisoryratings of in-role performance and organizational citizenship behavior. In other words, having a supportive social environment at work was equally important for older and younger employees with regard to these three forms of work performance. This finding may suggest that social support resources other than LMX or POS may play a key role in these relationships. For example, support from coworkers or support from family members may be more important for older workers.

These results have implications for theory and practice. As for the main effect of age on performance, the findings in this study were in line with the meta-analytical findings reported by $\mathrm{Ng}$ and Feldman (2008) that age was largely unrelated to core task performance and only slightly related to OCBI (.05) and OCBO (.06) when supervisory ratings were used. In terms of the non-significant interaction effects in this study, however, there could be two explanations as prior research noted (McEvoy \& Cascio, 1989; Ng \& Feldman, 2008; Sturman, 2003): First, employees, independent of their age, 
are likely to show utmost effort to satisfy the demands of their core job performance to keep themselves employed. Therefore, this study might fail to find a pronounced difference of the influences of LMX and POS on older and younger workers' in-role performance. For example, a recent study (Yaldiz et al., 2018) found support for the agebased differential relationship of LMX to predict perceived stress in a sample of 243 U.S. construction workers. Accordingly, Yaldiz and colleagues (2018) found that baseline LMX was differentially related to employee stress after one year for older and younger workers: When LMX was high, all employees reported lower levels of stress. However, when LMX was low, older workers reported greater stress compared to their younger colleagues. The present study builds on this current research of Yaldiz et al. (2018) by examining job performance as an outcome. It may be that, although the presence/ lack of social support resources such as LMX and POS show age-based differences in employee well-being outcomes, these relationships may not be present for job performance. A second explanation may be that poor performing employees may withdraw from employment situation over time, and only good performing employees may remain at work, so that no major differences remained in performance scores between those who stay, independent of their age.

\section{Limitations and Future Research}

As in any study, the present study has some limitations that should be addressed. First, the generalizability of the findings is limited as this study was conducted with a male-dominated manufacturing employee sample in Turkey. Future research should examine these relationships in diverse worker samples across cultures, gender, industries, 
and job types. Second, it is important to note the small sample size of participants $(N=$ 156) grouped under a large number of managers $(N=24)$ in this study. Thus, before concluding that age did not moderate the relationships between these two social support resources and job performance dimensions, one needs to be cautious. It may be the case that the limited number of observations under each manager might create a low power issue in analyzing the data at multi-level, and, therefore, the data might fail to detect significant relationships at $p=.05$ significance level. Therefore, replication of this study with larger sample sizes and increased statistical power may help detect the age differences in the LMX-job performance and POS-job performance links.

It is also worthwhile to add that employees in this study were nested under workgroups, and the data were analyzed as multilevel. As workgroups may develop certain characteristics over time, examining potential group-level variables (e.g., team climate) or supervisory characteristics (e.g., age, gender, personality) may help detect age-based differences in these three forms of job performance. For example, metaanalytic findings on LMX (Dulebohn, Bommer, Liden, Brouer, \& Ferris, 2012) have shown that employee characteristics (e.g., conscientiousness), leader characteristics (e.g., extraversion and agreeableness), and contextual variables (e.g., cultural dimensions such as collectivism) were significant covariates of LMX. Likewise, Zacher and colleagues (Zacher, Rosing, Henning, \& Frese, 2011) showed that leader age was negatively related to followers' extra effort. In the light of the organizational literature, an ancillary set of analyses were conducted to consider additional control variables. The bivariate correlations indicated that, in the current study, supervisor age was negatively correlated 
with subordinate in-role performance, OCBI, and OCBO $(r \mathrm{~s}=-.24,-.36$, and -.28 , respectively; $p$ s $<.01)$; supervisor gender $(1=$ male, $2=$ female) was negatively correlated with subordinate OCBO $(r=-.20, p<.05)$ such that OCBO scores was lower for female supervisors; supervisor in-role performance was positively correlated with subordinate in-role performance, OCBI, and $\mathrm{OCBO}(r \mathrm{~s}=.21, .51$, and .25 , respectively; $p \mathrm{~s}<.01)$, supervisor OCBI was positively correlated with subordinate OCBI and OCBO $(r \mathrm{~s}=.44$, .29 , respectively; $p \mathrm{~s}<.01$ ), supervisor OCBO was positively correlated with subordinate OCBO $(r=.26 ; p<.01)$, and, finally, supervisor collectivism scores were positively correlated with subordinate $\operatorname{OCBO}(r=.31 ; p<.01)$ and $\operatorname{LMX}(r=.16 ; p<.05)$. Thus, future research may utilize some of these variables as statistical control variables to investigate whether the usefulness of social support resources are different for older and younger employees in relation to their job performance.

\section{Conclusion}

This study sought to examine the age-based differences in the relationship between social support resources at work (LMX, POS) and three forms of job performance (in-role performance, OCBI, OCBO). A Turkish employee sample from the manufacturing industry $(N=156)$ was utilized to collect data, and employees reported their own perceptions of LMX and POS, whereas performance scores were obtained from their respective managers. Drawing on COR theory and two lifespan development theories (SOC, SST), it was hypothesized that the positive relationship between LMX, POS, and three forms of job performance would be stronger for older employees compared to younger employees. However, no support was found for the hypothesized 
relationships. Thus, the findings of this study suggest that having a good-quality relationship with managers and support from one's organization seemed to be equally important for in-role performance and citizenship behaviors of all employees, independent of their age. 


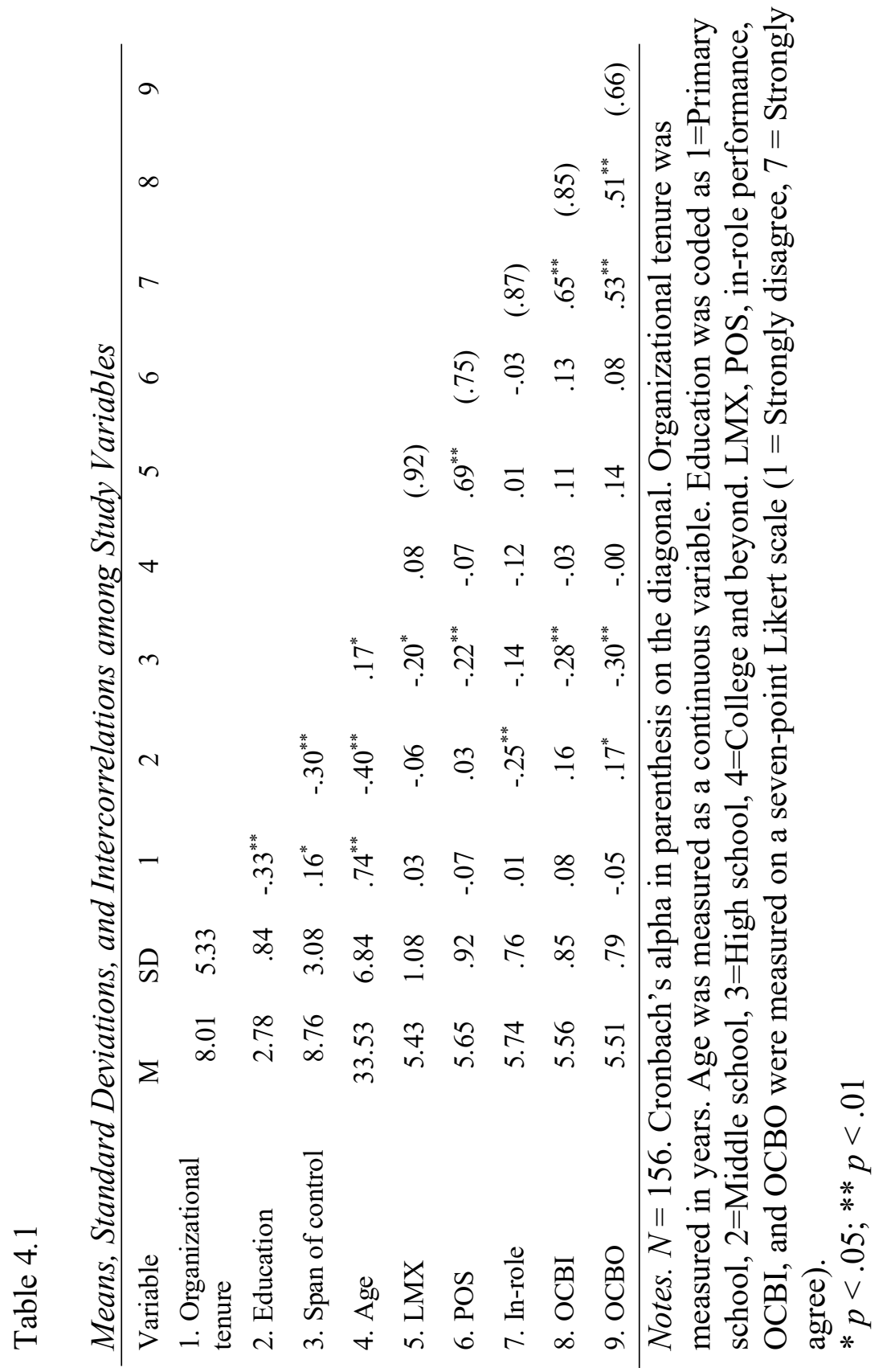


Table 4.2

Moderating Effect of Age on the Association between Leader-Member Exchange (LMX) and Employee Performance

\begin{tabular}{|c|c|c|c|}
\hline & \multicolumn{3}{|c|}{ Outcome } \\
\hline & $\begin{array}{c}\text { In-role } \\
\text { Performance }\end{array}$ & OCBI & OCBO \\
\hline Predictor & Estimate $(S E)$ & Estimate $(S E)$ & Estimate $(S E)$ \\
\hline \multicolumn{4}{|l|}{ Fixed Effects } \\
\hline Intercept & $7.13(1.56)^{* *}$ & $7.73(1.36)^{* *}$ & $7.56(1.51)^{* *}$ \\
\hline Organizational Tenure & $0.02(0.01)$ & $0.02(0.01)$ & $-0.00(0.01)$ \\
\hline Education & $0.17(0.07)^{*}$ & $0.06(0.06)$ & $0.07(0.07)$ \\
\hline Span of Control & $-0.01(0.03)$ & $-0.04(0.04)$ & $-0.07(0.03)^{*}$ \\
\hline LMX & $-0.32(0.26)$ & $-0.33(0.22)$ & $-0.35(0.25)$ \\
\hline Age & $-0.06(0.04)$ & $-0.07(0.04)$ & $-0.05(0.04)$ \\
\hline LMX x Age & $0.01(0.01)$ & $0.01(0.01)$ & $0.01(0.01)$ \\
\hline
\end{tabular}

Notes. $N=156$.

$* p<.05 ; * * p<.01$ 
Table 4.3

Moderating Effect of Age on the Association between Perceived Organizational Support (POS) and Employee Performance

\begin{tabular}{|c|c|c|c|}
\hline & \multicolumn{3}{|c|}{ Outcome } \\
\hline & $\begin{array}{c}\text { In-role } \\
\text { Performance } \\
\end{array}$ & OCBI & $\mathrm{OCBO}$ \\
\hline Predictor & Estimate $(S E)$ & Estimate $(S E)$ & Estimate $(S E)$ \\
\hline \multicolumn{4}{|l|}{ Fixed Effects } \\
\hline Intercept & $5.42(1.79)^{* *}$ & $6.17(1.56)^{* *}$ & $5.83(1.75)^{* *}$ \\
\hline Organizational Tenure & $0.01(0.01)$ & $0.02(0.01)$ & $-0.01(0.01)$ \\
\hline Education & $0.17(0.07)^{*}$ & $0.06(0.06)$ & $0.06(0.07)$ \\
\hline Span of Control & $-0.02(0.03)$ & $-0.05(0.04)$ & $-0.08(0.04)^{*}$ \\
\hline POS & $-0.01(0.29)$ & $-0.04(0.25)$ & $-0.03(0.28)$ \\
\hline Age & $0.01(0.05)$ & $-0.00(0.04)$ & $0.02(0.05)$ \\
\hline POS x Age & $-0.00(0.01)$ & $-0.00(0.01)$ & $-0.01(0.01)$ \\
\hline
\end{tabular}

Notes. $N=156$.

$* p<.05 ; * * p<.01$ 


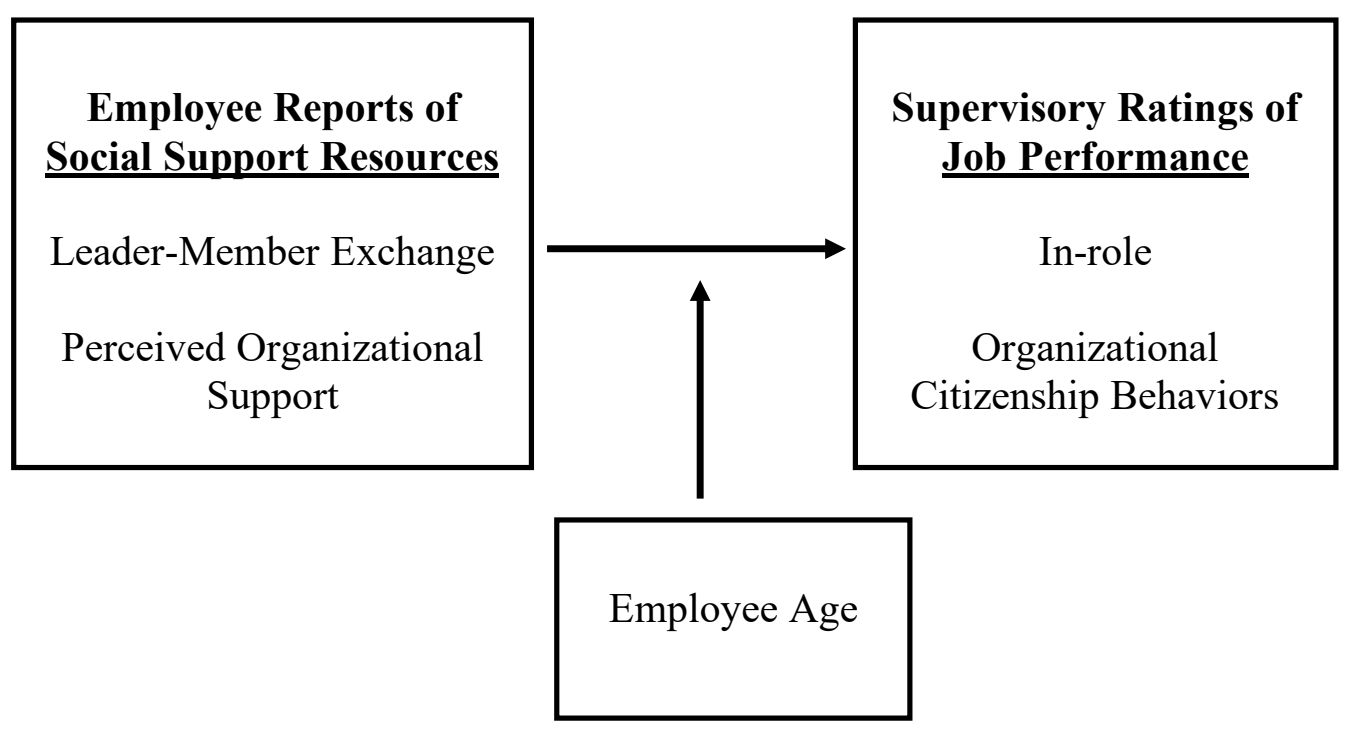

Figure 4.1 Summary model of the proposed relationships examined in Study 2. 
Chapter 5: Investigating the Relationship Between the Job-related and Personal Resources and Employee Attitudes and Well-being: The Moderating Role of Age

\author{
Lale M. Yaldiz, Donald M. Truxillo, and David M. Cadiz \\ Portland State University
}

(in preparation for submission) 


\section{Extending the Investigation: Examining the Age-based Differences in the}

\section{Understudied Personal Resources and Their Associations with Job Attitudes}

In Study 1 (Yaldiz, Truxillo, Bodner, \& Hammer, 2018) and Study 2, I examined the role of social and job-specific resources and how they interacted with employee age to influence perceived stress and different forms of job performance. The data did not support the proposed relationships in Study 2, that is, LMX and POS seemed to be equally important for all employees independent of their age when predicting their in-role performance and organizational citizenship behavior.

Building on this body of work, there are other research questions remained to be investigated such as the role of personal resources and other employee outcomes. For example:

1. In addition to job-specific and social resources, how do personal resources interact with age to influence work and non-work outcomes including job attitudes and employee well-being?

2. What is the generalizability of the findings to health care employees who work under high job constraints?

Guided by these research questions, the third and final study in this dissertation seeks to examine the moderating role of employee age in the relationship between resources from job (e.g., decision-making autonomy) and two understudied personal resources (e.g., optimism, perceived work ability) and work and well-being outcomes including job satisfaction, work engagement, perceived stress, and emotional exhaustion. Utilizing a 1-week time-lag study design and relying on employee reports, data were 
collected from a female-dominant nurse sample in the Pacific Northwest, U.S. This final study is presented below. 


\section{Introduction}

The composition of the workforce has become more age-diverse due to the increase in the participation of older workers in the employment settings (Dychtwald, 2000; Finkelstein \& Truxillo, 2013). To understand this age-diverse work group and help organizations manage their human capital, researchers have called for studies to examine the age-based differences in work-related factors, work attitudes and well-being of older and younger employees (Halbesleben, Neveu, Paustian-Underdahl, \& Westman, 2014; Hertel \& Zacher, 2015; Kunze \& Boehm, 2013; Truxillo, Cadiz, \& Hammer, 2015; Truxillo, Fraccaroli, Yaldiz, \& Zaniboni, 2017). This study aims to respond to this call in the literature and investigates the possibility that the perceived utility of job-related resources would be differentially related to the job attitudes and well-being outcomes of younger and older workers. Specifically, I investigate the moderating role of employee age in the relationship between three potential job resources (i.e., decision-making autonomy, optimism, and perceived work ability) and two job attitudes (i.e., job satisfaction, work engagement) and two well-being outcomes (i.e., perceived stress, emotional exhaustion).

This study contributes to the literature in three ways. First, utilizing a resourcebased approach, I aim to integrate Conservation of Resources theory (COR; Hobfoll, 1989) and lifespan development theories (i.e., Selection-Optimization-Compensation;

SOC; Baltes \& Baltes, 1990; Socio-emotional Selectivity Theory; SST; Carstensen, Isaacowitz, \& Charles, 1999) to explain why decision-making autonomy, optimism, and 
perceived work ability will be differentially helpful for job attitudes and well-being of employees of different ages.

Second, this study aims to increase knowledge about perceived work ability as an antecedent and how it relates to different employee outcomes including employee wellbeing. To date, perceived work ability has been studied mostly as an outcome, and the few studies investigating work ability as an antecedent have focused largely on its relationship to employee withdrawal behaviors such as absence from work and sick leaves while neglecting other important employee outcomes (McGonagle, Beatty, \& Joffe, 2014; McGonagle, Fisher, Barnes-Farrell, \& Grosch, 2015).

A third contribution of this study relates to uncovering the boundary conditions of the link between optimism as a personality-based resource and different occupational outcomes. Although research has investigated the interaction between optimism and pessimism to predict positive and negative affect of younger and older groups (Palgi, Shrira, Ben-Ezra, Cohen-Fridel, \& Bodner, 2011), to my knowledge, this study is the first study that utilizes employee age as a moderator to shed light on whether older or younger individuals benefit from this key personal resource equally in a work context.

Finally, conducted with a female-dominated health care worker sample, this study helps understand whether older and younger female workers hold different perceptions about the utility of different job resources in relation to their job attitudes and well-being. A summary of the proposed relationships is presented in Figure 5.1.

\section{Theoretical Background}

\section{COR Theory and Lifespan Development Models}


COR theory (Hobfoll, 1989) suggests that people are motivated to protect their current resources (conservation), seek to obtain new resources (acquisition), and experience stress when confronted with an actual or a potential loss of resource or when they fail to renew resources after spending from their resource reservoir. In this respect, COR theory is considered as a resource-adaptation model (Hobfoll, 2002). Specifically, the theory posits that resource loss is key to the stress experience, and therefore people seek to obtain, retain, and protect their resources in order to maintain well-being. The theory also suggests that the ability to gain new resources becomes especially important in the face of resource loss to pursue life goals and restore emotional well-being. One of the recent criticisms against COR theory is that it assumes that the resource value is robust across situations and individuals (Halbesleben et al., 2014). In other words, according to COR theory, the usefulness of resources is the same for different people. However, as shown by the lifespan development theories, people experience physical and cognitive changes as they get older, and their needs and motivation change by age (e.g., Kanfer \& Ackerman, 2004), - thus, what is perceived as useful by older individuals may not hold the same value for younger individuals. In this vein, this study addresses this call to examine moderators of when resources will matter, capitalizing on two lifespan development theories (SOC and SST) to explain why some job-related resources would be more valuable for older workers' job attitudes and well-being.

The SOC model (Baltes \& Baltes, 1990) recognizes individuals as adaptive agents who employ various strategies to cope with age-related cognitive and physical changes for a successful functioning. Accordingly, selection includes strategies such as narrowing 
down one's goals and prioritizing them to match one's needs with limited resources including time and energy. Following the selection of goals, optimization takes place where one reviews his or her available resources and capitalizes on them to improve performance. These resources may include personal (e.g., knowledge, skills, and abilities) or social resources (e.g., support from others). After narrowing down goals and carefully considering available resources that may help achieve them, individuals develop compensation strategies where they actively search ways to offset a weak performance due to limited resources. From a resource-based approach, as these strategies help review, mobilize, and manage declining resources due to age (Baltes et al., 2011; Moghimi et al., 2017), older workers may especially benefit from SOC strategies to maintain favorable attitudes toward job and better well-being.

Another lifespan development model, SST (Carstensen et al., 1999), focuses on the difference in the perception of future time among individuals of different ages and argues how it influences affect-related goals. According to SST, younger individuals have an expansive view of future time and therefore they tend to invest more on growthrelated goals where they can acquire new knowledge and information. On the other hand, compared to younger individuals, older individuals have a more limited perception of remaining time in life. Since the perceived future time is limited and as older individuals have already accumulated job-related knowledge and experience over time, they prioritize affect-related goals over growth-related goals. Consequently, they invest their time to build and maintain meaningful relationships in life, seek social acceptance and enhance self-identity. 
Based on these age-related differences in selecting strategies to maintain performance and the prioritization of the affect-related goals over the growth-related goals throughout the lifespan, I argue that there will be differences between older and younger individuals' perceptions about the usefulness of job-related resources that help them form job attitudes and maintain well-being. Following the propositions of SOC and SST, this study investigates age-based differential usefulness of resources from the job (decision-making autonomy) and personal resources (optimism, perceived work ability) to explain job attitudes (job satisfaction, work engagement) and emotional well-being (perceived stress, emotional exhaustion) among nurses.

\section{Hypothesis Development}

\section{Resources from Job}

Decision-making autonomy. Job autonomy refers to the extent to which a job allows freedom, independence, and discretion in decision-making, work scheduling, and work methods to perform tasks (Morgeson \& Humphrey, 2006). Autonomy on one's job has an intrinsic motivational role that helps individuals increase their efforts and engagement (Kuhnel, Sonnentag, \& Bledow, 2012). Meta-analyses have shown that, among other types of job characteristics, job autonomy is strongly and positively associated with work attitudes and outcomes including job satisfaction, work engagement, and objective and subjective reports of job performance; and negatively with absenteeism (Fried \& Ferris, 1987; Humphrey, Nahrgang, \& Morgeson, 2007; Kuhnel et al., 2012; Spector, 1986; Xanthopoulou, Bakker, Demerouti, \& Schaufeli, 2009). In terms of well-being outcomes, studies have showed that as job autonomy 
increases, anxiety, burnout, stress, and emotional exhaustion decreases (Diestel \& Schmidt, 2012; Humphrey et al., 2007).

Among the different facets of job autonomy (Morgeson \& Humphrey, 2006), decision-making autonomy refers to the freedom to make decisions at work (Karasek et al., 1998). Compared to other types of job autonomy, both meta-analyses and empirical studies have demonstrated that decision-making autonomy is the strongest predictor of employee attitudes such as job satisfaction (Humphrey et al., 2007; Morgeson \& Humphrey, 2006).

Research has mixed results in terms of how age interacts with job autonomy to influence different employee outcomes (Zacher \& Schmidt, 2016). Recent meta-analytic findings (Ng \& Feldman, 2015) have reported that job autonomy is related to emotional exhaustion and job performance of older worker samples more strongly than of younger worker samples, whereas it is related to job satisfaction, work engagement, and stress more strongly among younger worker samples. On the other hand, a recent empirical study (Zaniboni et al., 2016) has demonstrated that the interaction between age and decision authority (Karasek et al., 1998), a similar construct to decision-making autonomy, is more positively related to the job satisfaction of older workers than younger workers among a sample of U.S. construction workers. Likewise, another recent study (Ramos, Jenny, \& Bauer, 2016) conducted with nearly 2,000 European workers across Germany, Austria, and Switzerland revealed that although high job control leads to higher work engagement for all employees, lower job control impairs work engagement of older workers more than younger counterparts. Thus, scholars have highlighted the 
need for future research that investigates these age-based differential relationships in different contexts and with different samples.

Based on lifespan development models, I propose that older employees will take advantage of higher decision-making autonomy to offset age-related declines in physical or mental capabilities more than younger workers. Exercising control over work-related decisions, they can enjoy the freedom to use additional resources such as accumulated job knowledge and experience at work (e.g., Weigl, Müller, Hornung, Zacher, \& Angerer, 2013). Moreover, from the lens of SST, it can be argued that decision-making autonomy is not only a critical resource that helps older workers mobilize other resources, but it also communicates trust from supervisors or work environments to the worker's discretion about how to carry their job tasks (Andreassi \& Thompson, 2007). In this respect, experiencing being autonomous in their jobs will satisfy the emotional needs of older workers for respect and being appreciated ( $\mathrm{Ng} \&$ Feldman, 2015), which in turn will be reciprocated with more positive attitudes towards their jobs, increased work engagement, and reduced stress and emotional exhaustion. Accordingly, the following hypotheses are developed.

Hypothesis $1 a, 1 b, 1 c, 1 d$. Employee age will moderate the relationship between decision-making autonomy and a) job satisfaction, b) work engagement, c) perceived stress, d) emotional exhaustion, such that the relationship will be stronger for older employees compared to younger employees.

\section{Personal Resources}


According to COR theory (Hobfoll, 1982), personal resources are defined as internal means that help people function, appraise situations positively, and deal with stress (Hobfoll, 2002). Personal resources such as perceived mental and physical capacities to meet the job demands and personality traits such as optimism are instrumental in fostering work motivation, work engagement, achieving work-related goals, and reducing the psychological costs of a job (Bakker \& Demerouti, 2007; Bakker, Demerouti, \& Sanz-Vergel, 2014; Demerouti, Bakker, Nachreiner, \& Schaufeli, 2001). In other words, personal resources help individuals adapt to their environments, better cope with job-related stress, improve their well-being (Hobfoll, 2002), become more stressresistant, develop favorable attitudes towards their jobs, and achieve their work goals (McGonagle et al., 2015). In this study, I examine two personal resources, optimism and perceived work ability, that have been understudied in relation to worker attitudes, health and well-being.

Optimism. Dispositional optimism is one of the key personality-based resources (Hobfoll, 2002). Optimism refers to the tendency to believe that one will generally experience good versus bad outcomes in life (Scheier \& Carver, 1985). Research on optimism yielded consistent results that it relates to favorable outcomes in life. Specifically, studies have shown that individuals with higher optimism tend to persistently and effectively pursue goals in life (Segerstrom \& Solberg Nes, 2006; Solberg Nes, Segerstrom, \& Sephton, 2005), actively pursue social relationships with friends and families (Brissette, Scheier, \& Carver, 2002), and tend to focus less on negative aspects of their lives (Scheier et al., 1989). In terms of well-being, those with 
higher optimism are likely to have greater physical and mental health, and they tend to deal with demanding conditions of their environment more effectively (Hobfoll, 2002). For example, in a longitudinal study conducted with law students over a 10-year period (Segerstrom, 2007), optimism was negatively related to psychological health including depression and anxiety, and, optimism assessed at the baseline is negatively related to follow-up reports of physical health symptoms such as pain and gastrointestinal symptoms.

Studies that have examined optimism as a personal resource with employee samples have yielded similar results. For example, Mache and colleagues (2012) found that optimism is moderately and positively related to work engagement in a sample of German health care workers. Similarly, Xanthopoulou and colleagues (Xanthopoulou, Bakker, Demerouti, \& Schaufeli, 2007) demonstrated that optimism is associated with higher work engagement and lower levels of exhaustion in an engineer sample in the Netherlands. Finally, being optimistic is found to be associated with higher job satisfaction, and lower levels of emotional exhaustion, mental distress, and physical symptoms such as back pain and headache in a Finnish sample of working adults (Mäkikangas \& Kinnunen, 2003). In this vein, from a resource-based perspective, optimism may help individuals mobilize resources and even accumulate more resources over time such as skills, friendship, and greater physical and mental well-being (Hobfoll, 2002; Mäkikangas \& Kinnunen, 2003; Segerstrom 2007). In fact, this is in line with the resource caravans principle of COR theory (Hobfoll, 2002) which suggests that resource 
gain is a developmental process where acquiring key resources are likely to lead to the possession of other important resources.

Although optimism has been linked to many positive work outcomes, as noted in research (Palgi et al., 2011), our understanding of the boundary conditions of optimism work outcomes is still limited, and this gap in the literature needs attention. Responding to this call in the literature, I examine employee age as a boundary condition that relates optimism to different work attitudes and well-being outcomes. Based on previous study findings and COR theory and lifespan development theories, I propose that the usefulness of optimism in relation to these employee outcomes will be higher for older workers than younger workers. COR theory suggests that resource gain and the associated positive feelings due to possessing a resource become especially important for emotional wellbeing and goal pursuit when individuals face resource loss. In this respect, following the basic premises of SOC and SST, I argue that as older workers are more prone to experience age-based resource loss in terms of physical, mental, and cognitive capacities (e.g., SOC) and have a narrower remaining time perception in life (e.g., SST), having optimism in their resource repertoire will benefit older workers more than younger counterparts. Likewise, from a socio-emotional perspective, the need for building and maintaining meaningful social relationships increases by age, and optimists have been shown to have greater satisfaction with their close relationships (Andersson, 2012a, 2012b; Rius-Ottenheim et al., 2012). In sum, I propose that being optimistic about work and future will help older workers more free up their resources and cope better with the demands of their work environment. Hence, they can develop more positive attitudes 
towards their jobs, enjoy, and engage in their job roles better which is manifested in the forms of higher job satisfaction and work engagement. Moreover, I expect that optimism will play a more critical role for the well-being of older workers compared to younger workers. Capitalizing on this personal resource in the face of limited future time perception (e.g., SST), they will feel less stressed and exhausted at work under conditions of high optimism. Looking from the reverse, under conditions of low optimism, I expect that they will experience greater stress and emotional exhaustion than younger workers. Accordingly, I propose the following hypotheses.

Hypothesis $2 a, 2 b, 2 c, 2 d$. Employee age will moderate the relationship between optimism and a) job satisfaction, b) work engagement, c) perceived stress, d) emotional exhaustion, such that the relationship will be stronger for older employees compared to younger employees.

Perceived work ability. Perceived work ability is defined as employees' assessment of their own physical and mental capacities to continue performing their job (Ilmarinen, 2007, 2009; Tuomi, Ilmarinen, Joahkola, Katajarinne, \& Tulkki, 1998). As proposed by Bakker and Demerouti (2007), mental and physical capacities, namely the foundations of one's work ability, constitute personal resources for employees to accomplish their jobs. As work ability is a recent construct within the IO/OB literature, however, research on work ability in this literature is limited; and existing studies have examined work ability mostly as an outcome rather than as a predictor of work attitudes and well-being. This is despite the fact that work ability is also considered an antecedent of critical outcomes such as retirement. When investigated as an antecedent, studies have 
shown that work ability is related to retirement intentions, retirement, disability leave, sick leave, and absence from work (Ahlstrom et al., 2010; von Bonsdorff et al., 2011; McGonagle et al., 2015). However, as noted in research (McGonagle et al., 2015), in addition to these withdrawal behaviors, research on work ability should extend to other work outcomes including individual health and well-being, job attitudes, and job performance. Limited research on this area demonstrated that work ability is positively associated with favorable outcomes including job satisfaction, life satisfaction, high quality work, productivity (Seitsamo \& Ilmarinen, 1997; Tuomi, Huuhtanen, Nykyri, \& Ilmarinen, 2001), and general well-being (Sjögren-Rönkä, Ojanen, Esko, Mustalampi, \& Mälkiä, 2002). In addition, in terms of its relationship to age, although research have reported that work ability declines with increasing age (e.g., Fisher et al., 2006; Ilmarinen et al., 1991; Tuomi et al., 1998), recent studies conducted with over a thousand health care workers from six different countries (McGonagle et al., 2014) have reported that age is not related to work ability in any of these national samples pointing out a need for further examination of this relationship. However, whether age moderates the effects of work ability on other outcomes has received little study. In summary, building on these gaps in the literature, I aim to uncover the moderating role of age in the relationship between perceived work ability and employee outcomes from a resource-based approach. Drawing on the principles of COR and lifespan development theories, I expect that, although perceived work ability will be important for all employees, it will stand up as a more critical resource for older workers than their younger counterparts. From the lens of SOC theory and aging literature, people tend to experience natural declines in 
physical and cognitive capabilities as they get older, and therefore possessing strategic resources to combat the potential age-based losses in performance should be more valuable in the eyes of older individuals. Moreover, instead of spending their energy and time to exclusively worry about these age-related declines, assessing own capacities as adequate to perform well will enable older employees to optimize workrelated goals and mobilize other resources such as accumulated job knowledge and experience gained throughout the years. On the other hand, work ability may not be particularly relevant to younger employees' work outcomes as much it does to older workers due to their expansive future time perceptions in life, greater mobility to change jobs, and fewer age-related impairments at young age (e.g., Weigl et al., 2013). In sum, there is reason to believe that positive assessments of one's work ability will be manifested as higher satisfaction and engagement with the job, and lower stress and emotional exhaustion among older workers than younger workers. When lacking this important personal resource, I expect that older employees will experience lower work engagement and job satisfaction, and higher levels of stress and exhaustion compared to younger colleagues. Accordingly, the following hypotheses are developed.

Hypothesis $3 a, 3 b, 3 c, 3 d$. Employee age will moderate the relationship between perceived work ability and a) job satisfaction, b) work engagement, c) perceived stress, d) emotional exhaustion, such that the relationship will be stronger for older employees compared to younger employees.

\section{Method}

\section{Sample and Procedures}


As part of a larger project, data for this study were collected from employed registered nurses in collaboration with the Psychology Department, Portland State University and the Oregon Nurses Association (ONA), U.S.A. as part of a faculty enhancement grant. The study includes three on-line surveys (registration survey, second survey to collect data on predictor variables, third survey to assess work-related outcomes). To reach out to potential participants, a recruitment letter was posted on the weekly e-mail blast that is sent out to ONA members who have opted into receiving communications from ONA. The recruitment letter involved a brief description of the study and an on-line link to a short registration survey about demographics. It also announced that the participants would receive a \$20 Amazon electronic gift card in return of their participation.

The goal of the first survey was to prescreen the participants to ensure that they were employed nurses at the time of participation. Specifically, this registration survey asked respondents about their age, work status, and work role. Interested participants were asked to provide their e-mail addresses to receive the second and third surveys and their electronic gift cards.

Those who registered to the first survey were sent e-mails over Qualtrics and invited to participate in the study. This e-mail included the link to the second survey. Specifically, the second survey collected data about the demographics (e.g., age) and the perceptions of job resources (e.g., decision-making autonomy, optimism, and perceived work ability). In addition, a system-generated anonymous and unique participation code was created for each respondent in Qualtrics, and this code was sent to the participants in 
the e-mail up on the submission of their second survey. They were asked to enter this code to take the third survey in the study.

Finally, one week later, participants received the third survey in their e-mail. This last survey included self-reports of outcome variables (e.g., job satisfaction, work engagement, perceived stress, emotional exhaustion). The purpose of using a one-week lag between the second and third surveys was to help reduce the common method variance while ensuring the antecedents and outcomes are still related to each other. After all data were collected, I matched responses across the second and third surveys utilizing the unique participation code of each respondent.

To ensure data quality, I included two attention-checking questions in the first survey, and three attention-checking questions in the third survey. Participants who had more than 1 wrong answer out of five questions were eliminated from the final sample. At the end, 131 participants responded to the second survey and 116 respondents took the follow-up survey. After dropping those who did not submit the follow-up survey (n= 15), who got more than one wrong response out of five attention checking questions $(\mathrm{n}=$ 2 out of 13$)$, who were retired $(n=2)$, and who were unemployed $(n=1)$, the final matched-sample included 111 participants.

The majority of the sample is White (86.5\%), female $(92.8 \%)$, married $(63.1 \%)$, are at least 4-year college graduates (79.3\%), and are full-time nurses $(72.1 \%)$. The age distribution ranges from 23 to 66 years, and the average age is 47.41 years $(S D=12.00)$. The average job tenure of the sample is 9.01 years $(S D=9.41)$, and the average number of hours worked per week is 34.32 hours $(S D=7.78)$. 


\section{Measures}

Employee self-reports were used to assess all measures in the study.

Age. Chronological age was assessed with a single item by asking respondents their age. As recommended by recent research on work and age (e.g., Hertel \& Zacher, 2015; Truxillo et al., 2014, 2015), this study treats age as a continuous variable instead of utilizing an arbitrary dichotomization (e.g., over-40/under-40 years) to refer to younger and older workers. Accordingly, younger and older workers are operationalized as those $1 \mathrm{SD}$ below and $1 \mathrm{SD}$ above the mean age of the study sample, respectively.

Resources. Decision-making autonomy was assessed by three items from the Work Design Questionnaire (WDQ; Morgeson \& Humphrey, 2006). Responses ranged from 1 (Strongly disagree) to 5 (Strongly agree). A sample item included, "This job gives me a chance to use my personal initiative or judgment in carrying out the work" $(\alpha=.90)$. Optimism was measured with two items from the shorter version of the Psychological Capital Questionnaire (Luthans, Avolio, Avey, \& Norman, 2007). Responses ranged from 1 (Strongly disagree) to 5 (Strongly agree). Items were, "I always look on the bright side of things regarding my job" and "I am optimistic about what will happen o me in the future as it pertains to work" $(\alpha=.78)$. Perceived work ability was assessed by three items (Weigl et al., 2013). Responses were given on a 5-point scale $(1=$ Very poor to $5=$ Very good). Participants were asked to rate their current work ability responding to the following three items: "How do you rate your current work ability with the respect to the physical demands of your work", "How do you rate your current work ability with 
respect to the mental demands of your work", and "Compared to your lifetime best, how would you rate your current work ability?” $(\alpha=.84)$.

Employee attitudes and well-being outcomes. Outcome variables were assessed after one week following the submission of the second survey that included items on demographics and job resources. Job satisfaction was measured with five items (Short form of the Brayfield and Rothe Job Satisfaction Scale, 1951; Judge, Bono, Amir, \& Locke, 2005). Responses ranged from 1 (Strongly disagree) to 5 (Strongly agree). A sample item was, "I feel fairly satisfied with my present job" $(\alpha=.90)$. Work engagement was assessed with the nine-item version of the Utrecht Work Engagement Scale (UWES; Schaufeli, Bakker, \& Salanova, 2006). Responses were given on a 7-point scale $(1=$ Never to $7=$ Every day $)$. A sample item included, "At my job, I feel strong and vigorous" $(\alpha=.92)$. Perceived stress was assessed with four items (Cohen, Karmarck, \& Mermelstein, 1983). Response options ranged from 1 (Never) to 5 (Very often). A sample item was, "During the last 30 days, how often have you felt that you were unable to control the important things in your life?" $(\alpha=.85)$. This scale assesses one's overall level of stress in life. Emotional exhaustion was measured with eight items utilizing the Oldenburg Burnout Inventory (Demerouti et al., 2011). Responses were given on a 4-point scale $(1=$ Totally disagree to $4=$ Totally agree $)$. A sample item included, "After my work, I usually felt worn out and weary" $(\alpha=.86)$.

Analytical strategy. Moderation hypotheses were analyzed using OLS regression utilizing the PROCESS macro for SPSS (Hayes, 2013). In the regression equations, I regressed employee outcomes onto age, focal predictor (e.g., decision- 
making autonomy), and the interaction between age and the focal predictor. As recommended by Hayes (2013), age and focal predictors were mean centered, and the interaction term was created using the centered variables. I reported the findings for the simple slope analyses for the low (1 SD below the mean) and high (1 SD above the mean) values of age whenever the results yielded a significant interaction effect.

\section{Results}

Means, standard deviations, and correlations among the study variables are presented in Table 5.1. Age was positively related to job satisfaction $(r=.22, p<.05)$ and work engagement $(r=.19, p<.05)$, and negatively related to emotional exhaustion $(r$ $=-.34, p<.01)$. Among the job resources, only perceived work ability was positively related to age $(r=.20, p<.05)$. All of the three job resources were related to employee outcomes including job satisfaction, work engagement, perceived stress, and emotional exhaustion. The only exception was that decision-making autonomy was not related to perceived stress. In addition, job tenure was positively associated with job satisfaction ( $r$ $=.19, p<.05)$, work engagement $(r=.20, p<.05)$, and emotional exhaustion $(r=-.31, p$ $<.01)$, and employee age $(r=.53, p<.01)$ in the study sample. Therefore, job tenure was used as a control in all the analyses.

\section{Hypothesis Tests}

As noted earlier, I used moderated regression analysis to test all hypotheses with tenure as a control variable. Note that due to the relatively small final sample of matched data $(N=111)$ and the chance of low statistical power, I reported simple slope analyses even when the interaction terms were not statistically significant at $p<.05$. 
Hypotheses 1a-d (decision-making autonomy as the predictor). Hypothesis

1 predicted that employee age would moderate the relationship between decision-making autonomy and a) job satisfaction, b) work engagement, c) perceived stress, d) emotional exhaustion, such that the relationship will be stronger for older employees compared to younger employees.

With regard to Hypothesis 1a, the interaction between age and decision-making autonomy was significant $\left(B=.02, F(1,106)=5.50, \Delta \mathrm{R}^{2}=.04, p<.05\right)$ when job satisfaction was the outcome (Table 5.2). Simple slope analysis revealed that decisionmaking autonomy was not related to job satisfaction for younger employees $(B=.20, S E$ $=.12 ; t=1.58, p>.05)$ whereas it was positively related to job satisfaction for older employees $(B=.70, S E=.17 ; t=4.18, p<.01)$. As depicted in Figure 5.2, when decision-making autonomy was perceived as low, older employees showed lower job satisfaction, and as decision-making autonomy increased, so did their satisfaction with the job. Thus, Hypothesis la was supported ${ }^{6}$.

With regard to hypothesis $1 \mathrm{~b}$, the interaction between age and decision-making autonomy was significant $\left(B=.02, F(1,106)=3.83, \Delta \mathrm{R}^{2}=.03, p=.05\right)$ when work engagement was the outcome. (Table 5.3). Simple slope analysis showed that decisionmaking autonomy was positively and more strongly related to work engagement for older employees $(B=.86, S E=.21 ; t=4.11, p<.01)$ than for younger employees $(B=.34, S E$ $=.16 ; t=2.15, p<.05)$. As depicted in Figure 5.3, when decision-making autonomy was perceived as low, older employees showed lower work engagement, and as decision-

\footnotetext{
${ }^{6}$ Based on the recommendation of Spector and Brannick (2011), all study hypotheses were tested with and without controlling for job tenure. The results from the models without job tenure were substantively similar.
} 
making autonomy increased, their work engagement increased. Thus, Hypothesis $1 \mathrm{~b}$ was supported.

With regard to Hypothesis 1c, the interaction between age and decision-making autonomy was not significant $\left(B=-.01, F(1,106)=2.60, \Delta \mathrm{R}^{2}=.02, p>.05\right)$ when perceived stress was the outcome (Table 5.4). Thus, no support was found for Hypothesis 1c. However, the results of the simple slope analysis were in the same direction as the hypothesized relationship: Decision-making autonomy was more strongly related to perceived stress for older employees $(B=-.39, S E=.16 ; t=-2.36, p<.05)$ than younger employees $(B=-.05, S E=.12 ; t=-.42, p>.05)$.

As for Hypothesis 1d, when emotional exhaustion was the outcome, the interaction between age and decision-making autonomy was significant $(B=-.02, F(1$, $\left.106)=7.71, \Delta \mathrm{R}^{2}=.06, p<.01\right)($ Table 5.5). Decision-making autonomy was not related to work engagement for younger employees $(B=-.01, S E=.08 ; t=-.07, p>.05)$, whereas it was negatively related to emotional exhaustion for older employees $(B=-.38$, $S E=.11 ; t=-3.58, p<.01)$. As depicted in Figure 5.4, when decision-making autonomy was perceived as low, older employees showed greater emotional exhaustion, and as decision-making autonomy increased, their level of exhaustion reduced. Thus, Hypothesis 1d was supported.

Hypotheses 2a-d (optimism as the predictor). Hypothesis 2 predicted that employee age would moderate the relationship between optimism and a) job satisfaction, b) work engagement, c) perceived stress, d) emotional exhaustion, such that the relationship will be stronger for older employees compared to younger employees. 
Regarding Hypothesis $2 \mathrm{a}$, the interaction between age and optimism was significant $\left(B=.02, F(1,106)=12.22, \Delta \mathrm{R}^{2}=.06, p<.01\right)$ when job satisfaction was the outcome (Table 5.6). Simple slope analysis revealed that although optimism was related to job satisfaction for all employees, it was more strongly related to job satisfaction of older workers $(B=.91, S E=.11 ; t=8.12, p<.01)$ than younger colleagues $(B=.35, S E$ $=.10 ; t=3.50, p<.01)$. As depicted in Figure 5.5, under conditions of lower optimism, older participants reported lower job satisfaction whereas older employees who are more optimistic reported higher job satisfaction. Thus, Hypothesis 2a was supported.

Regarding Hypothesis $2 \mathrm{~b}$, the interaction between age and optimism was significant $\left(B=.02, F(1,106)=4.13, \Delta \mathrm{R}^{2}=.03, p<.05\right)$ when work engagement was the outcome (Table 5.7). As predicted, Figure 5.6 depicts that optimism was more strongly related to work engagement for older employees $(B=.90, S E=.16 ; t=5.59, p<$ $.01)$ than younger employees $(B=.44, S E=.15 ; t=3.01, p<.01)$. Thus, support was found for Hypothesis $2 b$.

Regarding Hypothesis 2c, when perceived stress was the outcome, the interaction between age and optimism was significant $\left(B=-.02, F(1,106)=6.79, \Delta \mathrm{R}^{2}=.05, p<\right.$ $.05)$ (Table 5.8). Optimism was not related to perceived stress for younger employees $(B$ $=-.13, S E=.11 ; t=-1.11, p>.05)$ whereas it was negatively related to perceived stress for older employees $(B=-.59, S E=.13 ; t=-4.70, p<.01)$. Figure 5.7 shows that older employees experienced greater stress under low optimism condition whereas they reported lower level of stress under high optimism condition. Thus, Hypothesis $2 \mathrm{c}$ was supported. 
As for Hypothesis $2 \mathrm{~d}$, the interaction between age and optimism was significant $\left(B=-.01, F(1,106)=4.91, \Delta \mathrm{R}^{2}=.03, p<.05\right)$ when emotional exhaustion was the outcome (Table 5.9). Thus, support was found for Hypothesis $2 \mathrm{~d}$. As can be seen in Figure 5.8, simple slope analysis confirmed that optimism was negatively and more strongly related to emotional exhaustion for older employees $(B=-.44, S E=.08 ; t=$ $5.63, p<.01)$ than younger employees $(B=-.20, S E=.07 ; t=-2.75, p<.05)$.

Hypotheses 3a-d (perceived work ability as the predictor). Hypothesis 3 predicted that employee age would moderate the relationship between perceived work ability and a) job satisfaction, b) work engagement, c) perceived stress, d) emotional exhaustion, such that the relationship will be stronger for older employees compared to younger employees.

Regarding Hypothesis 3a, when job satisfaction was the outcome, the interaction between age and perceived work ability was not significant $(B=.01, F(1,106)=1.68$, $\left.\Delta \mathrm{R}^{2}=.01, p>.05\right)($ Table 5.10). Thus, Hypothesis 3a was not supported. Although the interaction term was not significant, simple slope analysis showed that the positive relationship between perceived work ability and job satisfaction was stronger for older employees $(B=.88, S E=.15 ; t=5.67, p<.01)$ than for younger colleagues $(B=.61, S E$ $=.12 ; t=4.97, p<.01)$.

Regarding Hypothesis 3b, when work engagement was the outcome, the interaction between age and perceived work ability was not significant $(B=.02, F(1$, $\left.106)=3.13, \Delta \mathrm{R}^{2}=.02, p=.08\right)($ Table 5.11). Thus, Hypothesis $3 \mathrm{~b}$ was not supported. Similar to the previous hypothesis, although the interaction term was not significant, 
simple slope analysis demonstrated that the positive relationship between perceived work ability and work engagement was stronger for older employees $(B=.93, S E=.22 ; t$ $=4.14, p<.01)$ than for younger employees $(B=.40, S E=.18 ; t=2.26, p<.05)$.

Regarding Hypothesis 3c, when perceived stress was the outcome, the interaction between age and perceived work ability was not significant $(B=-.00, F(1,106)=.27$, $\left.\Delta \mathrm{R}^{2}=.00, p>.05\right)($ Table 5.12). Thus, no support was found for Hypothesis 3c. Yet, simple slope analysis yielded results similar to the previous two hypotheses: The negative relationship between perceived work ability and perceived stress was stronger for older nurses $(B=-.62, S E=.16 ; t=-3.98, p<.01)$ than younger nurses $(B=-.51, S E=.12 ; t=$ $-4.14, p<.01)$ which was in the expected direction.

Regarding Hypothesis 3d, the interaction between age and perceived work ability was significant $\left(B=-.01, F(1,106)=7.27, \Delta \mathrm{R}^{2}=.04, p<.05\right)$ when emotional exhaustion was the outcome (Table 5.13). Simple slope analysis revealed that the negative relationship between perceived work ability and emotional exhaustion was stronger for older nurses $(B=-.64, S E=.09 ; t=-6.83, p<.01)$ than younger nurses $(B=$ $-.31, S E=.07 ; t=-4.11, p<.01)$. As can be seen in Figure 5.9, when work ability is perceived as low, older nurses showed greater exhaustion, and as their perception of own work ability increased, they reported less exhaustion. Thus, Hypothesis $3 \mathrm{~d}$ was supported.

\section{Summary}

In summary, 8 out of the 12 proposed relationships were supported by the data. Specifically, the results of the first hypothesis showed that age moderated the relationship 
between decision-making autonomy and job satisfaction (H1a), work engagement (H1b), and emotional exhaustion (H1d), whereas the interaction between age and decision-making autonomy on perceived stress was not significant (H1c). As for the second hypothesis, age moderated the relationship between optimism and all four outcomes including job satisfaction $(\mathrm{H} 2 \mathrm{a})$, work engagement $(\mathrm{H} 2 \mathrm{~b})$, perceived stress $(\mathrm{H} 2 \mathrm{c})$, and emotional exhaustion $(\mathrm{H} 2 \mathrm{~d})$. Finally, regarding the third hypothesis, age moderated only one of the four proposed relationships: The interaction between age and perceived work ability was significant only when emotional exhaustion was the outcome (H3d), and it was not significant for job satisfaction (H3a), work engagement (H3b), and perceived stress (H3c).

Due to the small sample size, I reported the findings of the simple slope analyses to explore the trend even when the interaction terms were not significant at $p<.05(\mathrm{H} 1 \mathrm{c}$, $\mathrm{H} 3 \mathrm{a}, \mathrm{H} 3 \mathrm{~b}, \mathrm{H} 3 \mathrm{c})$. Interestingly, the results showed that all the four proposed relationships were in the expected direction, that is the relationship between these resources and the employee outcomes were stronger for older employees.

\section{Additional Analyses}

A set of supplemental analyses was conducted to rule out alternative explanations. Specifically, because employees who hold supervisory status may have greater job satisfaction, work engagement, emotional exhaustion or stress, supervisory status of the participants was controlled beyond job tenure that was used as control in the primary analyses. Out of 111 participants, there were 38 nurses who reported that they supervise people in the workplace (34\% of the sample). The results were substantively similar to 
those reported in the primary analyses, that is the lack of resources were equally harmful for all nurses whereas older nurses reported more beneficial outcomes under high resource conditions. The only two exceptions were Hypothesis $1 \mathrm{~b}$ and Hypothesis $3 \mathrm{~b}$. As for Hypothesis $1 \mathrm{~b}$, the interaction between age and decision-making autonomy on work engagement was no longer significant when controlling for supervisory status $(B=.02, F$ $\left.(1,105)=1.19, \Delta \mathrm{R}^{2}=.03, p=.06\right)$. On the other hand, Hypothesis $3 \mathrm{~b}$, which tested the interaction between age and perceived work ability on work engagement, was now significant $\left(B=.02, F(1,105)=1.95, \Delta \mathrm{R}^{2}=.03, p=.05\right)$ when controlling for supervisory status.

Second, the interactions were tested together in a single model for each of the four outcomes. Specifically, I tested the interactions between age and a) autonomy, b) optimism, and c) perceived work ability together for four of the outcomes (job satisfaction, work engagement, emotional exhaustion, and perceived stress). In Step 1, I entered the control variable (job tenure). In Step 2, I entered age and the resources (autonomy, optimism, perceived work ability). Finally, in Step 3, I entered the mean-centered interactions (age x autonomy, age $\mathrm{x}$ optimism, age $\mathrm{x}$ perceived work ability). Below are the findings of these analyses.

a) Job satisfaction: In Step 3, only age x optimism remained significant $(B=.02$, $p<.01) . \Delta R^{2}$ due to interactions as a block $=.03(p<.05) ; R^{2}$ for the final model $=.62$. 
b) Work engagement: In Step 3, none of the interactions remained significant. $\Delta R^{2}$ due to interactions as a block $=.02(p>.05) ; R^{2}$ for the final model $=.42$.

c) Emotional exhaustion: In Step 3, none of the interactions remained significant. $\Delta R^{2}$ due to interactions as a block $=.04(p=.05) ; R^{2}$ for the final model $=.56$.

d) Perceived stress: In Step 3, only age x optimism remained significant $(B=$ $.01, p=.05) . \Delta R^{2}$ due to interactions as a block $=.03(p>.05) ; R^{2}$ for the final model $=.32$

\section{Discussion}

This study responds to the recent research calls to investigate the moderating role of age in the relationship between job-related resources and employee outcomes (Halbesleben et al., 2014). Specifically, I investigated the age-related differences in the usefulness of decision-making autonomy, optimism, and perceived work ability with regard to their influences on employee attitudes and well-being. Drawing on the mainstream resource theories (COR theory) and lifespan development models (SOC and SST), this study found support that the importance of these resources was different for younger and older workers' outcomes. Overall, the results suggest that, when these resources were low, all employees had lower job satisfaction and work engagement, and greater emotional exhaustion and perceived stress independent of their ages. However, under high resource conditions, older employees reported greater job satisfaction and work engagement, and lower emotional exhaustion and overall perceived stress in life 
compared to younger colleagues. Thus, the presence of these three resources helped older workers flourish at work and in life at the same time: When resourceful, they enjoyed their job more and felt strong and vigorous at work, and they perceived an overall sense of control over life as well as had an ease of mind at and outside of their work environments.

\section{Implications for Research}

The results of the current study contribute to the prior research in several ways. To my knowledge, no studies have examined the age-based differential relationships between work-related resources and employee attitudes and well-being by integrating COR theory and lifespan development models (except Yaldiz et al., 2018). Specifically, Yaldiz and colleagues (2018) examined the relationship of baseline resources from the job (e.g., skill discretion) and support resources (i.e., leader-member exchange, procedural fairness) with overall stress after one year in a sample of construction workers integrating COR theory and two lifespan development theories (i.e., SOC and SST). They found that having autonomy to utilize skills on the job and supportive treatment from the supervisors and organization were more beneficial for older workers. When these resources were high at the workplace, older workers experienced lower levels of stress than their younger counterparts. The present study adds to Yaldiz et al.'s (2018) findings and responds to the research calls about the COR theory (Halbesleben et al., 2014) by examining the age-based relative usefulness of additional resources and employee outcomes. Capitalizing on the age-related differences in physical capabilities, needs, motivation, and goals among people of different ages, the findings of this study indicate 
that resources were not equally important for all workers. Generally speaking, it seems that exercising decision-making autonomy on the job, assessing one's work ability as good, and being optimistic about the future were more critical resources for employees at older ages than for those at younger ages for a happier work and non-work life.

Second, this study makes a major contribution to the literature on optimism and perceived work ability. To my knowledge, this study is the first to investigate the moderating role of age in the relationships between these personal factors and job satisfaction, work engagement, emotional exhaustion, and perceived stress. Thus, these findings present chronological age as a new boundary condition for these relationships. The findings indicated that, among the three resources, optimism was differentially related to all of the four employee outcomes of younger and older nurses. In line with COR and lifespan development theories, the importance of optimism was more pronounced for older employees: Instead of focusing on the negative aspects of aging, when being optimistic about the future, they had more positive attitudes towards their jobs, dealt with the demands of their jobs better, and maintained higher well-being than their younger counterparts. Thus, this personality trait acted as a buffer at an older age (Hobfoll, 2002; Mäkikangas \& Kinnunen, 2003; Segerstrom 2007). On the other hand, the results of this study showed that perceived work ability was almost equally important for nurses of all ages. As nurses' perceptions of work ability increased, they reported higher job satisfaction and work engagement and lower stress. The only age-based differential relationship was found for emotional exhaustion: Under the high work ability condition, older nurses felt less exhausted than younger nurses. With that said, it is 
noteworthy to add that when the simple slopes of the non-significant relationships were analyzed, the trend was in the expected direction: In the high work ability condition, the outcomes were more beneficial for older participants. I believe that this is a potentially important finding considering the small sample size of this study and warrants future research on this topic.

Other than the interactive effect of work ability with age, one finding that merits attention is the positive association between work ability and age in this worker sample. Prior research on perceived work ability yielded mixed results in terms of its main effects relationship with age. Some studies have shown that age and work ability were negatively correlated (e.g., Fisher et al., 2006; Ilmarinen et al., 1991; Tuomi et al., 1998), while a few have found that it was not correlated at all (McGonagle et al., 2014). In this study, however, I found that work ability had a positive, albeit small relationship with age, an atypical finding. Given that nurses work under high job strain, one explanation for this finding might be that as healthcare employees get older, they may figure out better strategies to handle the demands of their jobs. That is, as suggested by the SOC model, unlike their younger colleagues, older nurses may have developed efficient ways of performing their jobs over time and rely on these methods to save time and energy. For example, while a younger colleague may spend too much time or effort to accomplish a task, an older nurse may be able to follow her proven methods to address a problem (e.g., seeking help for tasks that requires physical strength). Likewise, from the lens of the SOC model, it can be argued that older nurses may enjoy acting as a mentor at work and transfer their work knowledge to younger colleagues, which in turn helps them perceive a 
higher perceived work ability. Before drawing a conclusion, however, future studies are needed to investigate whether this positive association between age and work ability holds true for employees across different occupations and industries. An alternative explanation about the positive relationship between age and work ability in this sample may be due to the selective attrition. That is, nurses who had poor work ability might have already left the profession, for example, by choosing another job or retiring, and the remaining nurses are those who had higher perceptions about mental and physical ability.

Finally, the findings of this study add to the mixed literature on the relationship between autonomy and age (e.g., Ng \& Feldman, 2015; Zacher \& Schmidt, 2016; Zaniboni et al., 2016). Specifically, in their meta-analysis, $\mathrm{Ng}$ and Feldman (2015) reported that job autonomy was more strongly related to emotional exhaustion for older worker groups than younger worker groups -which is in line with the finding of this study. However, their meta-analysis revealed that job autonomy was related to job satisfaction, work engagement, and job stress generally weaker for older worker groups than younger workers. On the other hand, in a sample of construction workers, Zaniboni and colleagues (2016) showed that job autonomy related to job satisfaction more strongly for older workers than for younger workers. Overall, the present study found that decision-making autonomy was a more critical resource for older employees in our sample. The findings of this study showed that, compared to younger counterparts, older nurses reported higher job satisfaction and work engagement, and lower exhaustion when they had high autonomy on their job. In line with SOC and SST, this means that, having the freedom to make work-related decisions helped older nurses both at work and 
beyond. When given a chance to make their own decisions at work, they hold a more positive attitude towards their jobs, feel proud of and happy about their work, and were more relaxed to carry out their daily activities at work and in life in general. Although the decision-making autonomy $\mathrm{X}$ age interaction did not influence employee stress significantly, it is important to add that the statistical significance remained at $p=.11$, and the trend of the simple slopes was in the expected direction where older employees had lower stress under high decision-making autonomy condition. In other words, this null result may have been due to limited statistical power. This finding is promising and necessitates future research to replicate these relationships with larger sample sizes.

\section{Practical Implications}

The present study contributes to our knowledge about the interactive effects of age and work-related resources and their influence on job attitudes and employee wellbeing. Organizations can utilize the findings of this study to develop age-diverse workplace interventions on employee well-being. To help cope with stress and exhaustion, management can take steps to create a work environment where older employees may fit better. Such steps may include, for example, recognizing the need to be more autonomous on the job and facilitating climates where older employees can use discretion about how they carry out their work routines. Managers may allow job redesigns as much as possible so that older workers may craft their own tasks by using more decision-making autonomy.

The findings of this study showed that optimistic older nurses had more positive work and life outcomes. Healthcare organizations may use this finding by adding 
optimism as an additional criterion during employee selection processes. Given that jobs in healthcare industry are usually demanding, organizations may help candidates to assess their own optimism by providing realistic job previews during interview processes.

\section{Limitations and Future Research}

Although the current study contributes to the literature in a number of ways, it has potential limitations that future research should address. First, this study is conducted with a relatively small nurse sample in the Pacific Northwestern US. Different and larger employee samples across industries and geographical locations should be investigated to generalize the findings of this study. Second, I aimed to shed light on the influence of the interactive effects of age and employee resources on outcomes from work and life domains, however the data were self-report for all measures. Instead of relying only on self-reported outcomes, researchers may collect, for example, supervisory ratings to investigate job performance or spousal reports to assess satisfaction with the non-work domains. Third, this study utilizes only a one-week time lag to assess the predicting and outcome variables of interest with an intent to reduce the common methods bias. This time lag may not be ideal to observe the long-lasting influence of the resources on the attitudes and well-being, especially when a behavior change is desired to be measured. Finally, the current study utilizes chronological age as a focal variable to explain the differences in the usefulness of resources and their relationship with employee attitudes and well-being. However, it is necessary to acknowledge that, chronological age is a more complex phenomenon, which may be contaminated with other constructs such as job experience, life experience, and changes in one's personality or status in an 
organization. Therefore, even people of the same ages may present different characteristics; hence, caution needs to be taken about not to overgeneralize the findings of this study. It is important to note that, to account for such factors, all hypotheses were tested with and without controlling for job tenure and organizational level in this study. Accordingly, the results were substantively similar.

\section{Conclusion}

The current study responds to the calls in the literature by investigating the moderating role of age in the relationship between work-related resources and employee attitudes and well-being. By integrating COR theory and two lifespan development models (SOC and SST), this study found that resources from the job (decision-making autonomy) and personal resources (optimism, perceived work ability) were differentially related to job satisfaction, work engagement, perceived stress, emotional exhaustion. In other words, the usefulness of these resources was different for employees of different ages, even after controlling for job tenure and organizational status. Overall, the lack of decision-making autonomy and optimism was equally harmful for employees of all ages. However, when these resources were high, older workers reported higher satisfaction and greater engagement with their jobs, as well as lower levels of exhaustion and overall stress in life. These findings have several theoretical and practical implications and provide suggestions for future research. 


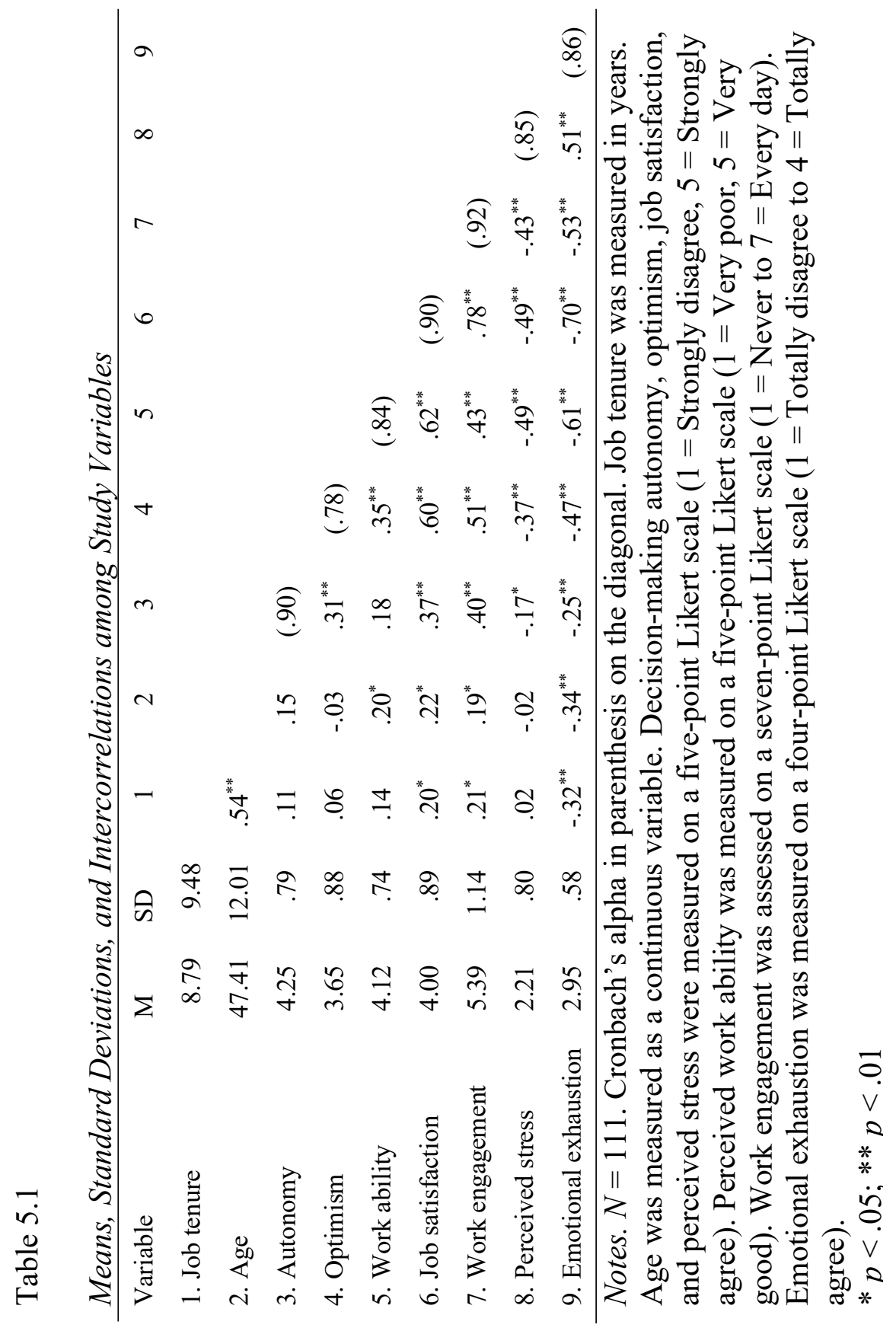


Table 5.2

Results of Moderated Regression Analyses: Job Satisfaction

\begin{tabular}{lrrrrrr}
\hline & \multicolumn{7}{c}{ Job Satisfaction (T2) } \\
\cline { 2 - 7 } Predictor variable (T1) & $B$ & $S E$ & $t$ & $p$ & $\Delta R^{2}$ & $R^{2}$ \\
\hline Job tenure & .01 & .01 & .95 & .34 & & \\
Decision-making autonomy & .44 & .10 & 4.36 & .00 & & \\
Age & .01 & .01 & 1.07 & .29 & & \\
Autonomy x Age & .02 & .01 & 2.35 & .02 & $.04 *$ & \\
& & & & & & $.21^{* *}$
\end{tabular}

Note. $N=111$. Focal predictor and age were mean centered.

Interaction term was computed from the mean-centered variables.

$B=$ unstandardized coefficient. ${ }^{*} p<.05$. ${ }^{* *} p<.01$. 
Table 5.3

Results of Moderated Regression Analyses: Work Engagement

\begin{tabular}{lrrrrrr}
\hline & \multicolumn{6}{c}{ Work Engagement (T2) } \\
\cline { 2 - 7 } Predictor variable (T1) & $B$ & $S E$ & $t$ & $p$ & $\Delta R^{2}$ & $R^{2}$ \\
\hline Job tenure & .02 & .01 & 1.25 & .22 & & \\
Decision-making autonomy & .60 & .13 & 4.65 & .00 & & \\
Age & .01 & .01 & .63 & .53 & & \\
Autonomy x Age & .02 & .01 & 1.96 & .05 & $.03 *$ & \\
& & & & & & $.22^{* *}$
\end{tabular}

Note. $N=111$. Focal predictor and age were mean centered.

Interaction term was computed from the mean-centered variables.

$B=$ unstandardized coefficient. $* p<.05$. $* * p<.01$. 
Table 5.4

Results of Moderated Regression Analyses: Perceived Stress

\begin{tabular}{|c|c|c|c|c|c|c|}
\hline \multirow[b]{2}{*}{ Predictor variable (T1) } & \multicolumn{6}{|c|}{ Perceived Stress (T2) } \\
\hline & $B$ & $S E$ & $t$ & $p$ & $\Delta R^{2}$ & $R^{2}$ \\
\hline Job tenure & .00 & .01 & .50 & .62 & & \\
\hline Decision-making autonomy & -.22 & .10 & $-\overline{2.17}$ & .03 & & \\
\hline Age & -.00 & .01 & -.17 & .87 & & \\
\hline Autonomy x Age & -.01 & .01 & $\begin{array}{c}- \\
1.61\end{array}$ & .11 & .02 & \\
\hline
\end{tabular}

Note. $N=111$. Focal predictor and age were mean centered.

Interaction term was computed from the mean-centered variables.

$B=$ unstandardized coefficient. ${ }^{*} p<.05$. ${ }^{* *} p<.01$. 
Table 5.5

Results of Moderated Regression Analyses: Emotional Exhaustion

\begin{tabular}{|c|c|c|c|c|c|c|}
\hline \multirow[b]{2}{*}{ Predictor variable (T1) } & \multicolumn{6}{|c|}{ Emotional Exhaustion (T2) } \\
\hline & $B$ & $S E$ & $t$ & $p$ & $\Delta R^{2}$ & $R^{2}$ \\
\hline Job tenure & -.01 & .01 & $\begin{array}{c}- \\
1.79\end{array}$ & .08 & & \\
\hline Decision-making autonomy & -.19 & .07 & $\begin{array}{l}- \\
2.95\end{array}$ & .00 & & \\
\hline Age & -.01 & .00 & $\begin{array}{l}- \\
1.97\end{array}$ & .05 & & \\
\hline Autonomy x Age & -.02 & .01 & $2 . \overline{78}$ & .01 & $.06^{*}$ & \\
\hline & & & & & & $.23 * *$ \\
\hline
\end{tabular}

Note. $N=111$. Focal predictor and age were mean centered.

Interaction term was computed from the mean-centered variables.

$B=$ unstandardized coefficient. ${ }^{*} p<.05$. ${ }^{*} * p<.01$. 
Table 5.6

Results of Moderated Regression Analyses: Job Satisfaction

\begin{tabular}{lrrrrrr}
\hline & \multicolumn{6}{c}{ Job Satisfaction (T2) } \\
\cline { 2 - 7 } Predictor variable (T1) & $B$ & $S E$ & $t$ & $p$ & $\Delta R^{2}$ & $R^{2}$ \\
\hline Job tenure & .00 & .01 & .38 & .70 & & \\
Optimism & .63 & .07 & 8.85 & .00 & & \\
Age & .01 & .01 & 2.26 & .03 & & \\
Optimism x Age & .02 & .01 & 3.50 & .00 & $.06^{* *}$ & \\
& & & & & & $.69^{* *}$ \\
\hline
\end{tabular}

Note. $N=111$. Focal predictor and age were mean centered.

Interaction term was computed from the mean-centered variables.

$B=$ unstandardized coefficient. $* p<.05$. $* * p<.01$. 
Table 5.7

Results of Moderated Regression Analyses: Work Engagement

\begin{tabular}{lrrrrrr}
\hline & \multicolumn{6}{c}{ Work Engagement (T2) } \\
\cline { 2 - 7 } Predictor variable (T1) & $B$ & $S E$ & $t$ & $p$ & $\Delta R^{2}$ & $R^{2}$ \\
\hline Job tenure & .01 & .01 & .86 & .39 & & \\
Optimism & .67 & .10 & 6.52 & .00 & & \\
Age & .01 & .01 & 1.52 & .13 & & \\
Optimism x Age & .02 & .01 & 2.03 & .04 & $.03 *$ & \\
& & & & & & $.33^{* *}$
\end{tabular}

Note. $N=111$. Focal predictor and age were mean centered.

Interaction term was computed from the mean-centered variables.

$B=$ unstandardized coefficient. ${ }^{*} p<.05$. ${ }^{* *} p<.01$. 
Table 5.8

Results of Moderated Regression Analyses: Perceived Stress

\begin{tabular}{|c|c|c|c|c|c|c|}
\hline \multirow[b]{2}{*}{ Predictor variable (T1) } & \multicolumn{6}{|c|}{ Perceived Stress (T2) } \\
\hline & $B$ & $S E$ & $t$ & $p$ & $\Delta R^{2}$ & $R^{2}$ \\
\hline Job tenure & .01 & .01 & 1.02 & .31 & & \\
\hline Optimism & -.36 & .08 & $\overline{4.47}$ & .00 & & \\
\hline Age & -.00 & .01 & $\begin{array}{c}- \\
.58\end{array}$ & .57 & & \\
\hline Optimism x Age & -.02 & .01 & $\begin{array}{l}- \\
2.61\end{array}$ & .01 & $.05^{*}$ & \\
\hline
\end{tabular}

Note. $N=111$. Focal predictor and age were mean centered.

Interaction term was computed from the mean-centered variables.

$B=$ unstandardized coefficient. ${ }^{*} p<.05$. ${ }^{*} * p<.01$. 
Table 5.9

Results of Moderated Regression Analyses: Emotional Exhaustion

\begin{tabular}{|c|c|c|c|c|c|c|}
\hline \multirow[b]{2}{*}{ Predictor variable (T1) } & \multicolumn{6}{|c|}{ Emotional Exhaustion (T2) } \\
\hline & $B$ & $S E$ & $t$ & $p$ & $\Delta R^{2}$ & $R^{2}$ \\
\hline Job tenure & -.01 & .01 & $\begin{array}{l}- \\
1.44\end{array}$ & .15 & & \\
\hline Optimism & -.32 & .05 & $\begin{array}{l}- \\
6.36\end{array}$ & .00 & & \\
\hline Age & -.01 & .00 & $\begin{array}{l}- \\
2.84\end{array}$ & .01 & & \\
\hline Optimism x Age & -.01 & .00 & $\overline{2} .22$ & .03 & $.03 *$ & \\
\hline & & & & & & $.39 * *$ \\
\hline
\end{tabular}

Note. $N=111$. Focal predictor and age were mean centered.

Interaction term was computed from the mean-centered variables.

$B=$ unstandardized coefficient. ${ }^{*} p<.05$. ${ }^{* *} p<.01$. 
Table 5.10

Results of Moderated Regression Analyses: Job Satisfaction

\begin{tabular}{lrrrrrr}
\hline & \multicolumn{7}{c}{ Job Satisfaction (T2) } \\
\cline { 2 - 7 } Predictor variable (T1) & $B$ & $S E$ & $t$ & $p$ & $\Delta R^{2}$ & $R^{2}$ \\
\hline Job tenure & .01 & .01 & .74 & .46 & & \\
Perceived work ability & .74 & .09 & 7.83 & .00 & & \\
Age & .01 & .01 & .82 & .41 & & \\
Perceived work ability x Age & .01 & .01 & 1.30 & .20 & .01 & \\
& & & & & & $.40^{* *}$
\end{tabular}

Note. $N=111$. Focal predictor and age were mean centered.

Interaction term was computed from the mean-centered variables.

$B=$ unstandardized coefficient. $* p<.05 .{ }^{* *} p<.01$. 
Table 5.11

Results of Moderated Regression Analyses: Work Engagement

Work Engagement (T2)

\begin{tabular}{lrccccc}
\cline { 2 - 6 } Predictor variable (T1) & $B$ & $S E$ & $t$ & $p$ & $\Delta R^{2}$ & $R^{2}$ \\
\hline Job tenure & .01 & .01 & .93 & .35 & & \\
Perceived work ability & .67 & .14 & 4.84 & .00 & & \\
Age & .01 & .01 & .71 & .48 & & \\
Perceived work ability x Age & .02 & .01 & 1.77 & .08 & $.02 \uparrow$ & \\
& & & & & & $.23 * *$
\end{tabular}

Note. $N=111$. Focal predictor and age were mean centered.

Interaction term was computed from the mean-centered variables.

$B=$ unstandardized coefficient. $\dagger p<.10 .{ }^{*} p<.05 .{ }^{*} * p<.01$. 
Table 5.12

Results of Moderated Regression Analyses: Perceived Stress

\begin{tabular}{lrrrrrr}
\hline & \multicolumn{6}{c}{ Perceived Stress (T2) } \\
\cline { 2 - 7 } Predictor variable (T1) & $B$ & $S E$ & $t$ & $p$ & $\Delta R^{2}$ & $R^{2}$ \\
\hline Job tenure & .01 & .01 & .79 & .43 & & \\
Perceived work ability & -.57 & .10 & - & 5.92 & .00 & \\
Age & .00 & .01 & .33 & .74 & & \\
Perceived work ability x Age & -.00 & .01 & -.52 & .60 & .00 & \\
& & & & & & $.25^{* *}$
\end{tabular}

Note. $N=111$. Focal predictor and age were mean centered.

Interaction term was computed from the mean-centered variables.

$B=$ unstandardized coefficient. ${ }^{*} p<.05$. ${ }^{* *} p<.01$. 
Table 5.13

Results of Moderated Regression Analyses: Emotional Exhaustion

\begin{tabular}{|c|c|c|c|c|c|c|}
\hline \multirow[b]{2}{*}{ Predictor variable (T1) } & \multicolumn{6}{|c|}{ Emotional Exhaustion (T2) } \\
\hline & $B$ & $S E$ & $t$ & $p$ & $\Delta R^{2}$ & $R^{2}$ \\
\hline Job tenure & -.01 & .01 & $\overline{1.49}$ & .14 & & \\
\hline Perceived work ability & -.47 & .06 & $\overline{8} 8.21$ & .00 & & \\
\hline Age & -.01 & .01 & $\begin{array}{l}- \\
1.99\end{array}$ & .05 & & \\
\hline Perceived work ability x Age & -.01 & .01 & $\begin{array}{l}- \\
2.70\end{array}$ & .01 & $.04 *$ & \\
\hline
\end{tabular}

Note. $N=111$. Focal predictor and age were mean centered.

Interaction term was computed from the mean-centered variables.

$B=$ unstandardized coefficient. ${ }^{*} p<.05$. ${ }^{*} * p<.01$. 


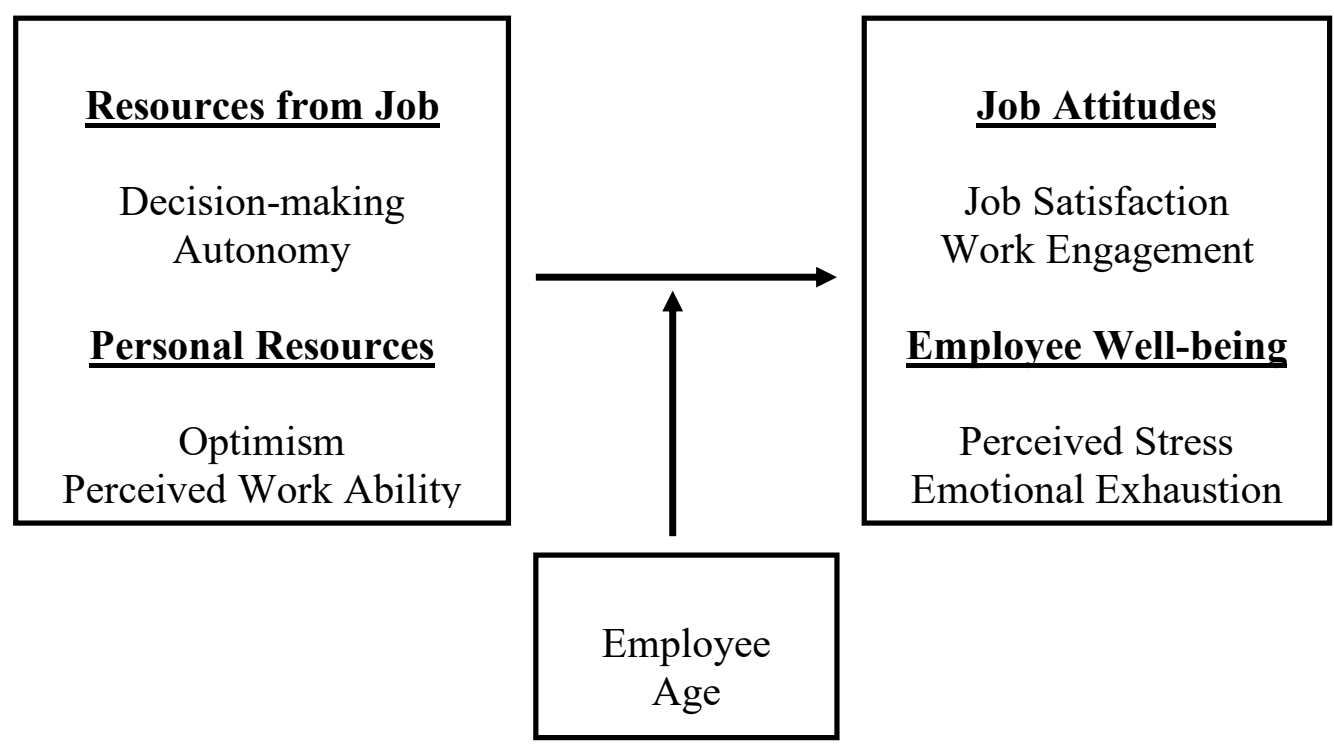

Figure 5.1 Summary model of the proposed relationships examined in Study 3. 


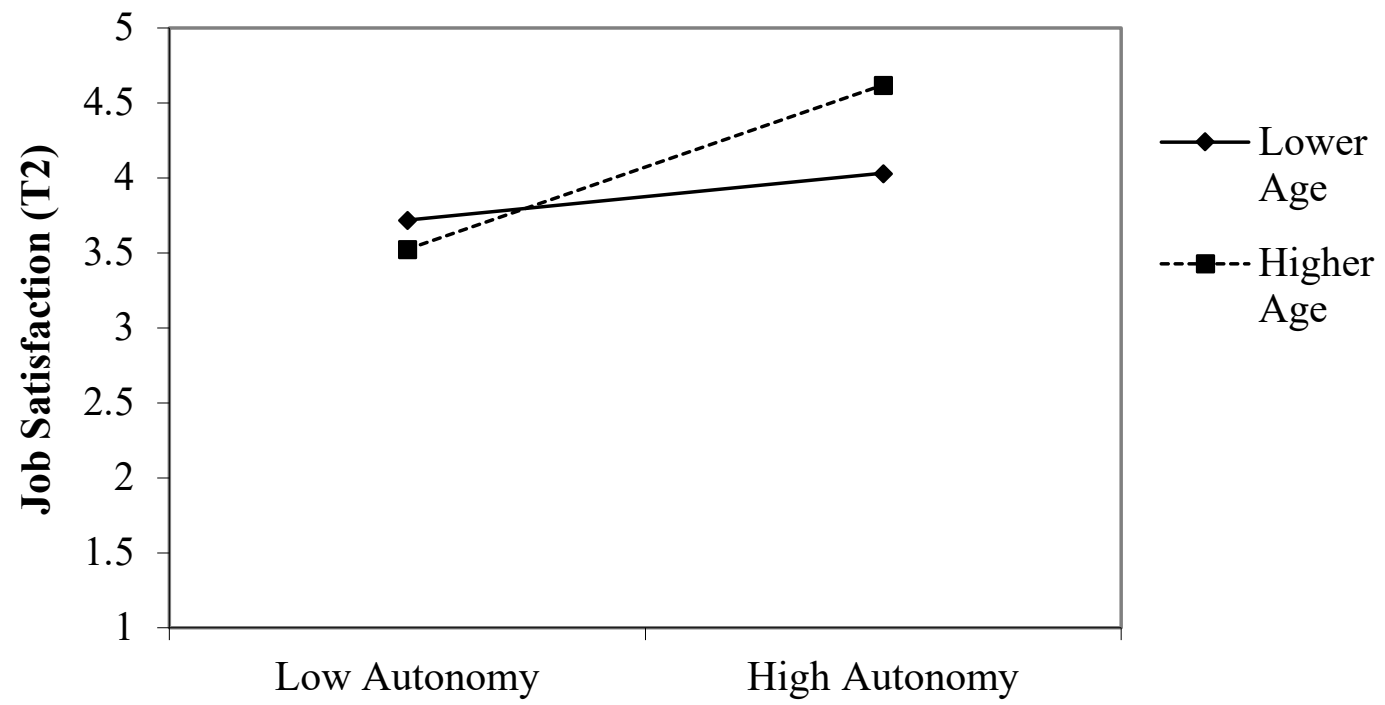

Figure 5.2 The interaction between decision-making autonomy and employee age on job satisfaction. Age $(M=47.41, S D=12.01)$. "Low Age" $=1$ SD below the mean $=35$. "High Age" $=1 \mathrm{SD}$ above the mean $=59$. 


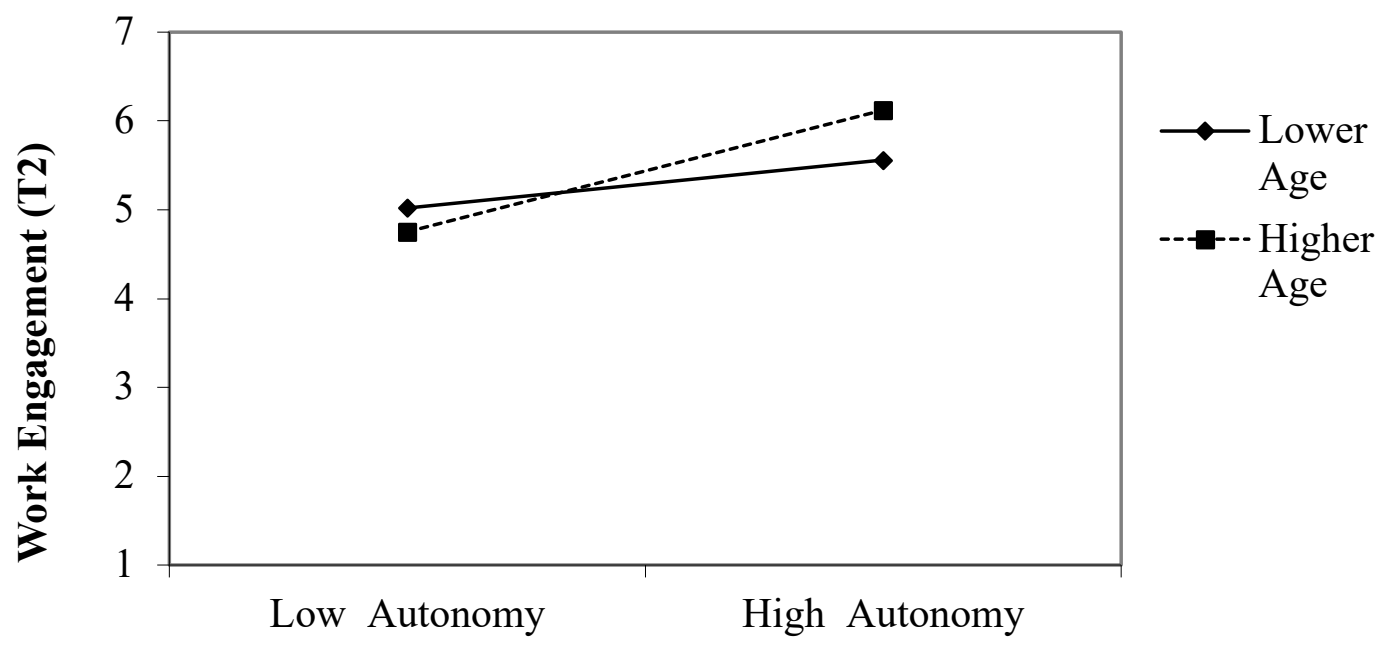

Figure 5.3 The interaction between decision-making autonomy and employee age on work engagement.

Age $(M=47.41, S D=12.01)$. "Low Age" $=1 \mathrm{SD}$ below the mean $=35$. "High Age" $=1$ SD above the mean $=59$. 


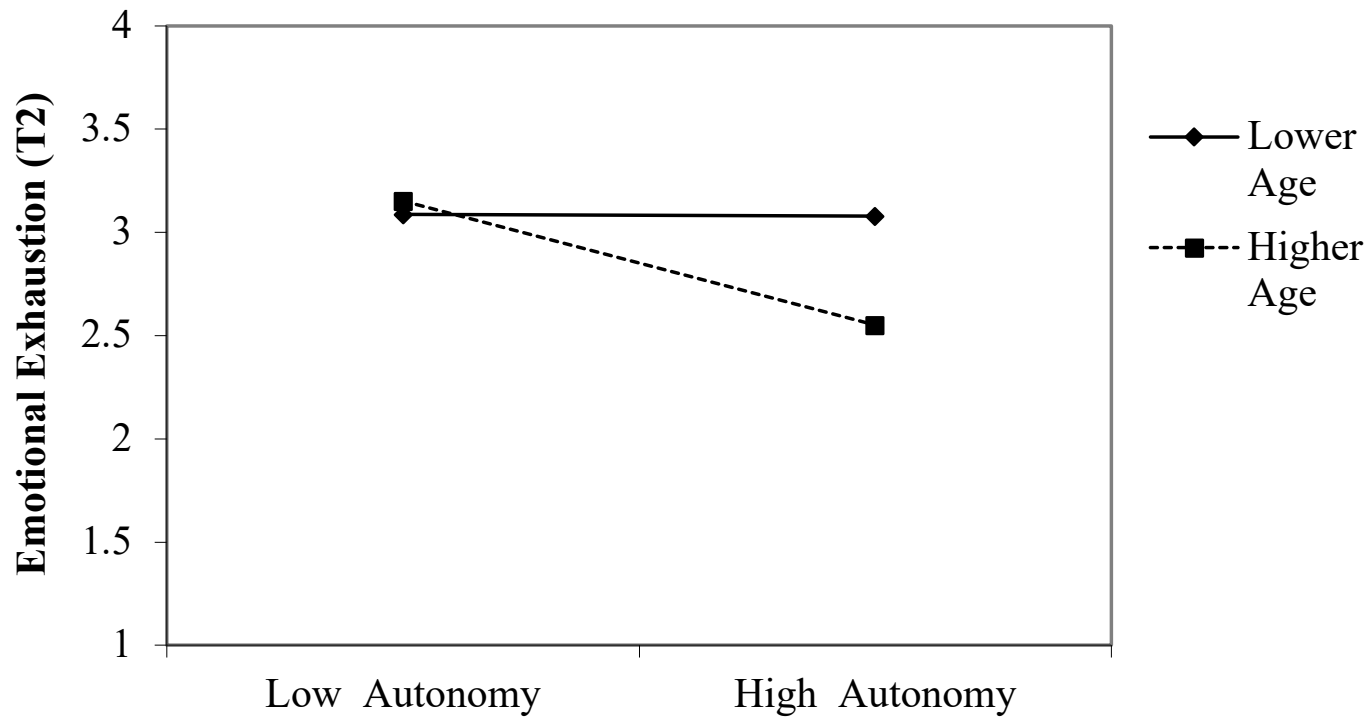

Figure 5.4 The interaction between decision-making autonomy and employee age on emotional exhaustion.

Age $(M=47.41, S D=12.01)$. "Low Age" $=1 \mathrm{SD}$ below the mean $=35$. "High Age" $=1 \mathrm{SD}$ above the mean $=59$. 


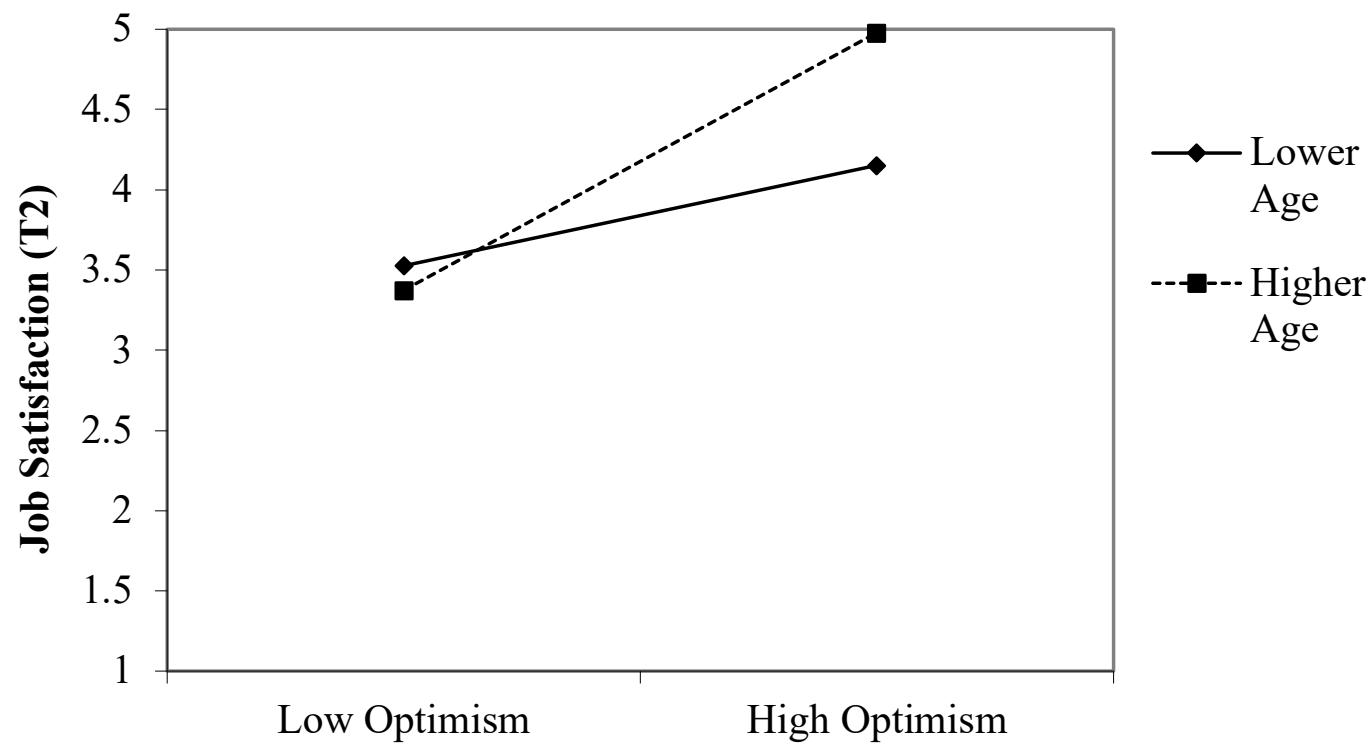

Figure 5.5 The interaction between optimism and employee age on job satisfaction. Age $(M=47.41, S D=12.01)$. "Low Age" $=1 \mathrm{SD}$ below the mean $=35$. "High Age" $=1$ SD above the mean $=59$. 


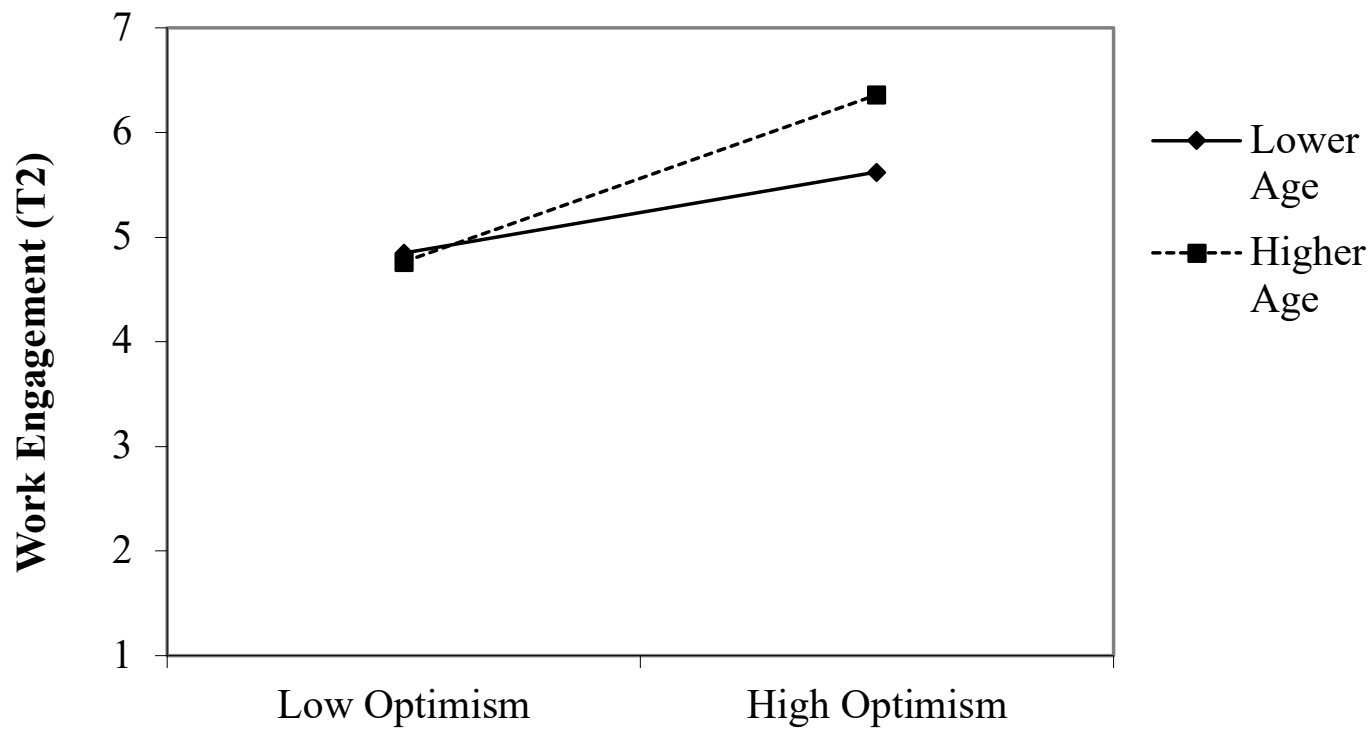

Figure 5.6 The interaction between optimism and employee age on work engagement. Age $(M=47.41, S D=12.01)$. "Low Age" = 1 SD below the mean $=35$. "High Age" $=1$ SD above the mean $=59$. 


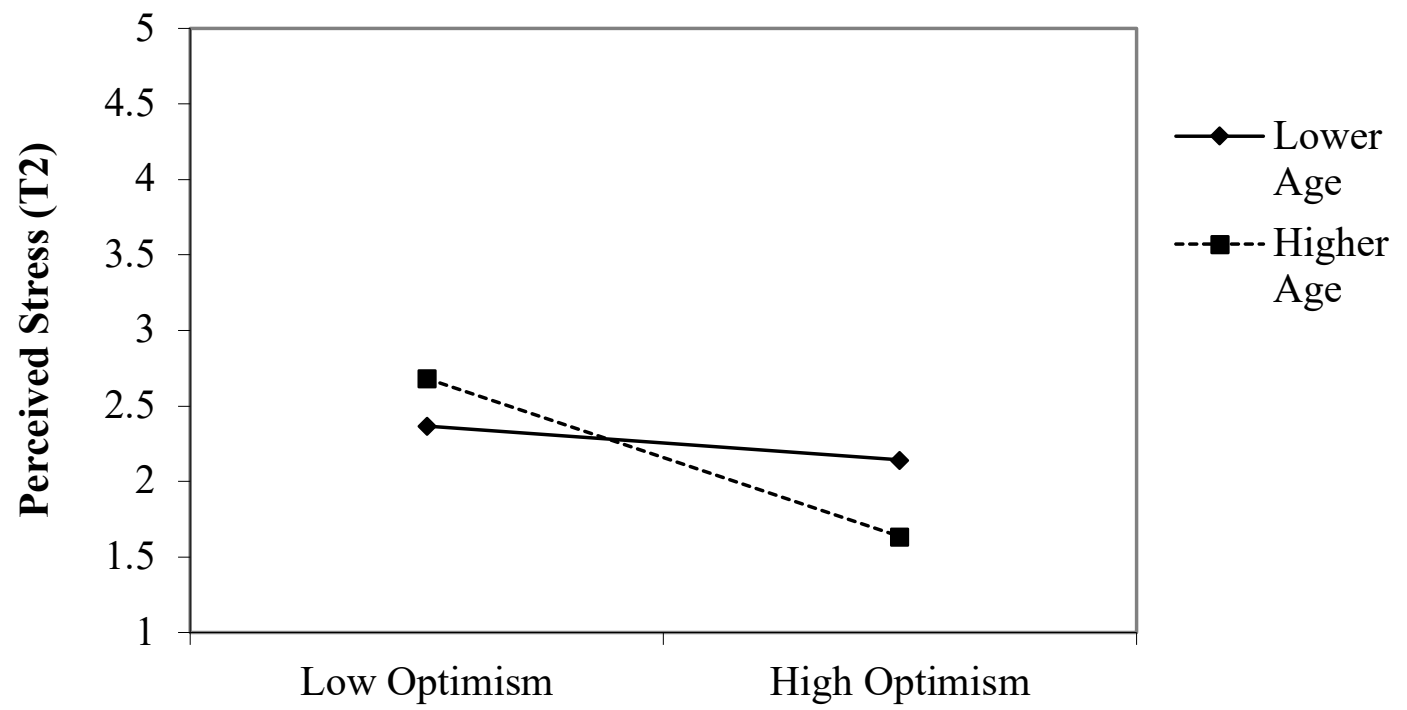

Figure 5.7 The interaction between optimism and employee age on perceived stress. Age $(M=47.41, S D=12.01)$. "Low Age" $=1 \mathrm{SD}$ below the mean $=35$. "High Age" $=1$ SD above the mean $=59$. 


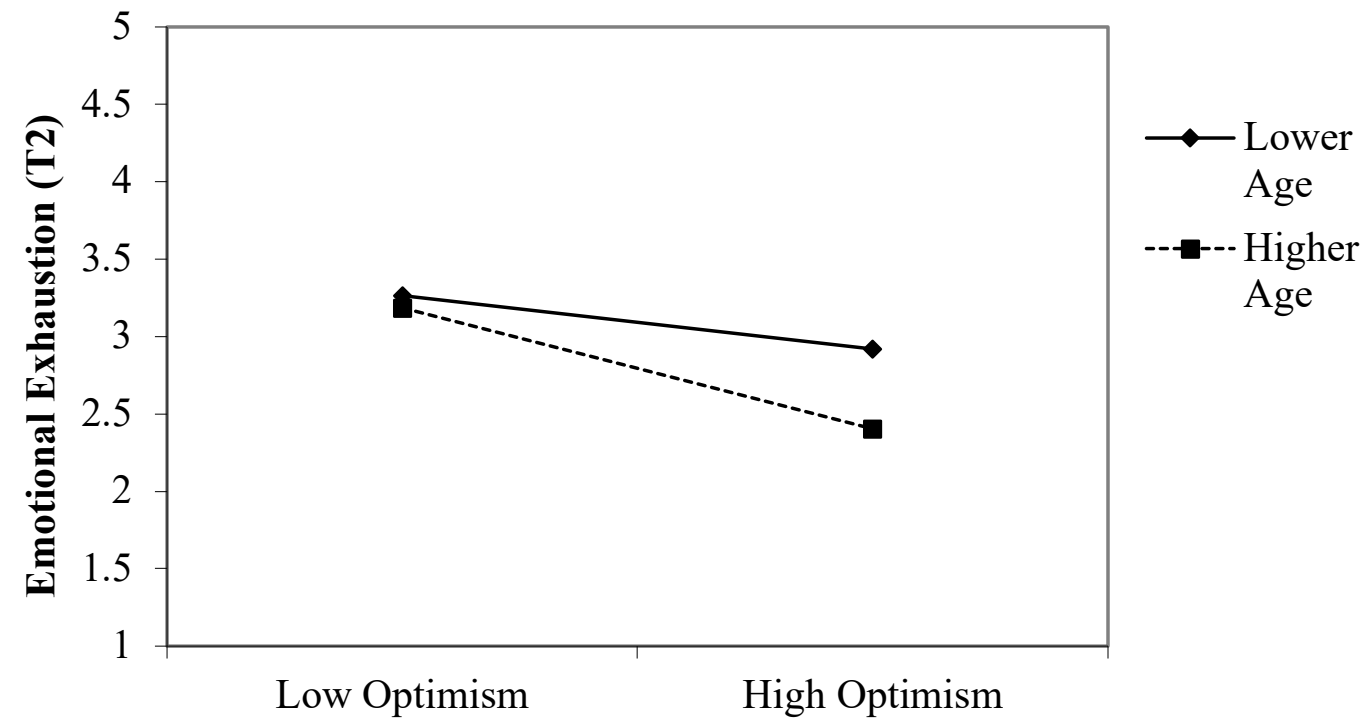

Figure 5.8 The interaction between optimism and age on emotional exhaustion. Age $(M=47.41, S D=12.01)$. "Low Age" = $1 \mathrm{SD}$ below the mean $=35$. "High Age" $=1$ SD above the mean $=59$. 


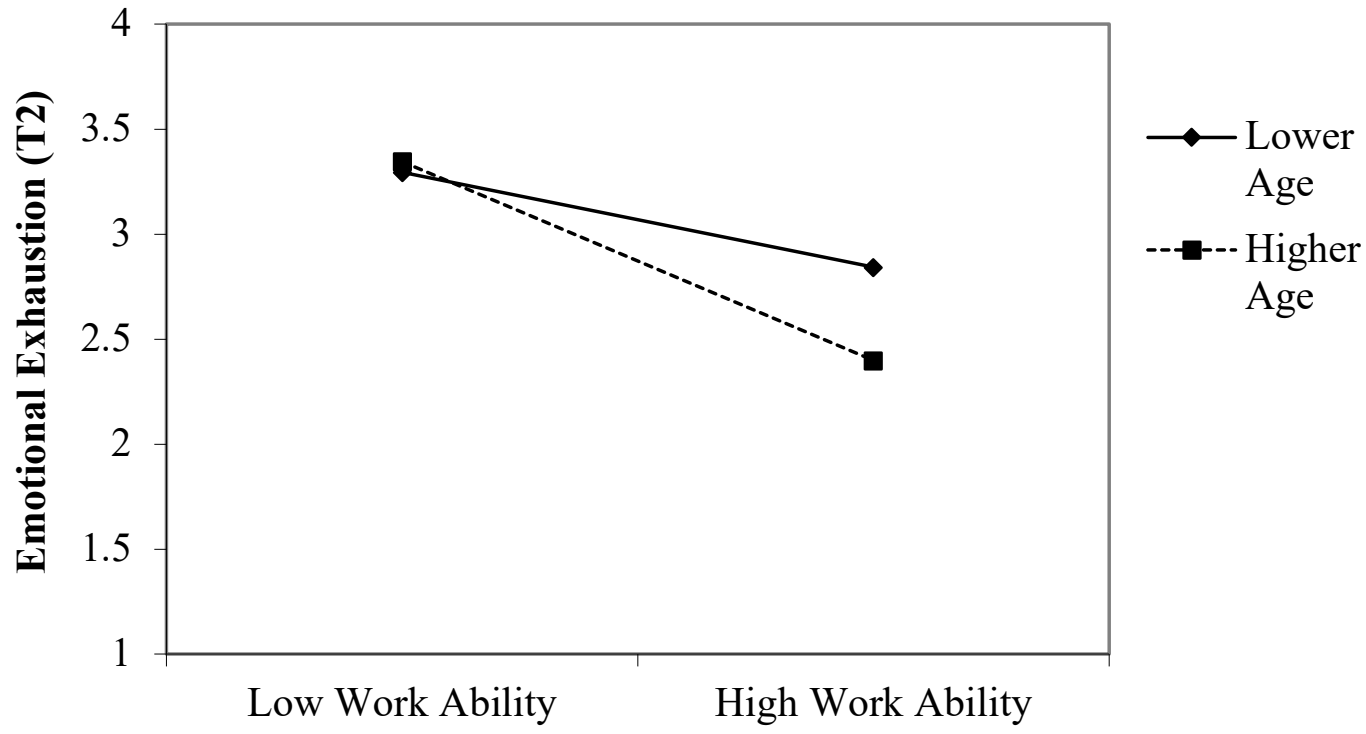

Figure 5.9 The interaction between perceived work ability and employee age on emotional exhaustion.

Age $(M=47.41, S D=12.01)$. "Low Age" $=1 \mathrm{SD}$ below the mean $=35$. "High Age" $=1 \mathrm{SD}$ above the mean $=59$. 


\section{Chapter 6: General Discussion}

The three studies presented in this dissertation responded to calls in the literature (e.g., Halbesleben et al., 2014, Hobfoll, 2002; Zacher \& Schmidt, 2016; Zaniboni et al., 2016) by examining the value of job resources in relation to work and well-being outcomes of older and younger workers. Guided by resource models, this body of work primarily drew on COR theory (Hobfoll, 1989) as the overarching framework to explain the role of resources on employee outcomes and sought to expand it to investigate whether the value of resources was robust across individuals and contexts. Summarizing the literature on the age-based changes in physical and cognitive capabilities, personality, prioritization of needs, and motivation across the life course, I capitalized on two Life span Resource Models (Hobfoll, 2002), specifically SOC (Baltes \& Baltes, 1990) and SST (Carstensen et al., 1999). In the end, these results may explain why not all job resources would be as equally beneficial - or harmful when lacking - for employees of different ages.

\section{Statement of Purpose Revisited}

Investigating different employee samples, cultural contexts, and study designs via a series of three studies, the findings of this dissertation contributed to our knowledge of the aging workforce in a number of ways. Specifically, the proposed dissertation sought to answer the following research questions:

1) Do certain job resources hold the same value for employees of different ages in relation to various work and well-being outcomes; or is the value of job 
resources age-dependent? (Overarching research question across Study 1, Study 2, and Study 3)

2) Can we detect age-related differences in the link between job resources and well-being utilizing a 1-year time-lagged study design? (Study 1)

3) How are job resources related to different forms of job performance for employees of different ages? Are certain job resources as equally valuable for older and younger workers to achieve in-role performance and citizenship behaviors? (Study 2)

4) How does the usefulness of certain job-specific and personal resources differ for older and younger workers in relation to different job attitudes and wellbeing outcomes? (Study 3)

5) What is the generalizability of the findings that demonstrate age-based differences to explain the relationship between job resources and work and non-work outcomes? In other words, is the relationship between the age-based usefulness of job resources and work and non-work outcomes generalizable to other cultures, industries, and job types? (Overarching research question across Study 1, Study 2, and Study 3)

Study 1 (Yaldiz et al., 2018; Chapter 3; Figure 3.1) examined the moderating role of age in the relationship between job-specific (skill discretion) and social support (LMX, procedural fairness) resources and employee stress in a longitudinal sample of U.S. construction workers. As hypothesized, the availability of these three job resources at baseline was more useful for older workers' well-being 12 months later, even after 
controlling for job tenure, organizational level, and overall stress at 6-month data collection. Compared to younger colleagues, older individuals reported greater stress when they could not utilize different skills on the job, had poor relationships with supervisors, and received unfair treatment at work. On the other hand, a work environment enriched with these important resources was associated with lower level of stress by employees of all ages. Thus, these findings suggest that the presence of baseline resources in the work domain spilled over to positively influence older employees' nonwork life after a year by helping reduce their level of overall stress.

Following these promising findings in Study 1, Study 2 (Chapter 4; Figure 4.1) sought to investigate the age-based differences in the link between additional social support resources (LMX, POS) and supervisory-ratings of job performance (in-role, OCBI, OCBO). Multi-source data were collected from manufacturing workers and their managers in a textile company in Turkey, which is known as a predominantly collectivistic culture compared to U.S. Guided by the same theoretical framework and the findings obtained in Study 1, I suggested that LMX and POS would have pronounced strategic roles for older workers to offset the age-based declines in performance, and also be more relevant to their prioritized socio-emotional needs than younger colleagues. In conclusion, I proposed that these resources would be more strongly related to in-role performance and OCB of older workers than younger colleagues. In these data, I did not detect significant interaction effects at $p=.05$ level, suggesting that the usefulness of LMX and POS was not significantly different for older and younger employees when predicting their job performance. Although this study did not reveal significant 
differences in the social support resources - job performance link for employees of different ages, it is noteworthy that the small sample size grouped under many managers might lead to power issues when analyzing the data at multilevel. Thus, before reaching to a conclusion, these relationships need to be examined with a larger sample size and thus greater statistical power.

Finally, Study 3 (Chapter 5; Figure 5.1) investigated whether job-specific (decision-making autonomy) and personal resources (optimism, perceived work ability) differentially related to job attitudes (job satisfaction, work engagement) and employee well-being (perceived stress, emotional exhaustion) of older and younger nurses. Guided by the same theories in Study 1 and Study 2, I proposed that these job-related resources would hold greater value for those workers at later ages. Overall, the findings of this study showed that older nurses who had discretion to make decisions at work, were optimistic about their future and job, and felt that their mental and physical capacities met the demands of their job had more favorable attitudes towards job and were better engaged in their work than younger colleagues. Moreover, they demonstrated lower stress and emotional exhaustion when these resources were high. Similar to the findings obtained from Study 1, the findings of this study also suggested that the availability of these critical resources influenced both work and non-work domains of nurses at later ages.

\section{Implications for Research}

This dissertation was developed based on two theoretical frameworks: Conservation of Resources Theory (COR; Hobfoll, 1989) and lifespan development 
theories, specifically, Selection-Optimization-Compensation (SOC; Baltes \& Baltes, 1990) and Socio-emotional Selectivity Theory (SST; Carstensen, Isaacowitz, \& Charles, 1999). Overall, support was found for these theories, and future research may examine additional aspects of these theories to explain how resource utilization may be agedependent in relation to work and well-being outcomes.

\section{Integrating Conservation of Resources (COR) theory with life span}

development theories. According to COR theory, any object that holds value for an individual may be defined as a resource. The theory suggests that when people experience resource loss they become stressed out. Therefore, people are motivated to obtain and protect their own resources to maintain well-being and pursue life goals successfully. However, as pointed out by recent reviews (e.g., Halbesleben et al., 2014), COR theory underestimates the relativity of resource value, that is, resources may not be equally important for everyone under every condition. Specifically, Halbesleben and colleagues (2014) suggested that time-related issues such as one's age may play a role to determine how critical a resource would be for an individual's work or well-being outcomes, and this needs to be tested empirically. Thus, to address this limitation in COR theory, the three studies in this dissertation investigated whether the relationship between different resources and employee work and well-being outcomes was different for older and younger workers. To explain the age-dependent nature of resources, I brought in two lifespan development theories, SOC and SST. In this respect, to my knowledge, this dissertation is the first that incorporates lifespan development theories with COR theory to address the age-based differences in the importance of resources and their influence on 
work and non-work outcomes. Within the lens of SOC theory, individuals experience declines in personal capacities as they age and therefore they actively search for strategies to offset any potential age-based weaknesses in their performance. The second theory, SST, focuses more on emotional goals and one's perspective about the remaining time in life. This theory suggests that younger individuals tend to have a more expansive perception of life ahead of them and therefore tend to prioritize growth- and careerrelated goals. On the other hand, as people get older, their perception about the remaining time becomes narrower, and, therefore they prefer investing on emotional goals such as maintaining relationships with significant others over growth-related goals. Thus, these two theories together acknowledge that people's needs and goals are not the same across the life course; and therefore the importance of resources that help achieve life goals and maintain well-being would be different at younger and older age. Building on this integrative approach, overall, the first and the third study in this dissertation found support for these theories. The findings of the first and the third study suggested that not every favorable resource was equally useful across individuals of different ages when the outcomes were employee attitudes and well-being. It seems that autonomy, relationships with supervisors, support from one's organization, being optimistic about the future, and having high work ability perceptions helped older workers in the study samples more than their younger counterparts to report lower levels of stress and emotional exhaustion, and higher job satisfaction, work engagement, and emotional exhaustion. In other words, in line with these theories, older employees seemed to benefit from a resourceful work environment more than their younger colleagues. 
In addition to integrating COR theory and lifespan development theories to explain age-based differences in resource utilization, this dissertation contributed to the prior research in a number of ways. First, one important finding from the studies included in this dissertation is that although the preliminary analyses did not find significant bivariate correlations between age and most of the predicting variables, the interactive effects between age and these predictive variables showed significant differences for older and younger participants. I believe that this understanding may encourage further examination of employee age as a potential boundary condition of the resource employee outcome relationships. The findings of this dissertation also echoed the need to examine age as a main study variable in Industrial-Organizational Psychology/Organizational Behavior literature rather than treating it as a control variable in statistical analyses without giving too much thought (Hertel \& Zacher, 2015). With that said, it is also worthwhile to note that age is a complex phenomenon which may include important covariates such as job tenure, career tenure, organizational status, cognitive and physical functioning, and even intra-individual changes in the personality characteristics, and major life experiences such as marriage or birth of a child (e.g., Soto \& John, 2012; Specht, Egloff, \& Schmuckle, 2011). Moreover, individuals of the same age do not necessarily behave in similar ways or share similar values and attitudes, for example, if they belong to different cultures. Although the three studies in this dissertation controlled some of the potential covariates of the chronological age in the proposed relationships (e.g., tenure, one's status in the organization) to rule out alternative explanations, I acknowledge that removing the influence of all covariates from 
chronological age is difficult and beyond the purpose and scope of this dissertation. Therefore, more research is needed to investigate the aged-based differences in the usefulness of resources and how they relate to work and non-work outcomes across job types, industries, gender, and cultures before reaching to a conclusion.

Second, to my knowledge, no studies have integrated COR theory and lifespan development theories to empirically test whether the job resources examined in this dissertation (skill discretion, LMX, organizational fairness, optimism, and perceived work ability) might differentially relate to older and younger employees' attitudes, wellbeing, and different forms of job performance. Although Industrial-Organizational Psychology/Organizational Behavior research has well-demonstrated that these psychosocial factors relate to important work and well-being outcomes, our understanding whether they are differentially beneficial - or harmful when lacking - for workers across different ages is still limited. The need for research in this area is important given that the workforce is expected to become more age-diverse and the participation rate of older workers in the labor force seems to increase in near future.

Third, the findings of the second study in this dissertation showed that there were no significant age-based differences in the importance of LMX and POS to predict in-role performance and OCBs. As discussed in detail in Chapter 4, employees, independent of their age, may work to achieve job tasks successfully to protect their employment. Therefore, support from leaders and organization may be equally important for older and younger workers to meet the demands of their jobs. Thus, age differences in the resources 
- job performance link may not be as pronounced as in the links between resources - job attitudes and resources - employee well-being.

\section{Practical Implications}

Overall, the three studies examined in this dissertation provide a number of potential implications for employees and organizations. Study 1 (Yaldiz et al., 2018) demonstrated that, compared to younger workers, older workers experienced greater stress in the face of low skill utilization. Moreover, Study 3 found that under low conditions of decision-making autonomy, older workers were less satisfied with their jobs, poorly engaged in their work, and experienced greater emotional exhaustion. Accordingly, organizations should be aware of these age-based differences in motivation and needs (e.g., Inceoglu et al., 2012; Hertel \& Zacher, 2015; Kanfer \& Ackerman, 2004; Kooij et al., 2011; Truxillo et al., 2015; Yaldiz et al., 2017a) when designing workplace interventions. For example, work redesign interventions targeting older workers would be more helpful to reduce stress or exhaustion when managers provide freedom to use decision-making and to exercise different skills to perform the job. In line with the principles of SOC model, organizations may help older workers maintain greater wellbeing by providing reasonable flexibility to craft their own jobs utilizing accumulated job knowledge and experience, or help them use compensation strategies to improve the perceived fit between the demands of their jobs and their mental and physical capabilities.

Another implication for the organization relates to the workplace interventions. The first study (Yaldiz et al., 2018) in this dissertation illustrated the importance of LMX 
for older workers' perceived stress. Accordingly, managers are critical resources representing both emotional and strategic values to regulate one's life in the eyes of older workers. Consequently, organizations may want to encourage managers to participate in trainings about effective communication and leadership skills focusing on how to motivate older workers thereby helping them have a positive state of mind outside work. Thus, managers need to be informed about their influence on employee well-being where their positive contributions at work may spill over to life domain for their older employees. In addition to the influence of leaders, Study 1 (Yaldiz et al., 2018) also demonstrated that procedural fairness perceptions acted as a critical resource to reduce overall stress for employees of older ages. This finding highlights the need to create a fair work environment where older workers would trust that work-related decisions are made consistently across organizational members, rewards and promotions are distributed on unbiased grounds, and employee opinion is taken into account when work-related decisions are made. There are several ways that managers can promote procedural fairness perceptions. For example, managerial training can be delivered to ensure that supervisors do not discriminate against subordinates in organizational processes such as hiring, selection, training, and promotion. Furthermore, to create an inclusive organizational climate, employee representatives can be selected to raise concerns of organizational members from diverse age groups.

Finally, the findings of Study 3 demonstrated that personal resources, optimism and work ability, helped older nurses to pursue a happier work and non-work life. Especially, optimism stood out as a key personal resource for employees at later ages: 
First, it enabled them bounce back more easily in hard times -optimistic older nurses reported lower emotional exhaustion at work and perceived less stress in life. Second, being optimistic had a pronounced influence on favorable outcomes, too. Compared to younger colleagues, optimistic older nurses were more satisfied with their job and engaged in their work. These findings are important especially for individuals who have high-strain jobs. Although optimism is a personality trait, healthcare organizations may consider delivering soft skills trainings or organize team events to boost positive feelings about the future among older members.

\section{Potential Limitations and Future Research}

The studies in this dissertation contribute to the theory and practice in several ways, however, as with any study; this dissertation has potential limitations that future research should address. First, out of the three studies, Study 2 used a cross-sectional design and Study 3 used only a short time-lag between employee reports of resources and job attitudes and well-being outcomes. Thus, these studies might fail to detect the longterm influence of resources on work and non-work outcomes; and future research should examine these relationships utilizing longer time-lags. That said, as this dissertation did not aim to assess causality or change in behavior, the short time-lag or cross-sectional nature of the data do not pose serious limitations to understand the correlational relationships between certain resources, employee age, and work and well-being outcomes. In addition, Study 1 (Yaldiz et al., 2018) attempted to overcome this methodological limitation by utilizing a longitudinal design where data on resources were collected at baseline and employee reports of stress were assessed after one year. 
Second, Study 1 (Yaldiz et al., 2018) and Study 3 consisted of self-report data from employees, thus raising concerns about common method variance. However, given the nature of the outcomes in these studies (perceived stress, emotional exhaustion, job satisfaction, work engagement), self-report measurements would be a suitable way to assess these well-being and job attitudes outcomes. On the other hand, Study 2 employed multi-source data: Employee self-reports provided data on social resources, and managerial ratings were obtained to assess job performance and OCB.

Third, the results of this multi-study investigation may not be generalizable to diverse employee populations. Specifically, the first study in this dissertation (Yaldiz et al., 2018) examined the relationships in a sample of blue-collar construction and field workers in the Pacific Northwest, USA; the sample for the second study consisted of manufacturing workers in Turkey; and, finally, the sample for the third study included registered nurses in the Pacific Northwest, USA. Moreover, while the participants in the first study were predominantly male, the participants in the third study included mostly female healthcare employees. Thus, future studies should examine the relationships that were found in these studies in diverse worker groups across industries, jobs, gender, and ethnicities while ensuring a wide age range (e.g., $\mathrm{Ng} \&$ Feldman, 2015). Furthermore, as the resource value may be culture-bound (Markus \& Kitayama, 1991), it would be necessary to replicate these studies in different cultural contexts. To this end, the second study in this dissertation sought to bring cultural diversity by investigating the age-based differences in the importance of social support resources - job performance link in a Turkish employee sample outside US. 
Another limitation of this research relates to the nature of chronological age. As mentioned earlier, under the Implications for Research, age is not a "clean" construct separated from several covariates such as job tenure, organizational tenure, and overall life experience. Therefore, the results of this dissertation warrant caution, specifically, not to overgeneralize the findings: Individuals of the same age may hold different attitudes and show differences in well-being and work performance outcomes. The intent of this dissertation is not to claim that the findings of these three studies hold true for all older individuals. While I acknowledge that to account for all covariates of chronological age is difficult, and beyond the purpose of this multi-study investigation, I controlled for potential confounding variables when analyzing the hypotheses including job tenure and supervisory status.

Finally, the results of this dissertation may guide new research directions. Specifically, future work may seek to examine potential resources that are differentially relevant to the needs of older and younger workers, and in turn may influence their workrelated outcomes differently. For example, the relative value of perceived overqualification for employees across different ages can be investigated from the lens of SOC and SST theories (Yaldiz, Erdogan, Bauer, Truxillo, \& Ordun, 2017).

Overqualification is defined as a form of person-job misfit where employees have surplus skills, knowledge, abilities, education, and experience that are not required by or utilized on one's job (Erdogan, Bauer, Peiro, \& Truxillo, 2011). Although research has shown that overqualification is unfavorably related to work outcomes such as lower satisfaction with job and supervisor, lower affective commitment, and poorer well-being and job 
performance (Erdogan \& Bauer, 2009; Feldman, Leana, \& Bolino, 2002; Feldman \& Turnley, 1995; Johnson, Morrow, \& Johnson, 2002; Maynard, Joseph, \& Maynard, 2006; Maynard \& Parfyonova, 2013; Wu, Luksyte, \& Parker, 2015), how age interacts with feelings of overqualification remains unanswered (Erdogan et al., 2011; Truxillo et al., 2017). Based on lifespan development theories, overqualified older workers may be more content with their job as having surplus skills, knowledge, and training may enable them to offer support to younger colleagues (e.g., in the form of mentoring). Thus, being overqualified may be instrumental for older workers to fulfill their need for relatedness. In contrast, underutilizing their skills and education would be perceived as more frustrating for younger workers. When they felt overqualified, employees of younger ages may consider that they are deprived from growth opportunities offered by alternative jobs, or they may feel stuck in their early career stages (Yaldiz et al., 2017b). In summary, in the light of the findings in this dissertation, the examination of potential jobrelated resources such as overqualification or support from family and coworkers and how they differ between work and well-being outcomes of older and younger workers needs further research attention.

Other avenues for future research are related to the theories used in this dissertation. To address the time-related limitations in COR theory (e.g., Halbesleben et al., 2014), this body of work examined the moderating role of age to uncover the link between resources and work and well-being outcomes. Future research may investigate when the value of resources shifts in one's life. To achieve this, employee perceptions of resource value can be assessed over time using longitudinal study designs (Zacher \& 
Schmitt, 2016). Finally, mediating mechanisms should be explored to shed light on how the interactions between resources and age influence employee outcomes (Hertel \& Zacher, 2018).

\section{Conclusion}

This multi-study dissertation contributes to the literature by addressing a gap in the research about the age-based differences in the usefulness of work-related resources and how they relate to different employee attitudes, job performance, and well-being outcomes. Responding to the recent criticisms of COR theory, the three studies in this dissertation tested the assumption that the value of job resources is robust across individuals by integrating two lifespan development models, SOC and SST, to explain the age-related differences. Overall, the findings supported that the resource value on work and non-work outcomes is age-dependent. Study 1 (Yaldiz et al., 2018) suggested that when resources from the job (e.g., skill discretion), supervisor (e.g., LMX), and organization (e.g., procedural fairness) were high, both younger and older workers had lower levels of stress - thus, as expected, the presence of these resources is equally beneficial for the well-being of all workers. However, when these resources were low, older workers reported significantly higher level of stress than their younger colleagues. In sum, the importance of skill discretion, LMX, and procedural fairness was higher among older workers, and the lack of these resources in the work environment was more detrimental for their well-being. Findings from Study 2 did not detect age-based differences in the social support resources (e.g., LMX, POS) - job performance (e.g., inrole, OCBO, OCBI) link. Finally, Study 3 found that resources from the job (decision- 
making autonomy) and personal resources (optimism, perceived work ability) were differentially related to the job satisfaction, work engagement, perceived stress, and emotional exhaustion of older and younger nurses. Overall, the lack of decision-making autonomy and optimism was equally harmful for employees of all ages. However, when these resources were high, older workers reported higher satisfaction and greater engagement with their jobs, as well as lower levels of exhaustion and overall stress in life. Taken together, these findings have several theoretical implications and provide suggestions for future research on the aging workforce, and they suggest possible organizational practices to support employees across the work lifespan. 


\section{References}

Ackerman, P. L. (2014). Adolescent and adult intellectual development. Current Directions in Psychological Science, 23, 246-251.

Ahlstrom, L., Grimby-Ekman, A., Hagberg, M., \& Dellve, L. (2010). The work ability index and single-item question: associations with sick leave, symptoms, and health-a prospective study of women on long-term sick leave. Scandinavian Journal of Work, Environment \& Health, 36, 404-412.

Allen, N. J., \& Meyer, J. P. (1990). The measurement and antecedents of affective, continuance and normative commitment to the organization. Journal of Occupational Psychology, 63, 1-18.

American Psychological Association (2016). Stress in America: The impact of discrimination. Stress in America ${ }^{\mathrm{TM}}$ Survey. Retrieved from: http://www.apa.org/news/press/releases/stress/2015/impact-of-discrimination.pdf

American Psychological Association (2012). Stress in America: Our health at risk. Stress in America ${ }^{\mathrm{TM}}$ Survey. Retrieved from: https://www.apa.org/news/press/releases/stress/2011/final-2011.pdf

Anand, S., Vidyarthi, P. R., Liden, R. C., \& Rousseau, D. M. (2010). Good citizens in poor-quality relationships: Idiosyncratic deals as a substitute for relationship quality. Academy of Management Journal, 53, 970-988.

Andersson, M. A. (2012a). Dispositional optimism and the emergence of social network diversity. Sociological Quarterly, 53, 92-115. 
Andersson, M. A. (2012b). Identity crises in love and at work: Dispositional optimism as a durable personal resource. Social Psychology Quarterly, 75, 290-309.

Anderson, S. E., \& Williams, L. J. (1996). Interpersonal, job, and individual factors related to helping processes at work. Journal of Applied Psychology, 81, 282-296.

Andreassi, J. K., \& Thompson, C. A. (2007). Dispositional and situational sources of control. Journal of Managerial Psychology, 22, 722-740.

Bakker, A. B., \& Bal, P. M. (2010). Weekly work engagement and performance: A study among starting teachers. Journal of Occupational and Organizational Psychology, 83, 189-206.

Bakker, A. B., \& Demerouti, E. (2007). The Job Demands-Resources model: State of the art. Journal of Managerial Psychology, 22, 309-328.

Bakker, A. B., Demerouti, E., \& Sanz-Vergel, A. I. (2014). Burnout and work engagement: The JD-R approach. Annual Reviews of Organizational Behavior, 1, $389-411$.

Baltes, M. M. (1996). The many faces of dependency in old age. New York: Cambridge University Press.

Baltes, P. B. (1997). On the incomplete architecture of human ontogeny: Selection, optimization, and compensation as foundation of development theory. American Psychologist, 52, 366-380.

Baltes, P. B., \& Baltes, M. M. (1990). Psychological perspectives on successful aging: The model of selective optimization with compensation. In P. B. Baltes \& M. M. 
Baltes (Eds.), Successful aging: Perspectives from the behavioral sciences (pp. 134). New York: Cambridge University Press.

Baltes, P. B., \& Finkelstein, L. M. (2011). Contemporary empirical advancements in the study of aging in the workplace. Journal of Organizational Behavior, 32, 151154.

Baltes, B. B., Zhdanova, L. S., \& Clark, M. A. (2011). Examining the relationship between personality, coping strategies, and work-family conflict. Journal of Business Psychology, 4, 517-530.

Barclay, L. J., Skarlicki, D. P., \& Pugh, S. D. (2005). Exploring the role of emotions in injustice perceptions and retaliation. Journal of Applied Psychology, 90, 629-643.

Bauer, T. N., \& Erdogan, B. (2015). Leader-member exchange (LMX) theory: An inrtoduction and overview. In T. Bauer \& B. Erdogan (Eds.), Oxford handbook of leader-member exchange (pp. 3-9). Oxford University Press.

Baumeister, R. F., \& Leary, M. R. (1995). The need to belong: Desire for interpersonal attachments as a fundamental human motivation. Psychological Bulletin, 117, 497-529.

Bayram, N., Gursakal, N., Bilgel, N. (2009). Counterproductive work behaviors among whilte-collar employees: A study from Turkey. International Journal of Selection and Assessment, 17, 180-188.

Blau, P. M. (1964). Exchange and power in social life. New York: Wiley. 
Bekker, J. A. H., Halbesleben, J. R. B., \& O’Hair, H. D. (2005). Defensive communication and buronout in the workplace: The mediating role of leadermember exchange. Communication Research Reports, 22, 143-150.

Bliese, P. D. (2016). Multilevel modeling in R (2.6): A brief introduction to $R$, the multilevel package and the nlme package. Retrieved from https://cran.rproject.org/doc/contrib/Bliese_Multilevel.pdf

Bliese, P. D., \& Hanges, P. J. (2004). Being too liberal and too conservative: The perils of treating grouped data as though they were independent. Organizational Research Methods, 7, 400-417.

Bloom, D. E. (2011). 7 billion and counting. Science, 333, 562-569.

Bodner, T., Kraner, M., Bradford, B., Hammer, L. B., \& Truxillo, D. M. (2014). Safety, health, and well-being of municipal utility and construction workers. Journal of Occupational and Environmental Medicine, 56, 771-778.

Brayfield, A. H., \& Rothe, H. F. (1951). An index of job satisfaction. Journal of Applied Psychology, 35, 307-311.

Brislin, R. W. (1970). Back-translation for cross-cultural research. Journal of CrossCultural Psychology, 1, 185-216.

Brissette, I., Scheier, M. F., \& Carver, C. S. (2002). The role of optimism in social network development, coping, and psychological adjustment during a life transition. Journal of Personality and Social Psychology, 82, 102-111. 
Burke, R. J. (2015). Managing an aging and multi-generational workforce: Challenges and opportunities. In J. Field, R. J. Burke, \& C. L. Cooper (Eds.), The Sage handbook on aging, work, and society (pp. 3-36). London: Sage Publications.

Carstensen, L. L., Isaacowitz, D. M., \& Charles, S. T. (1999). Taking time seriously: A theory of socioemotional selectivity. American Psychologist, 54, 165-181.

Carstensen, L. L., Paspuathi, M., Mary, U., \& Nesselroade, J. R. (2000). Emotional experience in everyday life across the adult life span. Journal of Personality and Social Psychology, 79, 644-655.

Cattell, R. B. (1943). The measurement of adult intelligence. Psychological Bulletin, 40, 153- 193.

Cattell, R. B. (1987). Intelligence: Its structure, growth, and action. Amsterdam: NorthHolland.

Chen, S., Westman, M., \& Eden, D. 2009. Impact of enhanced resources on anticipatory stress and adjustment to new information technology: A field-experimental test of conservation of resources theory. Journal of Occupational Health Psychology, 14, 219-230.

Cohen-Charash, Y., \& Spector, P. E. (2001). The role of justice in organizations: A metaanalysis. Organizational Behavior and Human Decision Processes, 86, 278-321.

Cohen, S., Karmarck, T., \& Mermelstein, R. (1983). A global measure of perceived stress. Journal of Health and Social Behavior, 385-396.

Colquitt, J. A. (2008). Two decades of organizational justice: Findings, controversies, and future directions. In C. L. Cooper \& J. Barling (Eds.), The Sage handbook of 
organizational behavior: Volume 1. Micro approaches (pp. 73-88). Newbury Park, CA: Sage.

Colquitt, J. A., Scott, B. A., Rodell, J. B., Long, D. M., Zapata, C. P., Conlon, D. E., \& Wesson, M. J. (2013). Justice at the millennium, a decade later: A meta-analytic test of social exchange and affect-based perspectives. Journal of Applied Psychology, 98, 199-236.

Costa, P. T., \& McCrae, R. R. (1992). Revised NEO Personality Inventory (NEO PI-R) and NEO Five-Factor Inventory (NEO-FFI) professional manual. Lutz, FL: Psychological Assessment Resources.

Cropanzano, R., Bowen, D. E., \& Gilliland, S. W. (2007). The management of organizational justice. Academy of Management Perspectives, 21, 34-48.

Cropanzano, R., Howes, J. C., Grandey, A. A., \& Toth, P. (1997). The relationship of organizational politics and support to work behaviors, attitudes, and stress. Journal of Organizational Behavior, 18, 159-180.

Darr, W., \& Johns, G. (2008). Work strain, health, and absenteeism: A meta-analysis. Journal of Occupational Health Psychology, 13, 293-318.

Demerouti, E., Bakker, A. B., Nachreiner, F., \& Schaufeli, W. B. (2001). The job demands-resources model of burnout. Journal of Applied Psychology, 86, 499512.

Demerouti, E., Mostert, K., \& Bakker, A. B. (2010). Burnout and work engagement: A through investigation of the independency of both constructs. Journal of Occupational Health and Psychology, 15, 209-222. 
Dienesch, R.M., \& Liden, R.C. (1986). Leader-member exchange model of leadership: A critique and further development. Academy of Management Review, 11, 618-634.

Diestel, S., \& Schmidt, K. (2012). Lagged mediator effects of self-control demands on psychological strain and absenteeism. Journal of Occupational and Organizational Psychology, 85, 556-578.

Dulebohn, J.H., Bommer, W.H., Liden, R.C., Brouer, R.L., \& Ferris, G.R. (2012). A meta-analysis of antecedents and consequences of leader-member exchange: Integrating the past with an eye toward the future. Journal of Management, 38, 1715-1759.

Dychtwald, K. (2000). Age power: How the 21th century will be ruled by the new old. New York: Jeremy Tarcher/Putnam.

Eisenberger, R., Huntington, R., Hutchison, S., \& Sowa, D. (1986). Perceived organizational support. Journal of Applied Psychology, 71, 500-507.

Elovainio, M., Kivimäki, M., \& Helkama, K. (2001). Organizational justice evaluations, job control, and occupational strain. Journal of Applied Psychology, 86, 418-424.

Elovainio, M., Kivimäki, M., Steen, N., \& Vahtera, J. (2004). Job decision latitude, organizational justice, and health: Multilevel covariance structure analysis. Social Science \& Medicine, 58, 1659-1669.

Elovainio, M., Kivimäki, M., \& Vahtera, J. (2002). Organizational justice: Evidence on a new

psychosocial predictor of health. American Journal of Public Health, 92, 105-108. 
Elovainio, M., Kivimäki, M., \& Vahtera, J., Keltikangas-Järvinen, L., \& Virtanen, M. (2003). Sleeping problems and health behaviors as mediators between organizational justice and health. Health Psychology, 22, 287-293.

Erdogan, B., \& Bauer, T. N. (2005). Enhancing career benefits of employee proactive personality: The role of fit with jobs and organizations. Personnel Psychology, 58, 859-891.

Erdogan, B., \& Bauer, T. N. (2009). Perceived overqualification and its outcomes: The moderating role of empowerment. Journal of Applied Psychology, 94, 557-565.

Erdogan, B., Bauer, T. N., Peiro', J. M., \& Truxillo, D. M. (2011). Overqualified employees: Making the best of a potentially bad situation for individuals and organizations. Industrial and Organizational Psychology, 4, 215-232.

Erdogan, B., \& Enders, J. (2007). Support from the top: Supervisors' perceived organizational support as a moderator of leader-member exchange to satisfaction and performance relationships. Journal of Applied Psychology, 92, 321-330.

Erdogan, B., Kraimer, M. L., \& Liden, R. C. (2004). Work value congruence and intrinsic career success: The compensatory roles of leader-member exchange and perceived organizational support. Personnel Psychology, 57, 305-332.

European Commission (2015). The 2015 Ageing Report: Economic and budgetary projections for the EU28 member states (2013-20160). Luxemburg.

Feldman, D. C., Leana, C. R., \& Bolino, M. C. (2002). Underemployment and relative deprivation among re-employed executives. Journal of Occupational and Organizational Psychology, 75, 453-471. 
Feldman, D. C., \& Turnley, W. H. (1995). Underemployment among recent business college graduates. Journal of Organizational Behavior, 16, 691-706.

Finkelstein, L., \& Truxillo, D. M. (2013). Age discrimination research is alive and well, even if it doesn't live where you'd expect. Industrial and Organizational Psychology, 6, 100-102.

Fisher, G. G., Chaffee, D. S., Tetrick, L. E., Davalos, D. B., \& Potter, G. G. (2017). Cognitive functioning, aging, and work: A review and recommendations for research and practice. Journal of Occupational Health Psychology, 22, 314-336. Advance online publication. http://dx.doi.org/10.1037/ocp0000086

Fischer, F. M., Notarnicola da Silva Borges, F., Rotenberg, L., do Rosario Dias de Oliveira Latorre, M., Santos Soares, N., Lima Ferreira Santa Rosa, P., . . . Landsbergis, P. (2006). Work ability of health care shift workers: What matters? Chronobiology International, 23, 1165-1179.

Fried, Y. \& Ferris, G. R. (1987). The validity of the job characteristics model: A review and meta-analysis. Personnel Psychology, 40, 287-322.

Ford, M. T., Matthews, R. A., Wooldridge, J. D., Mishra, V., Kakar, U. M., \& Strahan, S. R. (2014). How do occupational stressor-strain effects vary with time? A review and meta-analysis of the relevance of time lags in longitudinal studies. Work \& Stress: An International Journal of Work, Health \& Organisations, 28, 9-30.

Gerstner, C.R., \& Day, D.V. (1997). Meta-analytic review of leader-member exchange theory: Correlates and construct issues. Journal of Applied Psychology, 82, 827844. 
Goodman, J. S., \& Blum, T. C. (1996). Assessing the non-random sampling effects of subject attrition in longitudinal research. Journal of Management, 22, 627-652.

Greenberg, J. (2011). Organizational justice: The dynamics of fairness in the workplace. In S. Zedeck (Ed.), APA handbook of industrial and organizational psychology (pp. 271-327). Washington, DC: APA.

Griffin, M. A., \& Clarke, S. (2011). Stress and well-being at work. In S. Zedeck (Ed). APA handbook of industrial and organizational psychology, (Vol. 3).

Washington, DC: American Psychological Association.

Hackman, J. R., \& Oldham, G. R. (1975). Development of the Job Diagnostic Survey. Journal of Applied Psychology, 60, 159-170.

Halbesleben, J. R. B. (2006). Sources of social support and burnout: A meta-analytic test of the conservation of resources model. Journal of Applied Psychology, 91, 11341145.

Halbesleben, J. R. B., Neveu, J. P., Paustian-Underdahl, S. C., \& Westman, M. (2014). Getting to the "COR": Understanding the role of resources in conservation of resources theory. Journal of Management, 40, 1334-1364.

Hayes, A. F. (2013). Introduction to mediation, moderation, and conditional process analysis: A regression-based approach. New York, NY: The Guildford Press.

Hertel, G., \& Zacher, H. (2015). Managing the aging workforce. In C. Viswesvaran, N. Anderson, D. Ones, \& H. K. Sinangil (Eds.), The SAGE handbook of industrial, work, \& organizational psychology, (2 $2^{\text {nd }}$ ed., Vol. 3). New York: Sage. 
Hobfoll, S. E. (1989). Conservation of resources: A new attempt at conceptualizing stress. American Psychologist, 44, 513-524. doi: 10.1037/0003-066X.44.3.513

Hobfoll, S. E. (2002). Social and psychological resources and adaptation. Review of General Psychology, 6, 307-324.

Hochwarter, W. A., Witt, L. A., Treadway, D. C., \& Ferris, G. R. (2006). The interaction of social skill and organizational support on job performance. Journal of Applied Psychology, 2, 482-489.

Hofstede, G. (1984). Culture's consequences: International differences in work-related attitudes. Beverly Hills, CA: Sage.

Huang, X., Chan, S. C. H., Lam, W., \& Nan, X. (2010). The joint effect of leadermember exchange and emotional intelligence on burnout and work performance in call centers in China. The International Journal of Human Resource Management, 21, 1124-1144.

Humphrey, S. E., Nahrgang, J. D., \& Morgeson, F. P. (2007). Integrating motivational, social, and contextual work design features: A meta-analytic summary and theoretical extension of the work design literature. Journal of Applied Psychology, $92,1332-1356$.

Ilies, R., Nahrgang, J. D., \& Morgeson, F. P. (2007). Leader-member exchange and citizenship behaviors: A meta-analysis. Journal of Applied Psychology, 92, 269277.

Ilmarinen, J. (2007). The work ability index (WAI). Occupational Medicine, 57, 160. 
Ilmarinen, J. (2009). Work ability -A comprehensive concept for occupational health research and prevention. Scandinavian Journal of Work, Environment \& Health, $35,1-5$.

Ilmarinen, J., Tuomi, K., Eskelinen, L., Nygård, C. H., Huuhtanen, P., \& Klockars, M. (1991). Summary and recommendations of a project involving cross-sectional and follow-up studies on the aging worker in Finnish municipal occupations (19811985). Scandinavian Journal of Work, Environment \& Health, 17, 135-141.

Inceoglu, I., Segers, J., \& Bartram, D. (2012). Age-related differences in work motivation. Journal of Occupational and Organizational Psychology, 85, 300329.

Jiang, J. Y., Law, K., S., \& Sun, J. J. M. (2014). Leader-member relationship and burnout: The moderating role of leader integrity. Management and Organization Review, 10, 223-247.

Johnson, W. R., Morrow, P. C., \& Johnson, G. J. (2002). An evaluation of a perceived overqualification scale across work settings. The Journal of Psychology, 136, 425-441.

Judge, T. A., Bono, J. E., Amir, E., \& Locke, E. A. (2005). Core self-evaluations and job and life satisfaction: The role of self-concordance and goal attainment. Journal of Applied Psychology, 90, 257-268.

Judge, T. A., \& Colquitt, J. A. (2004). Organizational justice and stress: The mediating role of work-family conflict. Journal of Applied Psychology, 89, 395-404. 
Judge, T. A., \& Kammeyer-Mueller, J. D. (2012). Job attitudes. Annual Review of Psychology, 63, 341-367.

Kanfer, R., \& Ackerman, P.L. (2004). Aging, work motivation, and adult development. Academy of Management Review, 29, 440-458.

Kaplan, P. S. (1993). The human odyssey: Life-span development. St. Paul, MN: West Publishing Company.

Karasek, R. (1990). Lower health risk with increased job control among white collar workers. Journal of Organizational Behaviors, 11, 171-185.

Karasek, R., Brisson, C., Kawakami, N., Houtman, I., Bongers, P., \& Amick, B. (1998). The Job Content Questionnaire (JCQ): An instrument for internationally comparative assessments of psychosocial job characteristics. Journal of Occupational Health Psychology, 3, 322-355.

Klein, R. M., Dilchert, S., Ones, D. S., \& Dages, K. D. (2015). Cognitive predictors and age-based adverse impact among business executives. Journal of Applied Psychology, 5, 1497-1510.

Kooij, D. T. A. M., De Lange, A. H., Jansen, P. G. W., Kanfer, R., \& Dikkers, J. S. E. (2011). Age and work-related motives: Results of a meta-analysis. Journal of Organizational Behavior, 32, 197-225.

Kuhnel, J., Sonnentag, S., \& Bledow, R. (2012). Resources and time pressure as daylevel antecedents of work engagement. Journal of Occupational and Organizational Psychology, 85, 181-198. 
Kulik, C. T., Ryan, S., Harper, S., \& George, G. (2014). Aging populations and management. Academy of Management Journal, 57, 929-935.

Kunze, F., \& Boehm, S. A. (2013). Research on age diversity in the workforce: Current trends and future research directions. In J. Field, R. J. Burke, \& C. L. Cooper (Eds.), The Sage handbook on aging, work, and society (pp. 41-58). London: Sage Publications.

Kunze, F., Boehm, S. A., \& Bruch, H. (2011). Age diversity, age discrimination climate and performance consequences -a cross organizational study. Journal of Organizational Behavior, 32, 264-290.

Leventhal, G. S. (1980). What should be done with equity theory? New approaches to the study of fairness in social relationships. In K. Gergen, M. Greenberg, \& R. Willis (Eds.), Social exchange: Advances in theory and research (pp. 27-55). New York, NY: Plenum Press.

Luthans, F., Avolio, B., Avey, J. B. \& Norman, S. M. (2007). Psychological capital: Measurement and relationship with performance and job satisfaction. Personnel Psychology, 60, 541-572.

Mache, S., Vitzhum, K., Wanke, E., Groneberg, D. A., Klapp, B. F., \& Danzer, G. (2014). Exploring the impact of resilience, self-efficacy, optimism, and organizational resources on work engagement. Work, 47, 491-500.

Mäkikangas, A., \& Kinnunen, U. (2003). Psychosocial work stressors and well-being: Self-esteem and optimism as moderators in a one-year longitudinal sample. Personality and Individual Differences, 35, 537-557. 
Markus, H. R., \& Kitayama, S. (1991). Culture and the self: Implucations for cognition, emotion, and motivation. Psychological Review, 98, 224-253.

Maynard, D. C., Joseph, T. A., \& Maynard, A. M. (2006). Underemployment, job attitudes, and turnover intentions. Journal of Organizational Behaviors, 27, 509536.

Maynard, D. C., \& Parfyonova, N. M. (2013). Perceived overqualification and withdrawal behaviours: Examining the roles of job attitudes and work values. Journal of Occupational and Organizational Psychology, 86, 435-455.

McGonagle, A. K., Beatty, J., \& Joffe, R. (2014). Coaching for workers with chronic illness: Evaluating an intervention. Journal of Occupational Health Psychology, 19, 385-398.

McGonagle, A. K., Fisher, G. G, Barnes-Farrell, J. L., \& Grosch, J. W. (2015). Individual and work factors related to perceived work ability and labor force outcomes. Journal of Applied Psychology, 100, 376-398.

Meyer, J. P., Stanley, D. J., Herscovitch, L., \& Topolnytsky, L. (2002). Affective, continuance, and normative commitment to the organization: A meta-analysis of antecedents, correlates, and consequences. Journal of Vocational Behavior, 61, $20-52$.

Moghimi, D., Zacher, H., Scheibe, S., \& Van Yperen, N. W. (2017). The selection, optimization, and compensation model in the work context: A systematic review and meta-analysis of two decades of research. Journal of Organizational Behavior, 38, 247-275. doi: 10.1002/job.2108 
Moorman, R. H. (1991). Relationship between organizational justice and organizational citizenship behavior. Do fairness perceptions influence employee citizenship? Journal of Applied Psychology, 76, 845-855.

Morgeson, F. P., \& Humphrey S. E. (2006). The Work Design Questionnaire (WDQ): Developing and validating a comprehensive measure for assessing job design and the nature of work. Journal of Applied Psychology, 91, 1321-1399.

Müller, A., Heiden, B., Herbig, B., Poppe, F., \& Angerer, P. (2015). Improving wellbeing at work: A randomized controlled intervention based on selection, optimization, and compensation. Journal of Occupational Health Psychology, 21, $169-181$.

Nahrgang, J. D., Morgeson, F. P., \& Hofmann, D. A. (2011). Safety at work: A metaanalytic investigation of the link between job demands, job resources, burnout, engagement, and safety outcomes. Journal of Applied Psychology, 96, 71-94.

National Institute for Occupational Safety and Health (NIOSH; 2010). Occupational health psychology (OHP). Retrieved from http://www.cdc.gov/niosh/topics/ohp/

Ng, T. W. H., Eby, L. T., Sorensen, K. L., \& Feldman, D. C. (2005). Predictors of objective and subjective career success: A meta-analysis. Personnel Psychology, $58,367-408$.

Ng, T. W. H., \& Feldman, D. C. (2008). The relationships of age to ten dimensions of job performance. Journal of Applied Psychology, 93, 392-423.

Ng, T. W. H., \& Feldman, D. C. (2010). The relationships of age with job attitudes: A meta-analysis. Personnel Psychology, 63, 677-718. 
Ng, T. W. H., \& Feldman, D. C. (2012). Evaluating six common stereotypes about older workers with meta-analytical data. Personnel Psychology, 65, 821-858.

Ng, T. W.H., \& Feldman, D. C. (2013). Employee age and health. Journal of Vocational Behavior, 83, 336-345.

Ng, T. W.H., \& Feldman, D. C. (2015). The moderating role of age in the relationships of job autonomy to work outcomes. Work, Aging, and Retirement, 1, 64-78.

Ng, T. W.H., \& Sorensen, K. L. (2008). Toward a further understanding of the relationships between perceptions of support and work attitudes: A meta-analysis. Group and Organization Management, 33, 243-268.

Niehoff, B.P., \& Moorman, R. H. (1993). Justice as a mediator of the relationship between methods of monitoring and organizational citizenship behavior. Academy of Management Journal, 36, 527-556.

Nixon, A. E., Mazzola, J. J., Bauer, J., Krueger, J. R., \& Spector, P. E. (2011). Can work make you sick? A meta-analysis of the relationships between job stressors and physical symptoms. Work \& Stress, 25, 1-22.

Palgi, Y., Shrira, A., Ben-Ezra, M., Cohen-Fridel, S., \& Bodner, E. (2011). The relationship between daily optimism, daily pessimism, and affect differ in young and old age. Personality and Individual Differences, 50, 1294-1299.

Papalia, D. E., Sterns, H. L., Feldman, R. D., \& Camp, C. J. (2007). Adult development and aging. New York, NY: McGraw-Hill Companies. 
Park, S., Sturman, M. C., Vanderpool, C., \& Chan, E. (2015). Only time will tell: The changing relationships between LMX, job performance, and justice. Journal of Applied Psychology, 100, 660-680.

Parker, S. K., \& Ohly, S. (2008). Designing motivating jobs. In R. Kanfer, G. Chen, \& R. Pritchard (Eds.), Work motivation: Past, present, and future (pp. 233-384). New York: Routledge.

Pasa, S. F., Kabasakal, H., \& Bodur, M. (2001) Society, organizations, and leadership in Turkey. Applied Psychology: An International Review, 50, 559-589.

Pellegrini, E. K., \& Scandura, T. A. (2006). Leader-member exchange (LMX), paternalism, and delegation in the Turkish business culture: An empirical investigation. Journal of International Business Studies, 37, 264-279.

Podsakoff, N. P., LePine, J. A., \& LePine, M. A. (2007). Differential challenge stressorhindrance stressor relationships with job attitudes, turnover intentions, turnover, and withdrawal behavior: A meta-analysis. Journal of Applied Psychology, 92, $438-454$.

Posthuma, R. A., \& Campion, M. A. (2009). Age stereotypes in the workplace: Common stereotypes, moderators, and future research directions. Journal of Management, $35,158-188$.

Ramos, R., Jenny, G., \& Bauer, G. (2016). Age-related effects of job characteristics on burnout and work engagement. Occupational Medicine, 66, 230-237.

Rhoades, L., \& Eisenberger, R. (2002). Perceived organizational support: A review of the literature. Journal of Applied Psychology, 87, 698-714. 
Richardson, K. M., \& Rothstein, H. R. (2008). Effects of occupational stress management intervention programs: A meta-analysis. Journal of Occupational Health Psychology, 13, 69-93.

Riggle, R. J., Edmonson, D. R., \& Hansen, J. D. (2009). A meta-analysis of the relationship between perceived organizational support and job outcomes: 20 years of research. Journal of Business Research, 62, 1027-1030.

Rius-Ottenheim, N., Kromhout, D., van der Mast, R. C., Zitman, F. G., Geleijinse, J. M., \& Giltay, E. J. (2012). Dispositional optimism and loneliness in older men. International Journal of Geriatric Psychiatry, 27, 151-159.

Roberts, B.W., Walton, K. E., \& Viechtbauer, W. (2006). Patterns of mean-level change in personality traits across the life course: A meta-analysis of longitudinal studies. Psychological Bulletin, 132, 3-27.

Rockstuhl, T., Dulebohn, J.H., Ang, S., \& Shore, L.M. (2012). Leader-member exchange (LMX) and culture: A meta-analysis of correlates of LMX across 23 countries. Journal of Applied Psychology, 97, 1097-1130.

Salthouse, T. A. (2012). Consequences of age-related cognitive declines. Annual Review of Psychology, 63, 201-226.

Salthouse, T. A. (2014). Why are there different age relations in cross-sectional and longitudinal comparisons of cognitive functioning? Current Directions in Psychological Science, 23, 252-256. 
Scandura, T. A., \& Graen, G. B. (1984). Moderating effects of initial leader-member exchange status on the effects of a leadership intervention. Journal of Applied Psychology, 69, 428-436.

Schaie, K. W. (1996). Intellectual development in adulthood: The Seattle longitudinal study. New York: Cambridge University Press.

Schaufeli, W. B., Bakker, A. B., \& Salanova, M. (2006). The measurement of work engagement with a short questionnaire: A cross-national study. Educational and Psychological Measurement, 66, 701-716.

Schaufeli, W. B., Bakker, A. B., \& Van Rhenen, W. (2009). How changes in job demands and resourcse predict buronout, work engagement, and suchness absenteeism. Journal of Organizational Behavior, 30, 893-917.

Scheier, M. F., \& Carver, C. S. (1985). Optimism, coping and health: Assessment and implications of generalized outcome expectancies. Health Psychology, 4, 219 247.

Scheier, M. F., Matthews, K. A., Owens, J. F., Magovern, G. J., Lefebvre, R. C., Abbott, R. A., \& Carver, C. S. (1989). Dispositional optimism and recovery from coronary artery bypass surgery: The beneficial effects on physical and psychological wellbeing. Journal of Personality and Social Psychology, 57, 1024-1040.

Schmitt, A., Zacher, H., \& Frese, M. (2012). The buffering effect of selection, optimization, and compensation strategy use on the relationship between problem 
solving demands and occupational well-being: A daily diary study. Journal of Occupational Health Psychology, 17, 139-149.

Seitsamo, J., \& Ilmarinen, J. (1997). Life-style, aging and work ability among active Finnish workers in 1981-1992. Scandinavian Journal of Work, Environment and Health, 23, 20-26.

Segerstrom, S. C. (2007). Optimism and resources: Effects on each other and on health over 10 years. Journal of Research in Personality, 41, 772-786.

Segerstrom, S. C., \& Solberg Nes, L. (2006). When goals conflict but people prosper: The case of dispositional optimism. Journal of Research in Personality, 40, 675693.

Settoon, R. P., Bennett, N., \& Liden, R. C. (1996). Social exchange in organizations: Perceived organizational support, leader-member exchange, and employee reciprocity. Journal of Applied Psychology, 81, 219-227.

Shore, L. M., \& Shore, T. H. (1995). Perceived organizational support and organizational justice. In R. Cropanzano \& K. M. Kacmar (Eds), Organizational politics, justice, and support: Managing social climate at work: 149-164. Westport, CT: Quorum Press.

Sjögren-Rönkä, T., Ojanen, M., Esko, L., Mustalampi, S. T., \& Mälkiä, E. A. (2002). Physical and psychosocial prerequisites of functioning in relation to work ability and general subjective well-being among office workers. Scandinavian Journal of Work, Environment and Health, 28, 184-190. 
Smith, P. B., Dugan, S., \& Trompenaars, F. (1996). National culture and the values of organizational employees: A dimensional analysis across 43 nations. Journal of Cross-cultural Study, 27, 231-264.

Solberg Nes, L., Segerstrom, S. C., \& Sephton, S. E. (2005). Engagement and arousal: Optimism's effects during a brief stressor. Personality and Social Psychology Bulletin, 31, 111-120.

Sonnentag, S., \& Frese, M. (2012). Stress in Organizations. In I. B. Weiner, N. W. Schmitt, \& S. Highhouse (Eds.), Handbook of psychology, (2 ${ }^{\text {nd }}$ ed., Vol. 12). Hoboken: Wiley.

Sonnentag, S., \& Pundt, A. (2015). LMX from a job-stress perspective. In T. Bauer \& B. Erdogan (Eds.), Oxford handbook of leader-member exchange (pp. 189-209). Oxford University Press.

Soto, C. J., \& John, O. P. (2012). Development of Big Five domains and facets in adulthood: Mean-level age trends and broadly versus narrowly acting mechanisms. Journal of Personality, 80, 881-915.

Soto, C. J., John, O. P., Gosling, S. D., \& Potter, J. (2011). Age differences in personality traits from 10 to 65 : Big Five domains and facets in a large cross-sectional sample. Journal of Personality and Social Psychology, 100, 330-348.

Specht, J., Egloff, B., \& Schmukle, S. C. (2011). Stability and change of personality across the life course: The impact of age and major life events on mean-level and rank-order stability of the Big Five. Journal of Personality and Social Psychology, 101, 862-882. 
Spector, P. E. (1986). Perceived control by employees: A meta-analysis of studies concerning autonomy and participation at work. Human Relations, 39, 10051016.

Spector, P. E., \& Brannick, M. T. (2011). Methodological urban legends: The misuse of statistical control variables. Organizational Research Methods, 14, 287-305.

Tepper, B. J. (2001). Health consequences of organizational injustice: Tests of main and interactive effects. Organizational Behaovior and Human Decision Processes, 86, 197-215.

Terry, D. J., Nielsen, M., \& Perchard, L. (1993). Effects of work stress on psychological well-being and job satisfaction: The stress-buffering role of social support. Australian Journal of Psychology, 45, 168-175.

Thibaut, J., \& Walker, L. (1975). Procedural justice: A psychological analysis. Hillsdale, NJ: Erlbaum.

Thomas, C. H., \& Lankau, M. J. (2009). Preventing burnout: The effects of LMX and mentoring on socialization, role stress, and burnout. Human Resource Management, 48, 417-432.

Toossi, M. (2012a). Employment Outlook: 2010-2020. Labor force projections to 2020: A more slowly growing workforce. Monthly Labor Review, January, 43-64.

Toossi, M. (2012b). Projections of the labor force to 2050: A visual essay. Monthly Labor Review, October, 3-16. 
Truxillo, D. M., \& Burlacu, G. (2015). Does age matter to LMX and its outcomes? A review and future research directions. In T. Bauer \& B. Erdogan (Eds.), Oxford handbook of leader-member exchange (pp. 397-411). Oxford University Press.

Truxillo, D. M., Cadiz, D. M., \& Hammer, L. B. (2015). Supporting the aging workforce: A research review and recommendations for workplace intervention research. Annual Review of Organizational Psychology and Organizational Behavior, 2, $351-381$

Truxillo, D. M., Cadiz, D. M., \& Rineer, J. R. (2014). The aging workforce: Implications for human resource management research and practice. In S. Jackson (Ed.), Oxford handbooks online: Business and Management.

Truxillo, D. M., Cadiz, D. M., Rineer, J. R., Zaniboni, S., \& Fraccaroli, F. (2012). A lifespan perspective on job design: Fitting the job and the worker to promote job satisfaction, engagement, and performance. Organizational Psychology Review, 2, $340-360$.

Truxillo, D. M., Fraccaroli, F., Yaldiz, L. M., \& Zaniboni, S. (2017). Age discrimination at work. In E. Parry \& J. MacCarthy (Eds.), The Palgrave handbook of age diversity and work (pp.447-473). London, UK: MacMillan.

Tuomi, K., Ilmarinen, J. A., Jahkola, A., Katajarinne, L., \& Tulkki, A. (1998). Work Ability Index (2nd ed.). Helsinki, Finland: Finnish Institute of Occupational Health.

Tuomi, K., Huuhtanen, P., Nykyri, E., \& Ilmarinen, J. (2001). Promotion of work ability, the quality of work and retirement. Occupational Medicine, 51, 318-324. 
U.S. Census Bureau (2016). An aging world: 2015. Washington DC: U.S. Government Publishing Office.

Viswesvaran, C., Sanchez, J. I., \& Fisher, J. (1999). The role of social support in the process of work stress: A meta-analysis. Journal of Vocational Behavior, 54, 314334.

von Bonsdorff, M. B., Seitsamo, J., Ilmarinen, J., Nygård, C., von Bonsdorff, M. E., \& Rantanen, T. (2011). Work ability in midlife as a predictor of mortality and disability in later life: A 28-year prospective follow-up study. Canadian Medical Association Journal, 183, 235-242.

Warr, P. (1997). Age, work, and mental health. In K. W. Schaie \& C. Schooler (Eds.), The impact of work on older adults (pp. 252-296). New York: Springer.

Warr, P. (2001). Age and work behaviour: Physical attributes, cognitive abilities, knowledge, personality traits, and motives. International Review of Industrial and Organizational Psychology, 16, 1-36.

Wayne, S. C., Shore, L. M., \& Liden, R. C. (1997). Perceived organizational support and leader-member exchange: A social exchange perspective. Academy of Management Journal, 40, 82-111.

Weigl, M., Müller, A., Hornung, S., Zacher, H., \& Angerer, P. (2013). The moderating effects of job control and selection, optimization, and compensation strategies on the age-work ability relationship. Journal of Organizational Behavior, 34, 607628. 
Williams, L. J., \& Anderson, S. E. (1991). Job satisfaction and organizational commitment as predictors of organizational citizenship and in-role behaviors. Journal of Management, 17, 601-617.

Witt, L. A., \& Carlson, D. S. (2006). The work-family interface and job performance. Moderating effects of conscientiousness and perceived organizational support. Journal of Occupational Health Psychology, 11, 343-357.

World Health Organization (2016). World health statistics 2016: Monitoring health for the SDGs, sustainable development goals. Switzerland: WHO Press.

Wu, C., Luksyte, A., \& Parker, S. K. (2015). Overqualification and subjective well-being at work: The moderating role of job autonomy and culture. Social Indicators Research, 121, 917-937.

Xanthopoulou, D., Bakker, A. B., Demerouti, E., \& Schaufeli, W. B. (2007). The role of personal resources in the job demands-resources model. International Journal of Stress Management, 14, 121-141.

Xanthopoulou, D., Bakker, A. B., Demerouti, E., \& Scahufeli, W. B. (2009). Reciprocal relationships between job resources, personal resources, and work engagement. Journal of Vocational Behavior, 74, 235-244.

Xanthopoulou, D., Bakker, A. B., Demerouti, E., \& Scahufeli, W. B. (2012). A diary study on the happy worker: How job resources relate to positive emotions and personal resources. European Journal of Work and Organizational Psychology, $21,489-517$. 
Yaldiz, L. M., Fraccaroli, F., \& Truxillo, D. M. (2017a). Aging workforce issues from a multi-level approach. In O. Braddick (Ed.), Oxford Research Encyclopedia of Psychology. doi: 10.1093/acrefore/9780190236557.013.22

Yaldiz, L. M., Erdogan. B., Bauer, T. N., Truxillo, D. M., \& Ordun, G. (2017b). Overqualification - work and well-being outcomes: The moderating role of age. Poster presented at the $32^{\text {nd }}$ Annual Conference of the Society of Industrial Organizational Psychology, Orlando, FL.

Yaldiz, L. M., Truxillo, D. M., Bodner, T., \& Hammer, L. B. (2018). Do resources matter for employee stress? It depends on how old you are. Journal of Vocational Behavior. 107, 182-194. doi: 10.1016/j.jvb.2018.04.005

Zacher, H., Rosing, K., Henning, T., \& Frese, M. (2011). Establishing the next generation at work: Leader generativity as a moderator of the relationships between leader age, leader-member exchange, and leadership success. Psychology and Aging, 26, 241-152.

Zacher, H., \& Schmitt, A. (2016). Work characteristics and occupational well-being: The role of age. Frontiers in Psychology, 7. doi: 10.3389/fpsyg.2016.01411

Zaniboni, S., Truxillo, D. M., \& Fraccaroli, F. (2013). Differential effects of task variety and skill variety on burnout and turnover intentions for older and younger workers. European Journal of Work and Organizational Psychology, 22, 306317. 
Zaniboni, S., Truxillo, D. M., Fraccaroli, F., Bertolino, M., \& McCune, E. (2014). Who benefits from more tasks? Older versus younger workers. Journal of Managerial Psychology, 29, 508-523.

Zaniboni, S., Truxillo, D. M., Rineer, J. R., Bodner, T. E., Hammer, L. B., \& Krainer, M. (2016). Relating age, decision authority, job satisfaction, and mental health: A study of construction workers. Work, Aging, and Retirement, 1-8. doi:10.1093/workar/waw006 